\title{
Assessing student learning outcomes in health professions service -learning courses
}

Tracey K. Anderson

West Virginia University

Follow this and additional works at: https://researchrepository.wvu.edu/etd

\section{Recommended Citation}

Anderson, Tracey K., "Assessing student learning outcomes in health professions service -learning courses" (2006). Graduate Theses, Dissertations, and Problem Reports. 2696.

https://researchrepository.wvu.edu/etd/2696

This Dissertation is protected by copyright and/or related rights. It has been brought to you by the The Research Repository @ WVU with permission from the rights-holder(s). You are free to use this Dissertation in any way that is permitted by the copyright and related rights legislation that applies to your use. For other uses you must obtain permission from the rights-holder(s) directly, unless additional rights are indicated by a Creative Commons license in the record and/ or on the work itself. This Dissertation has been accepted for inclusion in WVU Graduate Theses, Dissertations, and Problem Reports collection by an authorized administrator of The Research Repository @ WVU.

For more information, please contact researchrepository@mail.wvu.edu. 


\title{
Assessing Student Learning Outcomes
}

\section{in Health Professions Service-Learning Courses}

\author{
Tracey K. Anderson
}

\author{
Dissertation \\ At West Virginia University \\ In partial fulfillment of the requirements \\ For the degree of \\ Doctor of Education \\ In \\ Educational Leadership Studies \\ Ernest Goeres, Ph. D., Chair \\ Elizabeth Jones, Ph. D. \\ Richard Hartnett, Ed. D. \\ David McCrory, Ph. D. \\ Imogene Foster, Ed. D. \\ Paul Chapman, Ph. D.
}

Submitted to the College of Human Resources and Education

Department of Educational Leadership Studies

\author{
Morgantown, West Virginia \\ 2006
}

Keywords: Assessment, service learning, student learning outcomes

Copyright 2006 Tracey K. Anderson 


\author{
Abstract \\ Assessing Student Learning Outcomes \\ in Health Professions Service-Learning Courses
}

Tracey K. Anderson

Service learning is a pedagogical method that is currently on the rise in health professions schools as a method of meeting Healthy People 2010 objectives (Narsavage, Lindell, Chen, Savin \& Duffy, 2002). The intended result for participating students is an increased awareness of health care issues, civic responsibility, and course content in this learning experience. However, there is no clear assessment documentation that shows health professions students are meeting the intended learning outcomes. Eyler (2000) indicates that outcomes in service learning have not been "well studied and relatively little attention has been given to defining learning outcomes that would be expected to be enhanced by service participation" (What we know, para. 1). The purpose of this study was to examine how health professions program faculty assess students in their service-learning courses and if students achieved intended learning outcomes. In this qualitative study, the researcher conducted interviews with health professions faculty and analyzed documents including their course syllabi. This study revealed that faculty were the main individuals responsible for the assessment of the learning outcomes in service-learning courses, and that the outcomes identified on course syllabi were mainly cognitive. Faculty implemented multiple measures to assess student learning and adjusted learning activities as necessary based on feedback from students. Recommendations for practice emerged from this study such as reaching consensus among faculty about what to consider as high quality service-learning courses. In addition, faculty should clearly articulate all of the learning outcomes they intended students to achieve on course syllabi. Another recommendation for practice is the implementation of faculty workshops or seminars to guide faculty in the identification of learning outcomes associated with high quality service-learning courses. This study also outlines areas for further research such as investigating formal types of faculty workshops or seminars offered through various units including service-learning centers as well as teaching and learning centers. 


\section{Table of Contents}

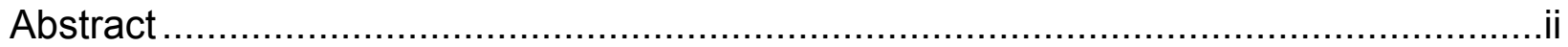

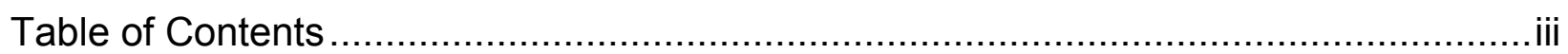

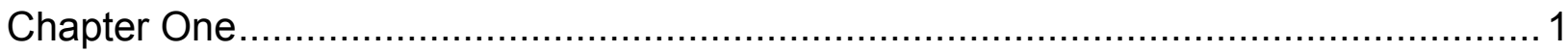

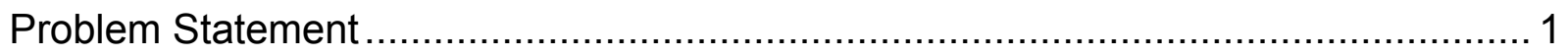

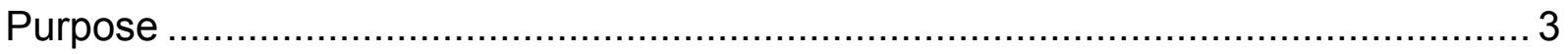

Chapter Two

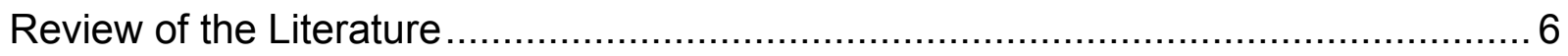

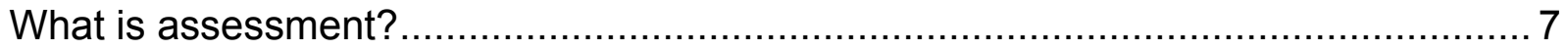

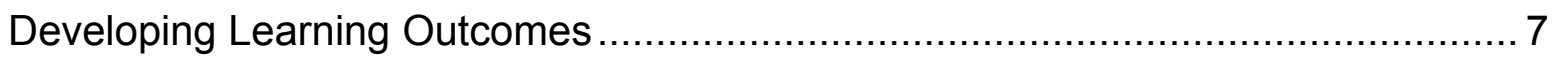

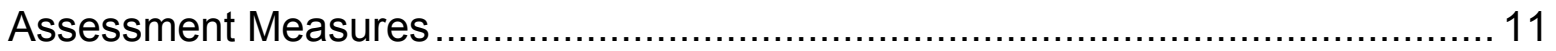

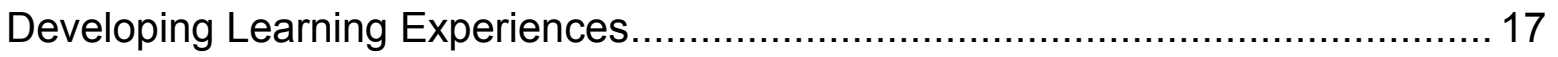

Reporting, Discussing and Using Assessment Results ..................................... 19

Defining Competencies by Cognitive, Affective, and Psychomotor Taxonomies ....... 26

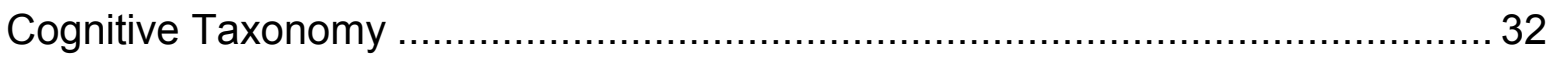

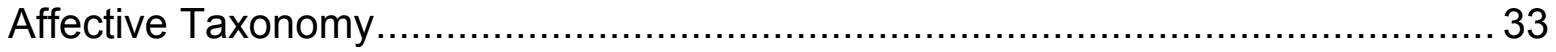

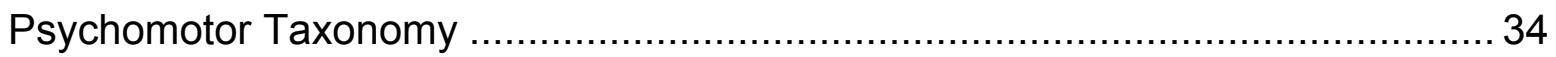

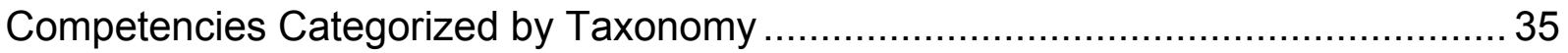

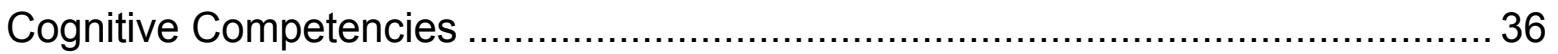

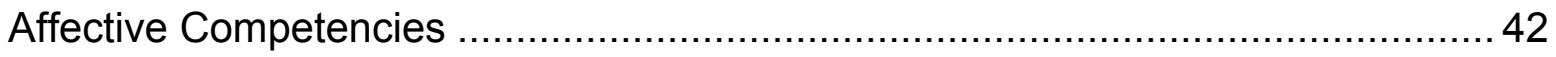

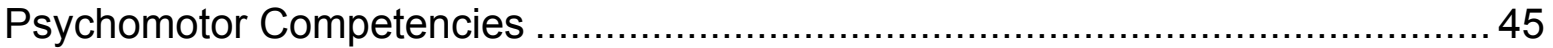

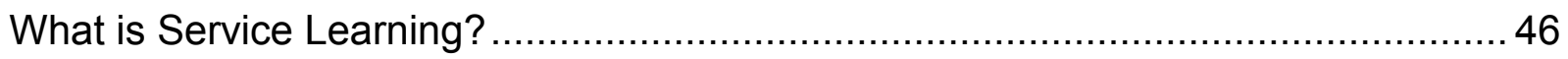

What is the Educational Foundation of Service Learning? .................................... 48 
What are the Outcomes of Service Learning? ..................................................... 51

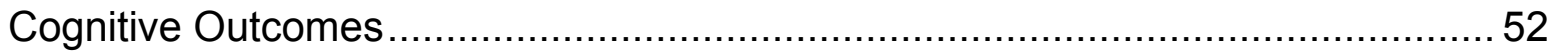

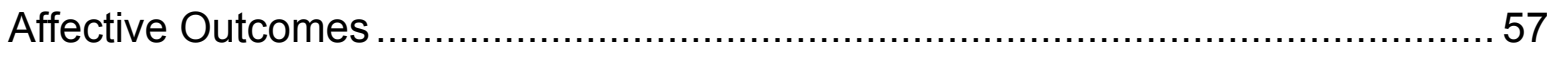

Contribution of Reflection on Both Types of Outcomes.......................................6 60

What are the Principles of Good Practice for Service Learning? ............................ 61

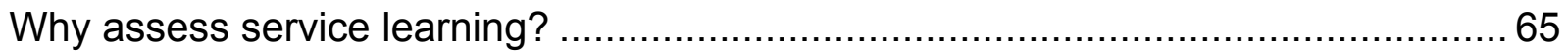

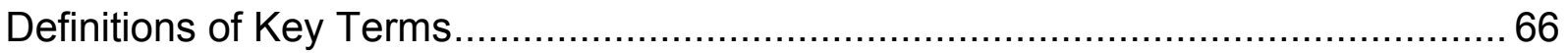

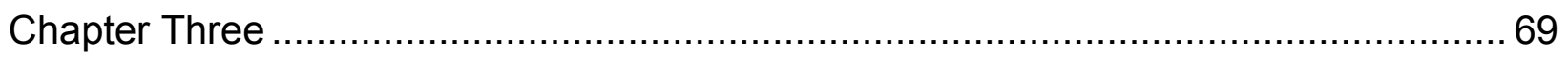

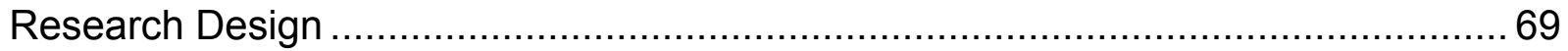

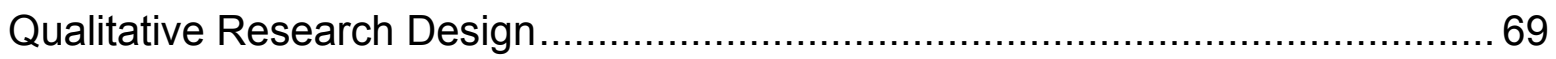

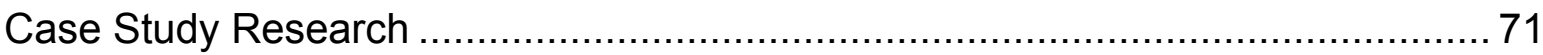

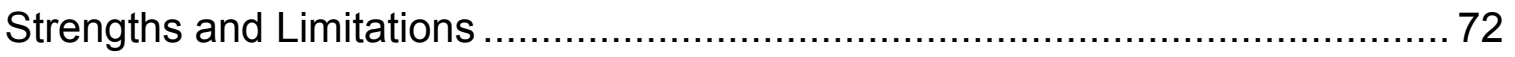

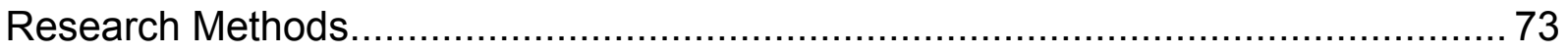

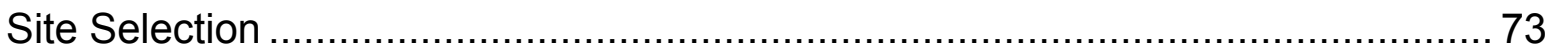

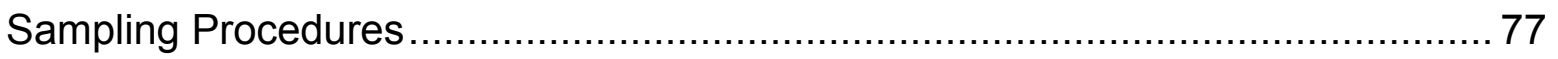

Initiating Contact and Institutional Approval .................................................. 78

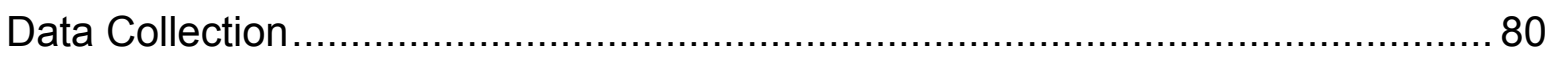

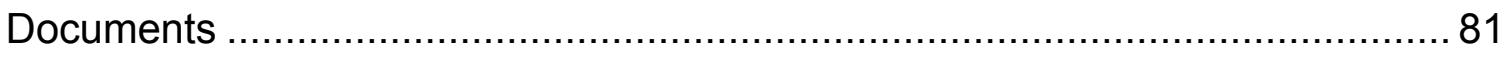

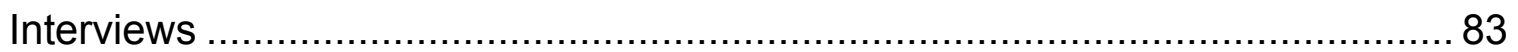

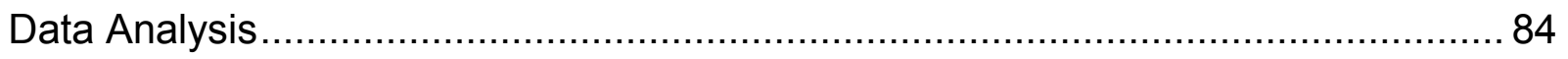

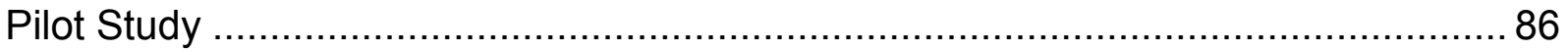

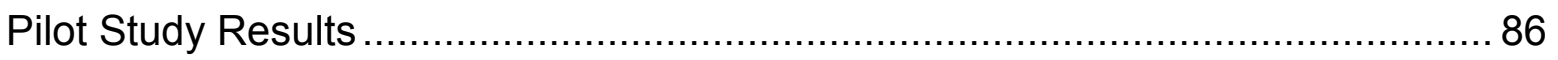

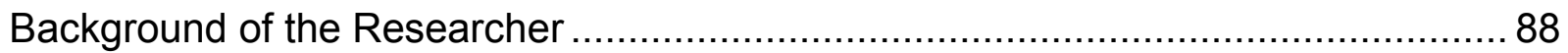




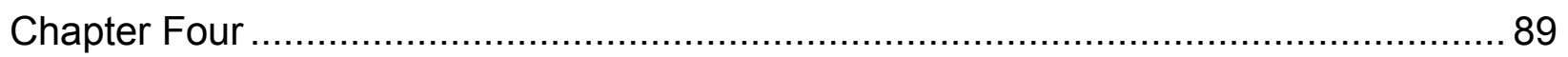

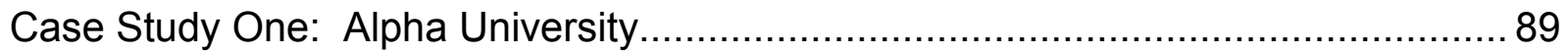

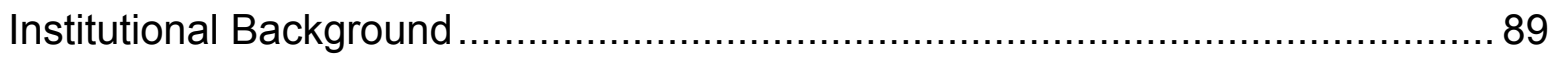

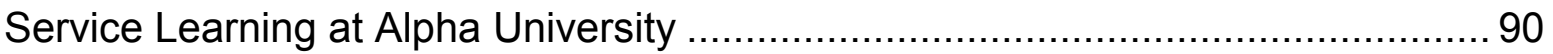

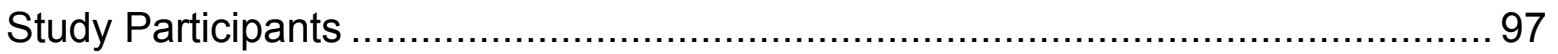

Intended Learning Outcomes for Service-Learning Courses ........................... 101

Assessing Learning Outcomes in Service-Learning Courses ........................... 105

Optimizing Student Learning and Development in Service-Learning Courses.... 109

Achieved Student Learning Outcomes in Service-Learning Courses.................. 113

Using Assessment Data and Results To Enhance Service-Learning Courses .... 116

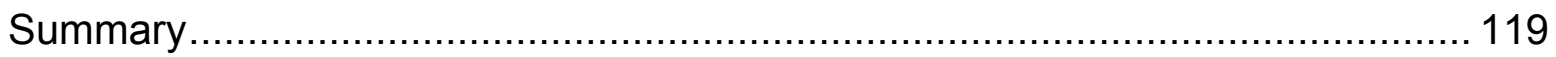

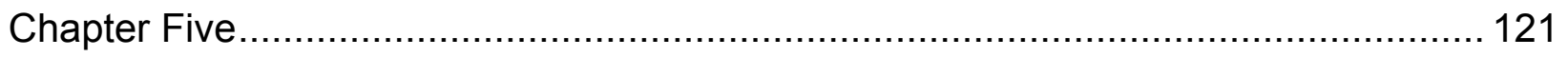

Case Study Two: Beta University .............................................................. 121

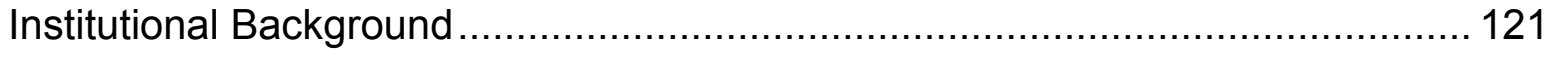

Service learning at Beta University …...................................................... 122

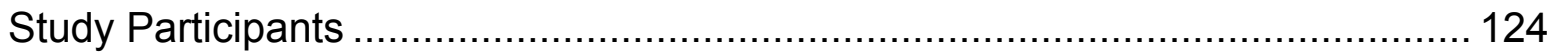

Intended Learning Outcomes for Service-Learning Courses ............................ 132

Assessing Learning Outcomes in Service-Learning Courses .......................... 135

Optimizing Student Learning and Development in Service-Learning Courses ..... 140

Achieved Student Learning Outcomes in Service-Learning Courses.................. 142

Using Assessment Data and Results To Enhance Service-Learning Courses .... 144

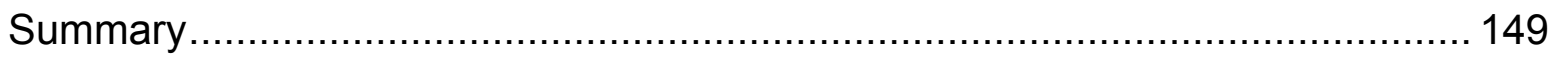




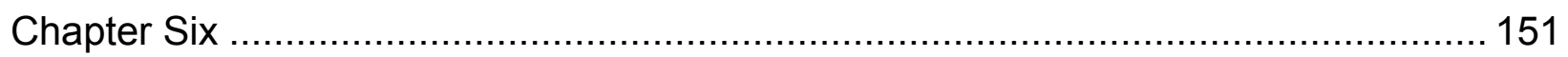

Case Study Three: Gamma University ......................................................... 151

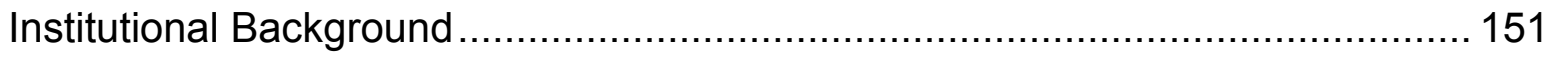

Service Learning at Gamma University .................................................... 152

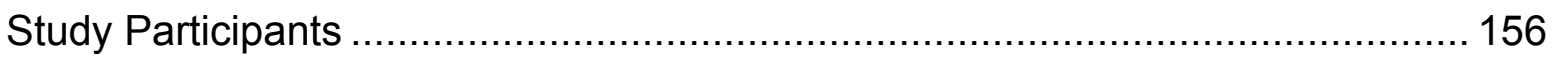

Intended Learning Outcomes for Service-Learning Courses ........................... 163

Assessing Learning Outcomes in Service-Learning Courses ........................... 165

Optimizing Student Learning and Development in Service-Learning Courses ..... 170

Achieved Student Learning Outcomes in Service-Learning Courses.................. 172

Using Assessment Data and Results To Enhance Service-Learning Courses .... 175

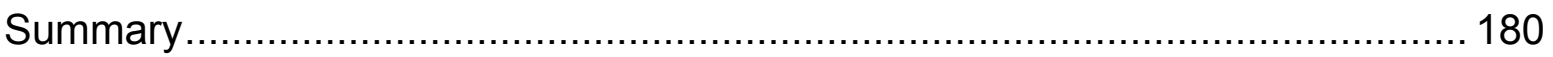

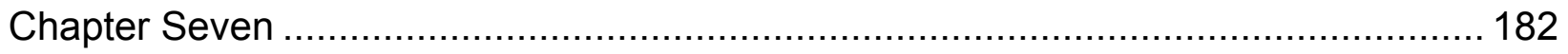

Assessment of Health Professions Service-Learning Courses: Cross Site Analysis of

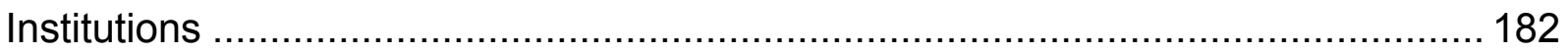

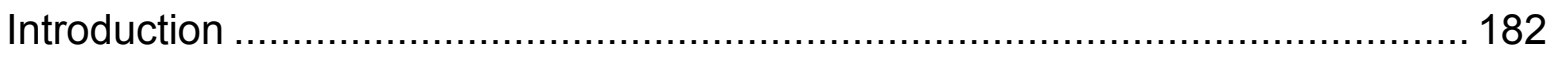

Intended Learning Outcomes for Service-Learning Courses ............................ 182

Assessing Learning Outcomes in Service-Learning Courses .......................... 187

Optimizing Student Learning and Development in Service-Learning Courses ..... 192

Achieved Student Learning Outcomes in Service-Learning Courses.................. 193

Using Assessment Data and Results to Enhance Service-Learning Courses...... 195

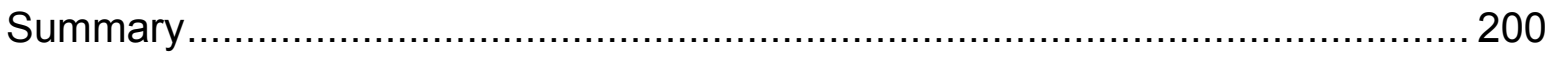

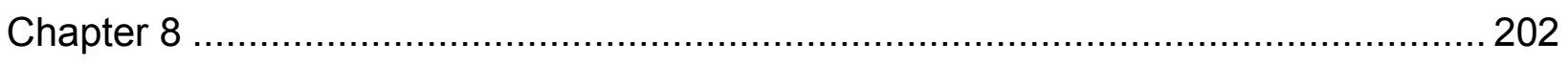

Recommendations for Practice and Further Research ..................................... 202 


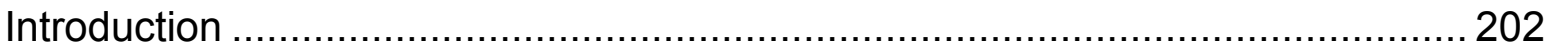

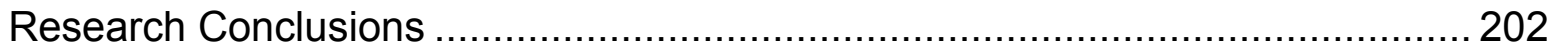

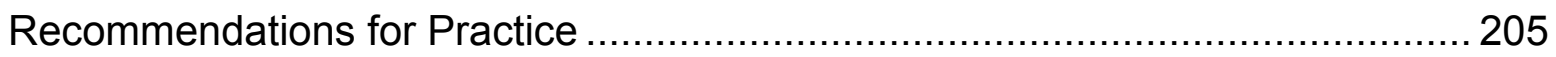

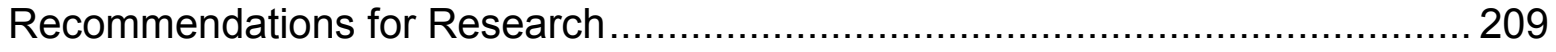

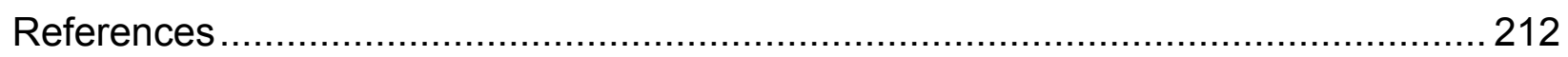

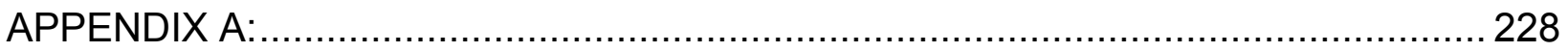

Letter to Request Institutional Site Approval .................................................. 228

APPENDIX B:

Letter from Institution Granting Permission for Site Visit................................... 231

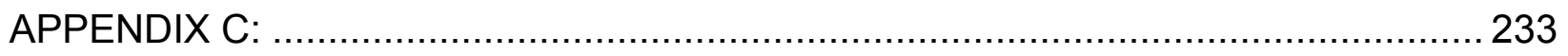

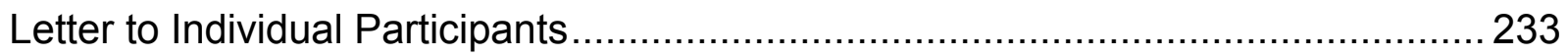

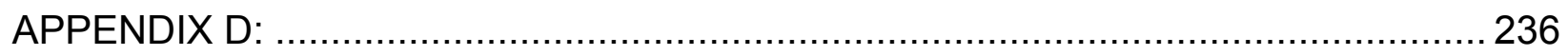

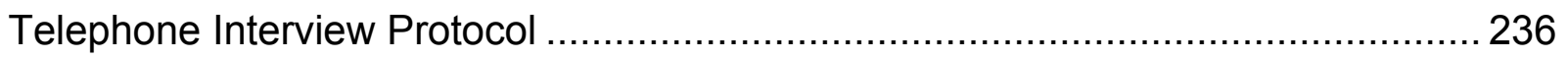

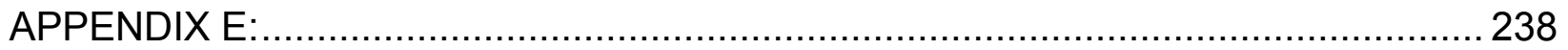

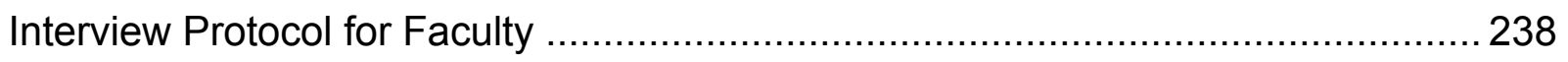

APPENDIX F:

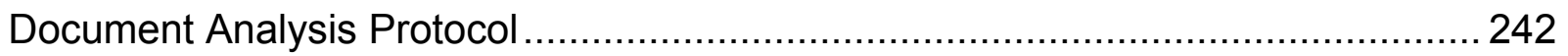




\section{Chapter One}

\section{Problem Statement}

Service learning is a pedagogical method that is currently on the rise in health professions schools as a method of meeting Healthy People 2010 objectives (Narsavage et al., 2002). Healthy People 2010: Understanding and Improving Health published by the U.S. Department of Health and Human Services (DHHS) is "a comprehensive, nationwide health promotion and disease prevention agenda" (2000, p. 1) to which all health professions are called upon to assist in the improvement of the health of the nation. The DHHS postulates that the health status of an individual is "inseparable from the health of the larger community and that the health of every community in every State [sic] and territory determines the overall health status of the Nation [sic]" (p. 3). In order to achieve the objectives set forth in that document, higher education health professions schools are developing partnerships with community health agencies (Narsavage, Lindell, Chen, Savin \& Duffy, 2002). Health professions programs are incorporating pedagogical methods for students to help communities meet specific needs they have identified. The intended result for participating students is an increased awareness of health care issues, civic responsibility, and course content in this learning experience.

There are other issues in healthcare that are spurring the implementation of service learning in health professions schools. Specifically in the field of nursing, one of those issues is that community based nursing is increasing; however, "many nurses in... [this environment] were educated or socialized into the profession in acute care settings" (Carter \& Dunn, 2002, p. 450). Service learning is the pedagogical method 
identified as having the "potential for promise as a curricular strategy" (Seifer, 1998, p. 275 ) to educate nurses about a variety of health issues and concerns in the community as well as utilize the knowledge they have gained in the classroom to problem solve, think critically and reflect about community needs.

Experiential learning has existed in colleges and universities for decades, but enthusiasm for service learning started in full swing with the "passage of the National and Community Service Trust Act of 1990" (Jacoby, 1996, p. 16) by President George H.W. Bush. This service-learning effort was continued by President Clinton in 1993 when he signed legislation that created the Corporation for National and Community Service, and continues today. As this movement began, many nursing faculty, for example, believed they had already incorporated service into the curriculum with the use of clinical experiences. "However, service learning has a somewhat different goal than clinical training" (Eyler, 2002, p. 453) since it combines application of course content with meeting community needs and understanding one's civic responsibilities.

Faculty expect service learning will produce better students and an active citizenry. Gray, Ondaatje, Fricker, Geschwind, Goldman, Kaganoff, et al. (1999) indicate that the appeal of service learning in regard to social problems is that it will help with the "perceived inadequacies in American...higher education" (p.1), and prepare students for the "responsibilities of living in a democratic society" (p.1) by becoming involved with the community. Health professions such as nursing have incorporated service learning into their curricula in order to meet community needs and increase understanding of course content. However, there is limited documentation that shows health professions students are meeting the intended learning outcomes. Eyler (2000) 
indicates that outcomes in service learning have not been "well studied and relatively little attention has been given to defining learning outcomes that would be expected to be enhanced by service participation" (What we know, para. 1).

Boland and Ladig (2001) state that "assessment is a key ingredient in ensuring that graduates will have the skills and knowledge necessary to meet today's and tomorrow's practice expectations effectively" (p. 92). It is not only important to have an assessment plan in place to assess the outcomes of service-learning courses, but it is also important to ensure that the plan is operational in order to make better informed decisions regarding the improvement of the courses. As a result, it is critical that the "findings from assessment studies... be communicated to faculty and systematically reviewed to improve student learning" (Thompson \& Bartels, 1999, p. 177).

In addition, it is not clear if or how health professions faculty are using assessment results to make targeted improvements and/or changes to service-learning courses. Based on the Commission on Collegiate Nursing Education (CCNE) (1998) accreditation standards for nursing, there is an expectation that assessment results be used to enhance and improve the program. With this in mind, there is no clear systematic investigative research that illustrates that students are reaching the intended learning outcomes of service learning or that the results of assessing service learning are actually used to implement improvements to the courses.

\section{Purpose}

Assessment is a relatively new phenomenon in higher education. Palomba and Banta (1999) note that in the late 1980's assessment became a necessity in higher education, and defined assessment as "the systematic collection, review, and use of 
information about educational programs undertaken for the purpose of improving student learning and development" (p. 4). Service learning is no exception. The purpose of this study was to determine how service-learning courses were assessed in order to determine if students achieved intended learning outcomes.

Civic engagement, meeting community needs and student development are important outcomes of service learning. This study added to the literature in both the service learning and assessment fields as it examined the student learning outcomes in service-learning courses. It also provided insight into how health professions students achieved the goals of service learning as well as how faculty assessed these outcomes. This study is significant in that it provided information from which researchers can better understand the assessment practices of service learning faculty within health professions programs that integrate service learning.

Much of the literature on service learning focuses on best practices for implementing service learning. However, this study attempted to add to the literature on service learning by determining what learning outcomes health professions faculty expected students to achieve as a result of participating in service-learning courses. It also determined what methods of assessment faculty implemented to assess problemsolving and critical thinking skills as well as what types of reflection activities students completed during the service-learning course. Finally, this study examined the manner in which service-learning courses were structured to enhance learning opportunities, and explored how assessment data were used to enhance and improve student learning. 
At the conclusion of this study, a clearer picture and comprehension of how service learning was assessed in health professions courses surfaced. It helped to illustrate the different ways service learning was assessed and provided health professions programs information on assessing their own service-learning courses in order to improve student learning and development. This study examined these questions:

1. What are the intended learning outcomes for students enrolled in servicelearning courses?

2. How are the learning outcomes assessed in service-learning courses?

3. How are service-learning courses designed to optimize student learning and development?
a. Assignments/activities
b. Reflections
c. Team vs. individuals
d. Active learning

4. How do faculty use assessment results to determine if students reach the intended learning outcomes developed for service-learning courses?

5. How are assessment data and the results used to enhance the course and improve student learning? 


\section{Chapter Two}

\section{Review of the Literature}

The first part of this literature review will offer a conceptual framework for assessment based on Huba and Freed's (2000) assessment process as seen in Figure 1. It will describe in detail each of the steps in the assessment process: developing learning outcomes; identifying and creating methods to measure those outcomes; designing appropriate experiences leading to the outcomes created; and discussing, using and reporting out the results of the assessment to improve student learning. It will then review definitions of competencies by accreditation requirements and taxonomies specifically within the professional nursing curricula. The next part of the literature review will discuss service learning and the role it serves in higher education to promote student learning, and present research that illustrates the outcomes that are often associated with service learning. Finally, this literature review will present operational definitions of key terms and concepts.

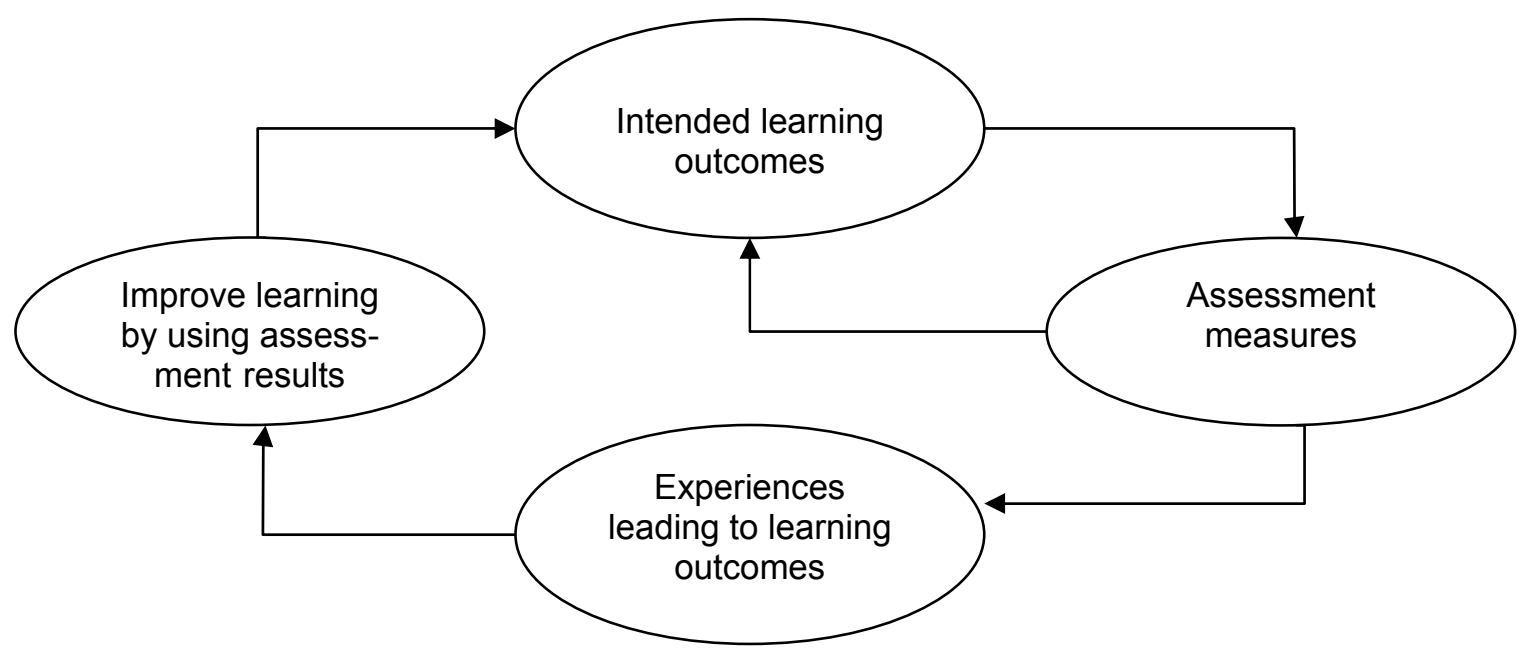

Figure 1. Assessment Process 
Note. From Learner-centered assessment on college campuses: Shifting the focus from teaching to learning (p. 10), by M. E. Huba and J. E. Freed, 2000, Boston: Allyn and Bacon. Copyright 2000 by Allyn and Bacon.

\section{What is assessment?}

Early in the assessment movement, Erwin (1991) defined assessment as "the process of defining, selecting, designing, collecting, analyzing, interpreting, and using information to increase students' learning and development" (p. 15). Palomba and Banta (1999) have since defined assessment as "the systematic collection, review, and use of information about educational programs undertaken for the purpose of improving student learning and development" (p. 4). Huba and Freed (2000) present yet another definition of assessment as

the process of gathering and discussing information from multiple and diverse sources in order to develop a deep understanding of what students know, understand, and can do with their knowledge as a result of their educational experiences; the process culminates when assessment results are used to improve subsequent learning (p.8).

The overarching similarity in these definitions of assessment is that there is a cyclical process in which data is collected about student learning from a variety of sources in order to use the information gained to improve student learning and development. Developing Learning Outcomes

The first step in the assessment process is to examine an institution's expectations regarding student learning. Information regarding intended learning outcomes is typically reflected in an institution's mission, values, or purpose statements 
(Huba \& Freed, 2000; Maki, 2002) and often "capture the knowledge, skills, and values that graduates of an institution have in common" (Palomba, 2001b, p. 15). There are a variety of institutions across the country with different missions and values, and "these differences are reflected in their learning outcomes" (Huba \& Freed, 2000, p. 100).

The institutional goals are the foundation for the intended learning outcomes developed for an academic program. At the program level faculty "should consider developing discipline-related goals or intended learning outcomes for the students in their program... [and] should reflect the type of knowledge and skills expected..." in the discipline of the academic program (Huba \& Freed, 2000, p. 107). Not only should the intended learning outcomes reflect the institutional and programmatic goals and objectives, but according to Huba and Freed the outcomes "should [also] be compatible with the best thinking in the discipline in terms of what is important to know..." (p. 116). Erwin (1991) suggests that as faculty begin to develop and construct programmatic learning objectives that they "first consult their professional organization or other colleagues for examples of objectives" (p. 45). For example, within baccalaureate nursing programs, "faculty must define program outcomes, identify assessment processes, and collect and analyze data to demonstrate student achievement of the stated outcomes" (Thompson \& Bartels, 1999, p. 170) for accreditation standards set by the Commission on Collegiate Nursing Education (CCNE). The National League for Nursing (NLN) is another accrediting agency that also sets standards for nursing programs.

Outcomes developed for the academic program are further refined and developed into learning outcomes for an individual course. These outcomes are 
important for students to be aware of because they "provide direction for all instructional activity, inform students about the intentions of the faculty (p. 94)... [and] help students develop a sense of direction as they participate in class, study, and complete assignments" (Huba \& Freed, 2000, p. 97). Intended learning outcomes are often stated in a manner that describes what students will know or be able to do upon completion of the course (Astin, Banta, Cross, El-Khawas, Ewell, Hutchings, et al., 1992; Huba \& Freed, 2000; Maki, 2002). As a result, the outcomes are more studentcentered.

Huba and Freed (2000) describe a learner-centered approach in the development of intended learning outcomes. In this approach, faculty should "focus on the learning resulting from an activity rather than on the activity itself' (p. 99). They emphasize that faculty should reflect on what the students will know, understand and be able to do when the course is complete. However, learning outcomes should not be trivial. The intended learning outcomes should be "general enough to capture important learning but clear and specific enough to be measurable" (p. 116).

As faculty develop intended learning outcomes, they should not focus on the "easy-to-measure" outcomes, but those that promote "complex thinking standards", "information processing", "effective communication", "collaboration/cooperation", and "habits of mind" (Huba \& Freed, 2000, p. 113). These are the types of outcomes in which learning for the students "will develop and endure but that can be assessed in some form now" (p. 117). Palomba and Banta (1999) identify three categories of objectives in which course outcomes can be developed: cognitive which is related to thinking skills; affective which is driven by attitudes, beliefs and values; and 
psychomotor which is related to skill learning and is an outcome that is performance driven.

Erwin (1991) describes cognitive and affective objectives as developmental and states these "concern the ways in which people express their mode of thinking and feeling...although the two are often interrelated and difficult to separate" (p. 39). The literature indicates that cognitive skills typically reflect the higher-order thinking skills associated with Bloom's taxonomy, including critical thinking skills and affective skills reflect the values, attitudes and beliefs held by students as they develop (Erwin, 1991; Field, Gallman, Nicholson, Dreher, 1984; Palomba \& Banta, 1999; The University of Mississippi, 2003a; The University of Mississippi, 2003b). The literature also indicates that psychomotor skills refer to one's ability to perform tasks that require manipulation and precision (Field et al., 1984; Palomba \& Banta, 1999; The University of Mississippi, 2003c).

Assessment experts (Banta, Lund, Black, \& Oblander,1996; Huba \& Freed, 2000; Maki, 2002; Palomba \& Banta, 1999) agree that the learning outcomes should indicate what students will be able to do upon completion of individual courses and as a result of the entire academic program. Descriptions about what students should be able to do ideally use "simple language... and describe [the] intended outcome rather than the subject matter" (Palomba \& Banta, 1999, p. 36). However, Erwin (1991) states that subject matter objectives help to identify outcomes in which students are "expected to learn the vocabulary, principles, and theories associated with the discipline" (p. 37) but these outcomes represent lower levels of thinking. 
It is important for faculty to remember, "one must know what is to be assessed before one knows how to assess it" (Erwin, 1991, p. 35). The intended learning outcomes they have identified should "describe [the] developmental expectations that enable... [them] to track learning and development over time" (Maki, 2002, p. 9). The intended learning outcomes articulated by faculty "must be the basis on which instructional methods are chosen and the criteria by which competency is measured" (Diamond, 1998, p. 57).

\section{Assessment Measures}

Developing measures to assess student learning is an important procedure in the process of assessment. The selection of assessment measures encourages faculty to thoroughly focus on what they mean regarding the intended learning outcomes originally developed (Banta \& Associates, 2002; Banta et al., 1996; Huba \& Freed, 2000; Maki, 2002). This procedure also promotes the discussion among faculty about how to best capture that information from students. For example, nurse educators often use the "California Critical Thinking Skills Tests" to evaluate students' critical thinking skills at a variety of times throughout their educational experience (Thompson \& Bartels, 1999, p. 171). The methods implemented to gather the assessment data may result in faculty "fine-tuning" (Huba \& Freed, 2000, p. 11) the learning outcomes originally developed.

There are many decisions to consider during this phase of the assessment cycle. One decision is at what point students should be assessed. There should be both formative and summative assessment opportunities. Formative assessments take place throughout the course and help "make immediate changes to [the] course to 
improve student learning" (Huba \& Freed, 2000, p. 123). Summative assessments take place at the end of the course at which time it is often too late and/or impossible to implement immediate changes to the course. If this is the case and useful information is obtained that improves student learning, then faculty would implement changes the next time the course is offered.

Determining the place and time of assessment is important as this will guide the types of assessment to implement. Faculty should consider whether they want a snapshot about student learning at one point in time or more of a longitudinal picture that shows growth and changes in student learning and development over time. Palomba and Banta (1999) advise that in "...most cases information will be collected at the program level.... [and because of the] uniqueness of individual academic programs...collection of information at that level" (p. 106) is encouraged. However, they also indicate that "many campuses are interested in tracking and comparing successive cohorts of students" (p. 107). As a result, the longitudinal assessment design would be most useful as it allows for the "collection of pre- and post- information" (p. 108) on students. Palomba and Banta caution when making interpretations from longitudinal assessment results from assessment because "students mature and change" (p. 108) and the scores do not always provide the reasons why students grow or develop over time.

Another decision when developing assessment measures is whether students will be assessed directly or indirectly. Huba and Freed (2000) and Palomba and Banta (1999) recommend implementing both types of measures into the assessment process. Students can be asked to demonstrate what they know or are able to perform through 
direct assessment measures (Huba \& Freed, 2000; Palomba, 2001b; Palomba \& Banta, 1999). Direct assessment measures such as "projects, products, paper/theses, exhibitions, performances, case studies, clinical evaluations, portfolios, interviews, and oral exams" (Huba \& Freed, 2000, p. 11) also promote the evaluation of "high order thinking" (p. 12) skills. These measures are qualitative in nature and provide students the opportunity to perform or "generate their own responses" (Palomba \& Banta, 1999, p. 12). A quantitative direct measure such as an objective test allows the student to "select a response from among those provided" (p. 12).

Students can also be asked to reflect on their learning or self-report on experiences faculty have implemented through indirect assessment measures (Huba \& Freed, 2000; Palomba, 2001b; Palomba \& Banta, 1999). Self-report opportunities "such as surveys and interviews" (Palomba \& Banta, 1999, p.12) are a few examples and include both qualitative and quantitative measures to obtain more useful information and may provide the means to better understand the question of why students have changed over time. The literature suggests that by implementing both direct and indirect, and qualitative and quantitative measures it will "provide accurate and useful information for making decisions about learning" (Huba \& Freed, 2000, p. 12). Palomba (2001a) stresses that faculty should implement "multiple methods to assess their programs... [in which] both quantitative and qualitative approaches" are utilized (p. 249). Performance assessments are "effective tools for assessing mastery of factual knowledge, but more importantly, for finding out if students can use their knowledge effectively to reason and solve problems" (Huba \& Freed, 2000, p. 13). Diamond (1998) recommends developing assessment measures that allow for the demonstration of 
student growth and "mastery of important skills" (p. 49). A portfolio is a good example of performance assessment in that it stresses the "reworking, rethinking, and revising" as well as provides students with an opportunity to "work toward a mastery level of performance by engaging them in the kind of activities experts carry out" (p.150). Palomba (2001b) points out that an advantage surfaces in the "development of performance assessments [in that it] encourages faculty to align expected learning outcomes, instructional activities, and assessment" (p. 19).

Palomba (2001b) advises that "assessment methods must gather evidence that is closely related to the expected learning outcomes selected by faculty" (p. 17). Huba and Freed (2000) indicate that learner-centered assessment should "evaluate students' ability to think critically and use their knowledge" (p. 12). They go on to suggest that when "instruction focuses on critical thinking and problem solving, assessment techniques should also focus on critical thinking and problem solving" (p. 221).

At the course level, Diamond (1998) advocates that faculty "design procedures and instruments that serve four distinct purposes" (p. 141):

- Identifying students for remediation and exemption

- Determining whether objectives (of individual units and entire courses) are being met by measuring student performance

- Determining whether and how students' attitudes toward the course and the discipline or field have changed

- Determining whether the overall course design and the materials and procedures are efficient and effective (p. 141). 
It is important to allow students to demonstrate what they have learned in the course and Diamond indicates that "in some instances the assessment technique [faculty select] can also facilitate the learning [they] hope to accomplish" (p. 142). Faculty are encouraged to be very specific in the "description of the performance expected" as this will reduce the amount of problems in "developing student testing instruments and procedures" (p. 149). In addition, when faculty implement "multiple methods of assessment [they] contribute to a more comprehensive interpretation of student achievement" (Maki, 2002, p. 10).

Along with the implementation of multiple methods of assessment, faculty need to consider whether they will implement locally developed or commercially developed instruments. There are advantages and disadvantages to both types and faculty must weigh the issues based upon the needs of the program or course. Palomba and Banta (1999) indicate that the main advantage of commercially and nationally developed instruments is that the "reliability and validity have already been addressed" (p. 99). Commercially developed instruments also provide important and useful information regarding how students are doing "compared to similar students elsewhere" (p. 99). A disadvantage of implementing these instruments is that some faculty "do not believe that commercial tests accurately or meaningfully measure whether students have achieved the education goals specific to the academic program or institution" and at the same time, they feel they "do not provide much direction nor guidance about where and how to improve student learning" which is the main purpose of assessment (Jones, Voorhees \& Paulson, 2002, p. 31). 
On the other hand, an advantage of using locally developed instruments is the opportunity "they provide for involving faculty in the assessment process and the likely result that the instruments they develop will closely match the local curriculum as well as local issues and concerns" (Palomba \& Banta, 1999, p. 100). Unlike commercially developed instruments, locally developed instruments can "only provide norms for local tests or survey takers over time or for subgroups of local students" (p.100); therefore, they cannot be compared to similar students elsewhere. However, if the main purpose of the assessment is to "assess the extent to which students are mastering the content of the institution's curricula, well-designed locally developed methods should yield the most valid inferences about student learning" (p. 100).

Reliability and validity of the instruments implemented in the assessment plan are important considerations. Reliability "refers to the consistency, precision, and dependability" of the measurements implemented in the assessment process while validity "deals with the worth, or applicability, of these measurements for one's stated objectives" (Erwin, 1991, p.59). Validity also addresses the question as to whether an instrument measures what faculty want it to measure (Palomba \& Banta, 1999). These serve as a guide from which to evaluate the assessment methods implemented. As Banta et al. (1996) state, "the questions of reliability and validity center around building confidence in assessment findings, determining the applicability of the findings to improving the educational experience, and assuring some level of precision or consistency with respect to replication" (p. 12).

The literature identifies three sources of errors to consider when examining the reliability of an instrument (Cherry \& Meyer, 1993; Erwin, 1991; Palomba \& Banta. 
1999). The three sources of errors for reliability are the students, the instrument, and the condition or circumstances under which the assessment is administered. The less reliable the method or the condition of administration of the assessment the less useful the results will be and the less likely the results will lead to improved student learning.

There can be no guarantee that an assessment method can be valid; however, "valuable information can still be collected and used for improving educational courses and programs" (Erwin, 1991, p. 66). Validity addresses the issue of whether an "assessment instrument measure[s] what it is supposed to measure" (p. 65). In addition, because the issue of validity is complex and gathering evidence to support it is "time-consuming and challenging task" validity is often "given insufficient attention in practice" (Palomba \& Banta, 1999, p. 90).

\section{Developing Learning Experiences}

As faculty create learning experiences for students, faculty need to revisit the intended learning outcomes. The programmatic curriculum should be developed so that "courses and experiences" are interrelated and "help students achieve the intended learning outcomes" (Huba \& Freed, 2000, p. 13). The organization of the curriculum will shape the experiences students have and will affect their learning. Huba and Freed (2000) advocate the development of opportunities for students to "critically analyze and interpret information" (p. 95) if that is an intended learning outcome. In the nursing curriculum, faculty should design experiences in the "classroom and clinical settings that require students to practice skills of analysis, interpretation, and inductive and deductive reasoning" (Thompson \& Bartels, 1999, p. 171). 
When designing individual courses, Diamond (1998) suggests three areas for faculty consideration: "the learning outcomes/objectives"; "instructional options available"; and "research on learning" (p. 153-4). For the latter, it is important for faculty to review current literature to determine what is occurring on the teaching and learning front of their field. The more faculty are able to find out and understand what research says about teaching and learning along with the advantages and disadvantages of the instructional options available the better and more informed their decisions will be (Diamond, 1998). Furthermore, as faculty decisions are better informed the more likely it will be for student learning outcomes to improve.

Instructional options for an individual course are broken down by Diamond (1998) into three additional options from which faculty may select:

- One option is process oriented, which focuses "on the design of instruction" (Diamond, 1998, p. 159). The design of the individual unit of a course should be based on "the number and quality of your students"; "the instructional objectives of the unit";" the resources available"; "the time available for teaching, for assignments between lessons for the production of new materials"; and "the individual strengths and preferences of the faculty" (p. 164).

- Another option is course-management, which focuses "on the overall organization of the course" (p. 160). Diamond recommends "several major management systems" (p. 165) to consider such as "...the audiotutorial approach, [which] uses media as a major source of instruction" and the “...mastery learning [system which].... emphasizes a high level of achievement on the part of all students" (p. 165). 
- Another option is structural, which focuses "on the instructional setting" ( $p$. 159). Faculty may implement "new ways of learning" (p. 160) in the classroom such as group sessions, guest speakers or video. No single approach should dominate the course and one approach may be better than another. Faculty must continually modify and adjust each approach. Off campus settings may include service learning and internship type approaches to teaching and learning.

As faculty consider these options, they should "match the process of learning with the outcomes" (p. 159).

Diamond offers a variety of structural experiences that are "fairly common in professional schools" (p. 162) such as service-learning experiences and internships. Service learning provides students an opportunity to combine theory and practice in the community setting while at the same time their activities benefit both the student and the community they are serving. Internships "provide students with meaningful experiences to connect theory and practice" (Jones, 2002, p. 66). These opportunities are purposeful experiences and have started to "gain popularity in undergraduate arts and sciences programs" (p. 162). By "providing formal educational experiences within the community" (p. 160) faculty focus on the "total experience" in which these "additional activities improve learning" (p. 162) for the students.

Reporting, Discussing and Using Assessment Results

Palomba and Banta (1999) indicate that as the assessment process begins, faculty should "clarify the purpose and intended uses of assessment information" ( $p$. 20). Deciding what to do with assessment results once they have been collected is part 
of the cyclical process of assessment. As the assessment process begins faculty should consider how the results will be reported, with whom they will be discussed and how the results will be used to improve student learning. Though these three steps occur once assessment results have been collected and analyzed, they should also serve as a guide for the next cycle of assessment processes.

"Practitioners [must] decide about relevant analyses, draw helpful comparisons, create various kinds of reports, and distribute them to appropriate individuals" in order for assessment information to be useful (Palomba \& Banta, 1999, p. 311). The latter may best occur in a feedback loop as described in a paper presented to the North Central Accreditation (NCA) Commission by Lopez (1997). A well-developed feedback loop will help communicate results as it "provide[s] those who generate data and or make recommendations with timely, accurate accounts of the use the recipients have made of information and the action they have taken on recommendations" (p. 10). Creating this loop early in the assessment process will make discussing and using assessment results much more efficient.

Another venue that is efficient in communicating the progress of assessment is written reports. Lopez (1997) indicates that these reports can be written by groups or individuals in order for assessment results to be communicated and distributed to appropriate audiences. Reports consist of "concise informational documents that present findings, interpretation of data, actions based on analyses of data, and results of those actions" (p. 10). When reporting the results of the assessment, it is important to keep the audience in mind and what needs they have regarding the results. These key stakeholders may include internal audiences such as faculty, staff, students and 
administrators as well as external audiences such as regional and professional accreditors and state governments (Palomba \& Banta, 1999). Huba and Freed (2000) suggest faculty "share summaries of the process with key stakeholder[s]... who may also provide insights about whether changes are needed in the programs intended learning outcomes" (p. 15).

Lopez (1997) describes reports which can take several forms. The multi-purpose progress report identifies the "results of assessment and the changes being introduced based on that information by academic units to improve student learning" as well as serving as a "morale booster to faculty... because the results of their efforts... are quickly brought to their attention" (p.10). The annual assessment report "brings the contents of the more frequent, brief Progress Reports into a single overview of student academic achievement and describes the effects of utilizing assessment results to improve learning throughout the institution" (p. 11). A third type of report described by Lopez is the report card. This kind of report offers several types of information including "how well their students appear to be meeting the faculty's objectives for academic achievement....[and] offers suggestions for how faculty might improve the assessment process being used in the academic unit" (p.11).

As assessment results become available, faculty should have "planned conversations... at regularly scheduled meetings or at special events such as retreats or brown bag lunches" (Palomba, 2001b, p. 21). The discussion of assessment results by faculty increase their ability to "make informed decisions about program changes" (Huba \& Freed, 2000, p. 15). These types of conversations should be held "before reports are written or recommendations are submitted" (Palomba, 2001b, p.22). This allows for 
faculty to examine the "strengths and weaknesses of individuals who were assessed" (p. 21) and these meetings should "include anyone who is likely to be affected by the assessment results" (p. 22). Maki (2002) states that using assessment results “...involves making decisions based on interpretations of assessment results...to improve student learning" (p. 12). As faculty develop conclusions and make recommendations regarding assessment results, they need to be "quite clear about the location of responsibility for action" (Palomba \& Banta, 1999, p. 326) as this will help to ensure that changes are appropriately implemented.

Once assessment results have been received and interpreted by key stakeholders, an institution's administration "need to be willing to support recommendations that are based on assessment findings and provide resources to carry out these recommendations" (Palomba \& Banta, 1999, p. 313). However, this is not likely the case if the assessment results are negative. As a result, Erwin (1991) suggests that every attempt should be made to offer a positive perspective on the findings "with an emphasis on the improvements that can results from assessment" ( $p$. 143). It may be useful to indicate how changes from past assessment results have been implemented to make positive changes in a course, program and across the institution. This may also help to reinforce, for all intended audiences, the fact that assessment is cyclical in nature and that change is to be expected and welcomed if student learning is to be improved.

A challenge for faculty is how to use the assessment results to make changes. Erwin (1991) identifies three factors that "influence the use of results for decision making" (p. 133). The first factor is the source of information which must be "credible in 
order for the results to be accepted.... [which] is determined by one's expertise, program knowledge, objectivity, and ability to work with other people" (p. 133-4). The next factor is the manner in which the results are delivered. The type of report distributed may not be the type the audience was anticipating and as a result these key stakeholders may not accept the findings. The third factor Erwin identifies as an influence on decision making about the result is the audience. With this in mind, it is important to understand what type and in what form the audience wants the assessment information. If assessment results are not easily accessible or comprehendible the information may be disregarded and not used. However, when the information is presented in a functional manner, Palomba and Banta (1999) and Shipman (2004) identify five areas in which assessment results can be used: continuous improvement, program review, planning and budgeting, teaching and learning, and improving assessment.

Continuous improvement describes a movement in assessment in which quality improvement and assessment are linked (Huba \& Freed, 2001; Palomba \& Banta, 1999). Total Quality Management (TQM), from the business sector, provides the context for assessment (Palomba \& Banta, 1999). TQM is characterized as "a comprehensive set of management ideas, which emphasize or promote quality in organizations" (Hoy \& Miskel, 2001, p. 308) and the goal is "long-term survival and effectiveness" p. 308).

Business management approaches to administration such as TQM have expanded into the academic arena. The American Association of Higher Education has devoted several conferences to this topic in order to examine how "assessment and 
continuous improvement are complementary activities" (Palomba \& Banta, 1999, p. 306). TQM helps focus on the overall process and not just the end results as well as encourages "campuses to search constantly for improvement, to study problems in depth, and to redistribute decision making beyond top levels of the hierarchy" (p. 306). There is a developing realization among assessment practitioners that there is a need to collect information regarding student learning and development in order to improve teaching and learning (Huba \& Freed, 2001; Palomba \& Banta, 1999).

"Part of the future for all of higher education will be deciding what programs to keep and which to retire because they are not being carried out at a competitive level" (O'Neil, 1997, The Customer, para. 3). Program review is a part of the broader process of institutional assessment and promotes the necessary changes to improve student learning and development (Huba \& Freed, 2001; Palomba \& Banta, 1999). Institutions often require departments or units to "conduct formal self-studies at regular intervals" (Palomba \& Banta, 1999, p. 307). In this process "a great deal of descriptive information" is collected and reported to both internal and external audiences (p. 308). If program review procedures and protocol are already in place, faculty may find assessment to be redundant, but should be encouraged to see program review as part of the same assessment component and not separately (Huba \& Freed, 2001; Palomba \& Banta, 1999). If data is collected in the interim, it will reaffirm the meaningfulness of assessment with faculty and promote continual improvement in the program review process. In addition, program assessment completed in conjunction with accreditors would "offer a review process" that would inform a program how it compared nationally 
to similar programs and would be a beneficial service to institutions (O'Neil, 1997, The Customer, para. 3).

Planning and budgeting is another "connection for assessment" (Palomba \& Banta, 1999, p. 308). "Planning generally deals with decisions about future programs; budgeting provides resources to put these programs in place" (p. 308). Unless the information obtained through the assessment process is "respected and valued in planning and budgeting decisions" (p. 309), it will not have a substantial impact for the program. Departments are often required to submit assessment reports on program accomplishments along with budgetary needs. When assessment is considered valuable in the information presented to justify a budget request, it "helps guarantee that assessment will be seen as a valuable process" (p. 309). In addition, "institutions will be expected to provide real demonstrations of how the resources allocated to them have produced a set of outcomes" (O'Neil, 1997, The Purpose, para. 10). As a result, through the assessment process the budget and the outcomes developed must be linked together.

Teaching and learning are the "heart of higher education" (Palomba \& Banta, 1999, p. 309). Assessment must contribute to the teaching and learning environment; otherwise, faculty and students will not willingly participate in the process. Classroom assessment methods can contribute to the overall programmatic review process. However, it is important to periodically confirm that methods implemented in assessment are meaningful and contribute to the improvement of teaching and learning. As a result, faculty development may be required in order to improve the assessment 
methods implemented as well as provide an opportunity to remain current on assessment practices.

In order to improve the assessment process itself, faculty need to make sure thorough information is being obtained from a variety of sources and that numerous opportunities exist to "share and discuss information" with key stakeholders (Palomba \& Banta, 1999, p. 311). Re-evaluating the assessment process periodically will help to ensure that methods of assessment focus on the appropriate outcomes and are revised as students' developmental and learning needs change.

Defining Competencies by Cognitive, Affective, and Psychomotor Taxonomies

During the late 1980's the Pew Charitable Trusts funded a commission whose mission it was to "help policy makers and educators produce health care professionals who meet the changing needs of the American health care system" (The Center for the Health Professions, n.d., Pew Health Professions Commission, para. 1). The third report of the Commission (1995) indicates that "the American health care system is now experiencing the most dramatic transformation in its history" (p. x). The American Association of Colleges of Nursing (AACN) (1998) points out that "increased population...incidence of chronic diseases, and...incidence of infectious diseases" (p. 1) have substantially added to the complexity of the health care environment.

O'Neil (1993) states that the "future will be more oriented toward health, stressing disease and injury prevention, health promotion, elimination of environmental hazards, as well as individual responsibility for health related behaviors" (p. 6). Since the future of health care is changing so will the "skills, values, and attitudes that practitioners and the professions must possess to be successful in this emerging world" (p. 7). The 
organization of health care will change and with it nurses will be required to "master complex information, to coordinate a variety of care experiences, to use technology for health care delivery and evaluation of nursing outcomes..." (AACN, 1998, p. 2).

Private and professional organizations have influenced the nursing profession for many years. Through the reports funded by the Pew Charitable Trusts, the Commission made recommendations that have been incorporated into educational curricula, state legislation, and the national health policy agenda. The Commission examined how to best prepare students to address changes in the health care environment (Boland \& Laidig, 2001).

In the Commission's final report, O'Neil outlined four accreditation recommendations and identified 21 health professions competencies that were intended "to serve as a guide for helping professional schools redirect and redesign their curricula" (Boland \& Laidig, 2001, p. 73). Health professions faculty were urged by the Commission to "review their current curriculum against these recommendations and competencies" (O'Neil, 1998, p. ii).

The accreditation recommendations made by the Commission are intended to strengthen the educational learning experiences designed for undergraduates who aspire to be health professionals. The first recommendation states that "educational institutions, programs and accreditors should recognize their shared responsibility for responding to the changing needs and demands of the public, employers, professional bodies and students (O'Neil, 1998, p. 82). In order to achieve this recommendation, the Commission notes that broad competencies need to be established "for practice 
through a collaborative approach among educators, professional organizations and employers and an on-going assessment of changing practice needs (p. 82).

A series of recommendations directly addresses assessments of student learning. For example, "educators and accreditors should work together to foster continuous assessment and improvement" (p. 82). The primary aim of this partnership is to "actually commit to making improvement a part of the daily work of institutions" ( $p$. 82). In addition, "the accreditation process should encourage creative methods and measures to enhance efficiency, minimize waste and duplication, and streamline assessment processes" (p. 83). Such a streamlined process should ideally increase accountability. The competencies and achievements of college students and graduates should be assessed. An effective process of on-going self-assessment, planning and improvement is crucial. Clearly the Commission feels that assessment is an important role in the accreditation process for health professions since it is included in four recommendations.

The Commission also made four recommendations for nursing. The nursing population is experiencing a rise in the age of registered nurses (RN) and at the time of this report the average age of an RN was 44 years (O'Neil, 1998). Women also dominate the profession, and as a result, the first recommendation for nursing is to "adjust education programs to produce the numbers and types of nurses appropriate to local or regional demand, rather than institutional and political needs" (p. 65). There are multiple levels of educational opportunities nurses can seize. In order to "maximize efficiency, improve coordination and articulation of programs, and reduce professional conflict and public confusion" (p. 65), the second recommendation is for the profession 
to define appropriate competencies for each educational level of entry. The third recommendation is to adjust learning experiences in order to "produce graduates with the competencies needed for differentiated practice" (p. 66). Finally, it has been recommended that the nursing profession "integrate the research, teaching, and practice....in order to further nursing's professional and practical goals" (p. 66).

The reports funded by the Pew Charitable Trusts helped nursing schools focus directly on essential student competencies. Boland and Laidig (2001) indicate that the first report published by the Commission in 1991 prompted nursing leaders and nursing organizations to begin to work together to "identify and describe the competenc[ies] that would advance the practice and education of nursing in maximizing nursing productivity outcomes" (p. 74). The American Association of Colleges of Nursing (AACN) convened a task force to "examine the right mix of knowledge and skills" nurses would need upon entering the practice (p. 74). The product of these discussions was the publication of The Essentials of Baccalaureate Education for Professional Nursing Practice in 1998 which documents the competencies required of baccalaureate prepared nurses. The Commission's recommendations also spurred the revision of the testing and licensing structure of the National Council of State Boards of Nursing (NCSBN) in the 1990s (Boland \& Laidig, 2001).

It is important to discuss what is meant by the term competency before discussing the Commission's list or those developed by the AACN. The literature is replete with a variety of definitions of competency (Bers, 2001; Bradshaw, 1997; Bradshaw, 1998; Hird, 1995; Jones et al., 2002; McMullan, Endacott, Gray, Jasper, Miller, Scholes et al., 2003; Zhang, Luk, Arthur \& Wong, 2001). In addition, some of the 
literature makes a distinction between certain spellings of this term, which in turn give it different meanings. For example, McMullan et al. (2003) and Zhang et al. (2001) indicate competence and competences are job-related and refer to one's ability to demonstrate or produce an output or performance while competency and competencies are person-related or person-oriented and refer to one's characteristics or attributes and lead to "superior performance in a job" (p. 285 and p. 469 respectively). Short (1984) offers a reason for the confusion in this terminology and indicates it stems from the assumption that competence is a descriptive concept as well as "its referral to a thing or an activity rather than a quality or a state of being" (p. 203).

The Working Group on Competency-Based Initiatives in Postsecondary Education offer a much clearer picture of what is meant by competency in higher education. The purpose of this group was to "develop a basic guide to postsecondary competencies" (p. iii). In the Report of the National Postsecondary Education Cooperative, Jones et al. (2002) define a competency as a "combination of skills, abilities, and knowledge needed to perform a specific task" (p.vii). It is further delineated that a hierarchy exists in the learning process where "traits and characteristics are the foundation for learning... on which further experiences can be built", "skills abilities, and knowledge are developed through learning experiences", "competencies are the result of integrative learning experiences" and "demonstrations are the results of applying competencies" (p. 7).

Jones et al. (2002) identify several reasons why competency-based initiatives which are "purposeful actions undertaken by postsecondary institutions directed at 
defining, teaching, and assessing competencies across their system" (p. vii) are important to incorporate at the postsecondary level:

- "...specific articulations of competencies inform and guide the basis of subsequent assessments at the course, program, and institutional level" (p.vii).

- “...specific competencies help faculty and students...as well as other stakeholders...to have a common understanding about specific skills and knowledge that undergraduates should master as a result of their learning experiences" (p. vii).

- “...specific competencies provide directions for designing learning experiences and assignments that will help students gain practice in using and applying these competencies in different contexts" (p. vii).

Students will benefit from their educational experiences as long as higher education institutions can describe, measure, and judge the "skills, knowledge, and abilities considered important with respect to whatever [students] are studying..." (p.9) and use this information to improve student learning.

The nursing profession is experiencing a "paradigm shift" since it has adopted competency-based education (Boland \& Laidig, 2001, p. 77). As a result, nursing leaders and nursing organizations are identifying and defining the knowledge, skills, and abilities required to educate future nurses. Though there is not a common competencybased model for nursing, several groups have made attempts to develop such commonalities within the profession (Boland and Laidig, 2001). In order for a common model to be developed there needs to be agreement regarding the skills, knowledge and abilities required of nurses at each level of entry into the profession. Unfortunately, 
this is not likely to occur in the near future; however, the Commission does offer 21 competencies for health professionals for the $21^{\text {st }}$ Century, which may serve as a starting point for discussion.

Well-established taxonomies already exist that define cognitive, affective and psychomotor skills for undergraduates. Field et al. (1984) indicate that a "taxonomy is viewed as a hierarchy; i.e., each skill or task is built upon and assumes acquisition of the previous skill or task" (p. 284). Nurse educators and employers require students to achieve the skills that "culminate in the higher categories of a taxonomy" (p. 284) and as a result, appropriate learning experiences must be developed in order to achieve this goal.

\section{Cognitive Taxonomy}

The cognitive domain consists of a hierarchy of knowledge, comprehension, application, analysis, synthesis and evaluation based on Bloom's (1956) taxonomy. This domain is a "mental functioning which includes activities of remembering and recalling knowledge, thinking problem solving and creating" (Field et al., 1984, p. 285). Greater emphasis is often focused on the cognitive behavior of students in baccalaureate nursing programs than other behaviors (Field et al., 1984). Table 1 illustrates the hierarchy of this domain and offers a definition for each level. 
Table1

Definitions of the Cognitive Taxonomy

\begin{tabular}{ll}
\hline \multicolumn{1}{c}{ Level } & \multicolumn{1}{c}{ Definition } \\
\hline Knowledge & $\begin{array}{l}\text { Remembering previously learned material. The skill may involve } \\
\text { recall of a wide range of material, from specific facts to complete } \\
\text { theories, but all that is required is the bringing to mind of the } \\
\text { appropriate information. Knowledge represents the lowest level of } \\
\text { learning outcomes in the cognitive domain. }\end{array}$ \\
Comprehension & $\begin{array}{l}\text { The ability to grasp meaning of material. This skill may be shown by } \\
\text { translating material from one form to another (words or numbers), by } \\
\text { interpreting material (explaining or summarizing), and by estimating } \\
\text { future trends (predicting consequences or effects). }\end{array}$ \\
Application & $\begin{array}{l}\text { The ability to use learned material in new and concrete situations. } \\
\text { Analysis }\end{array}$ \\
$\begin{array}{l}\text { This may include the application of such things as rules, methods, } \\
\text { concepts, principles, laws, and theories. }\end{array}$ \\
$\begin{array}{l}\text { The ability to break down material into its component parts so that its } \\
\text { organizational structure may be understood. This skill may include } \\
\text { the identification of the parts, analysis of the relationship between } \\
\text { parts, and recognition of the organizational principles involved. }\end{array}$ \\
$\begin{array}{l}\text { The ability to put parts together to form a new whole. This may } \\
\text { involve the production of a unique communication (theme or speech), } \\
\text { a plan of operations (research proposal), or a set of abstract relations } \\
\text { (scheme for classifying information). }\end{array}$ \\
$\begin{array}{l}\text { The ability to judge the value of material (statement, novel, poem, } \\
\text { research report) for a given purpose. The judgments are to be based } \\
\text { on definite criteria. These may be internal criteria (organization) or } \\
\text { external criteria (relevance to the purpose) and the student may } \\
\text { determine the criteria or be given them. }\end{array}$ \\
\hline Evaluation
\end{tabular}

Note: From "Bloom's Taxonomy: Cognitive Domain" by The University of Mississippi,

2003, Retrieved May 19, 2003, from

http://www.olemiss.edu/depts/educ_school2/docs/stai_manual/manual8.htm

Affective Taxonomy

The affective domain consists of a hierarchy of receiving, responding, valuing, organization, and characterization by value set (Krathwohl, Bloom \& Masia, 1964). It is 
the "assessment of a feeling, tone, and emotion, or a degree of acceptance or rejection, expressed as interest, attitudes, application, values and emotional sets or biases" (Field et al., 1984, p. 287). One of the challenges Field et al. identify is the ability to "evaluate students' values and attitudes...objectively" (p. 287). Table 2 illustrates the hierarchy of this domain and offers a definition for each level.

Table 2

Definitions of the Affective Taxonomy

\begin{tabular}{|c|c|}
\hline Level & Definition \\
\hline Receiving & $\begin{array}{l}\text { Being aware of or sensitive to the existence of certain ideas, material, } \\
\text { or phenomena and being willing to tolerate them. }\end{array}$ \\
\hline Responding & $\begin{array}{l}\text { Committed in some small measure to the ideas, materials, or } \\
\text { phenomena involved by actively responding to them. }\end{array}$ \\
\hline Valuing & $\begin{array}{l}\text { Willing to be perceived by others as valuing certain ideas, materials, } \\
\text { or phenomena. }\end{array}$ \\
\hline Organization & $\begin{array}{l}\text { To relate the value to those already held and bring it into a } \\
\text { harmonious and internally consistent philosophy. }\end{array}$ \\
\hline $\begin{array}{l}\text { Characterization } \\
\text { by Value Set }\end{array}$ & $\begin{array}{l}\text { To act consistently in accordance with the values he or she has } \\
\text { internalized. }\end{array}$ \\
\hline
\end{tabular}

Note: From "Krathwohl's Taxonomy of Affective Domain" by George Mason University, 2003, Retrieved July 6, 2003, from

http://classweb.gmu.edu/ndabbagh/Resources/Resources2/krathstax.htm.

Psychomotor Taxonomy

The psychomotor domain consists of a hierarchy of imitation, manipulation, precision, articulation, and naturalization (The University of Mississippi, 2003c). It is the use of a "knowledge base to implement a procedure in a manner that indicates progress in mastery of the performance" (Field et al., 1984, p. 289). Table 3 illustrates the hierarchy of this domain and offers a definition for each level. 
Table 3

Definitions of the Psychomotor Taxonomy

\begin{tabular}{ll}
\hline \multicolumn{1}{c}{ Level } & \multicolumn{1}{c}{ Definition } \\
\hline Imitation & $\begin{array}{l}\text { Early stages in learning a complex skill, overtly, after the individual } \\
\text { has indicated a readiness to take a particular type of action. Imitation } \\
\text { includes repeating an act that has been demonstrated or explained, } \\
\text { and it includes trial and error until an appropriate response is } \\
\text { achieved. }\end{array}$ \\
Manipulation & $\begin{array}{l}\text { Individual continues to practice a particular skill or sequence until it } \\
\text { becomes habitual and the action can be performed with some } \\
\text { confidence and proficiency. The response is more complex than at } \\
\text { the previous level, but the learner still isn't "sure of him/herself." }\end{array}$ \\
Precision & $\begin{array}{l}\text { Skill has been attained. Proficiency is indicated by a quick, smooth, } \\
\text { accurate performance, requiring a minimum of energy. The overt } \\
\text { response is complex and performed without hesitation. }\end{array}$ \\
Articulation & $\begin{array}{l}\text { Involved an even higher level of precision. The skills are so well } \\
\text { developed that the individual can modify movement patterns to fit } \\
\text { special requirements or to meet a problem situation. }\end{array}$ \\
Naturalization & $\begin{array}{l}\text { Response is automatic. The individual begins to experiment, creating } \\
\text { new motor acts or ways of manipulating materials out of }\end{array}$ \\
understandings, abilities, and skills developed. One acts "without \\
thinking."
\end{tabular}

Note: From "Bloom's Taxonomy: Psychomotor Domain" by The University of

Mississippi, 2003, Retrieved May 19, 2003, from

http://www.olemiss.edu/depts/educ_school2/docs/stai_manual/manual10.htm.

Competencies Categorized by Taxonomy

The purpose of Tables 4 through 6 is to categorize the professional nursing standards for accreditation and competencies for health professionals into the appropriate level within the cognitive, affective or psychomotor taxonomy. Health professional competencies are identified in the second column as recommended in the Fourth Report funded by the Pew Charitable Trusts (1998). The third column is based 
on the competencies defined by the American Association of Colleges of Nursing's autonomous accrediting agencies, Commission on Collegiate Nursing Education (CCNE), 2003 amended standards for accreditation of baccalaureate and graduate nursing programs.

The reason for using the AACN guidelines as a comparison to the Commission's competencies stems from the CCNE's 2002 Annual Report where it states that it "is the only national accrediting agency to focus exclusively on advancing bachelor's... programs as a distinct subset of nursing education" (p.4). This group serves as the "national voice for nursing education programs in universities and four-year colleges" (p.4). As a result, it is appropriate to compare the guidelines these organizations recommend to the professional nurse educator. In addition, the AACN's essentials represent and define the "knowledge, values, and professional behaviors expected of the baccalaureate nursing graduate" (AACN, 1998, p. 1).

\section{Cognitive Competencies}

The majority of the AACN's baccalaureate essentials and the health professional competencies from the Fourth Report of the Pew Health Professions Commission can be categorized into the cognitive taxonomy (see Table 4). This confirms the statement that Field et al. (1984) make regarding how the greatest focus in baccalaureate nursing programs is on cognitive behaviors. Each level in the cognitive domain builds on previous levels achieved. Health professionals are required to use abstract ideas and make judgments about those ideas, which are activities that reside at the top of the cognitive taxonomy; however, the knowledge behind a given competency must already be in place. 
Furthermore, the AACN (1998) recommends students obtain "broad-based knowledge" (p. 7). However, knowledge cannot be separated from the higher order cognitive levels as it is necessary to perform in advanced levels of the cognitive domain. Once a knowledge base is developed, it will provide the framework for the development of higher order skills in the cognitive domain. As students move into a professional nursing program, they "must be accountable for previous knowledge" and be able to integrate concepts, interpret data, apply knowledge, and a variety of other mental functions (p. 7).

There are several pieces of core knowledge that nursing students must have before applying this knowledge at higher cognitive levels. For example, in order for nursing students to be able to apply health promotion protocol, they must first have the knowledge about "health risks and methods to prevent or reduce" (AACN, 1998, p. 12) them.

Most of the nursing cognitive competencies and baccalaureate essentials are at the application level. At this level, students begin practicing what they have learned and incorporate and transform this information upward into higher levels of thinking. At the analysis, synthesis and evaluation stages, students are able to construct new meanings, decisions and value from the knowledge obtained at the beginning of their education. For example, students use the knowledge and understanding gained about health promotion and apply this knowledge to assess a patient's health then synthesize the data from this assessment in order to evaluate a health plan to best fit the patient's needs. 
Table 4

Cognitive Competencies for Professional Nursing Students

\begin{tabular}{|c|c|c|}
\hline $\begin{array}{l}\text { Competency type } \\
\text { cognitive }\end{array}$ & $\begin{array}{l}\text { Health professional } \\
\text { competencies* }^{*}\end{array}$ & $\begin{array}{c}\text { AACN baccalaureate nursing } \\
\text { essentials** }\end{array}$ \\
\hline - Knowledge & $\begin{array}{l}\text { Knowledge of new } \\
\text { sciences. }\end{array}$ & $\begin{array}{l}\text { Liberal Education } \\
\text { - } \quad \text { Broad-based knowledge } \\
\text { that provides a } \\
\text { "framework of knowledge } \\
\text { in the arts and sciences } \\
\text { (p. 7). } \\
\text { Core Knowledge } \\
\text { - Health promotion } \\
\text { requires "knowledge } \\
\text { about health risks and } \\
\text { methods to prevent or } \\
\text { reduce these risks" (p. } \\
\text { 12). } \\
\text { "Disease prevention } \\
\text { knowledge includes } \\
\text { methods of keeping an } \\
\text { illness or injury from } \\
\text { occurring...treating a } \\
\text { disease early...and } \\
\text { preventing further } \\
\text { deterioration" as a result } \\
\text { of the disease (p. 12). } \\
\text { Knowledge about } \\
\text { pharmacology, } \\
\text { pathophysiology of } \\
\text { disease, and assessment } \\
\text { and management of } \\
\text { symptoms across the } \\
\text { lifespan" (p. 13). }\end{array}$ \\
\hline - Comprehension & $\begin{array}{l}\text { Understand the role } \\
\text { of primary care ( } p \text {. } \\
\text { 33). }\end{array}$ & $\begin{array}{l}\text { Core Knowledge } \\
\text { - "Human diversity } \\
\text { includes understanding } \\
\text { the ways cultural, racial, } \\
\text { socioeconomic, religious, } \\
\text { and lifestyle variations } \\
\text { are expressed" (p. 15). }\end{array}$ \\
\hline
\end{tabular}


Table 4 (continued)

Cognitive Competencies for Professional Nursing Students

\begin{tabular}{|c|c|c|}
\hline $\begin{array}{l}\text { Competency type } \\
\text { cognitive }\end{array}$ & $\begin{array}{l}\text { Health professional } \\
\text { competencies* }\end{array}$ & $\begin{array}{c}\text { AACN baccalaureate nursing } \\
\text { essentials** }\end{array}$ \\
\hline & & $\begin{array}{l}\text { - "Global health care } \\
\text { knowledge includes an } \\
\text { understanding of the } \\
\text { implications of living } \\
\text { with transportation and } \\
\text { information technology } \\
\text { that link all parts of the } \\
\text { world" (p. 15). } \\
\text { Health care system } \\
\text { "includes an } \\
\text { understanding of the } \\
\text { organization and } \\
\text { environment in which } \\
\text { nursing and health care } \\
\text { is provided..." (p. 15). }\end{array}$ \\
\hline - Application & $\begin{array}{l}\text { - Apply knowledge of } \\
\text { the new sciences } \\
\text { (p. 31). } \\
\text { - Incorporate the } \\
\text { multiple } \\
\text { determinants of } \\
\text { health in clinical } \\
\text { care (p. 31). } \\
\text { - Rigorously practice } \\
\text { preventive health } \\
\text { care (p. 33). } \\
\text { Use communication } \\
\text { and information } \\
\text { technology } \\
\text { effectively and } \\
\text { appropriately ( } p \text {. } \\
\text { 38). } \\
\text { Practice leadership } \\
\text { (p. 40). }\end{array}$ & $\begin{array}{l}\text { Core Knowledge } \\
\text { " } \text { "Information technology } \\
\text { includes traditional and } \\
\text { developing methods of } \\
\text { discovering, retrieving, } \\
\text { and using information } \\
\text { in nursing practice" } \\
\text { (p.13). } \\
\text { "Ethics includes values, } \\
\text { codes, and principles } \\
\text { that govern decisions in } \\
\text { nursing practice, } \\
\text { conduct, and } \\
\text { relationships" (p.14). } \\
\text { Health care policy is } \\
\text { "an ability to determine } \\
\text { accessibility, } \\
\text { accountability, and } \\
\text { affordability" in a health } \\
\text { care system (p. 15). }\end{array}$ \\
\hline
\end{tabular}


Table 4 (continued)

Cognitive Competencies for Professional Nursing Students

\begin{tabular}{|c|c|c|}
\hline $\begin{array}{l}\text { Competency type } \\
\text { cognitive }\end{array}$ & $\begin{array}{l}\text { Health professional } \\
\text { competencies }^{*}\end{array}$ & $\begin{array}{c}\text { AACN baccalaureate nursing } \\
\text { essentials }\end{array}$ \\
\hline & & $\begin{array}{l}\text { Role Development } \\
\text { Provider of care "uses } \\
\text { theory and research- } \\
\text { based knowledge in the } \\
\text { direct and indirect } \\
\text { delivery of care to } \\
\text { patients, and in the } \\
\text { formation of partnerships } \\
\text { with patients and the } \\
\text { interdisciplinary health } \\
\text { care team" (p. 16). } \\
\text { Designer/manager/coord } \\
\text { inator of care uses } \\
\text { "information from } \\
\text { numerous sources... [to } \\
\text { guide] the patient } \\
\text { through the health care } \\
\text { system. Skills essential } \\
\text { to this role development } \\
\text { are communication, } \\
\text { collaboration, } \\
\text { negotiation, delegation, } \\
\text { coordination, and } \\
\text { evaluation..." (p. 16). }\end{array}$ \\
\hline - Analysis & - None applicable & $\begin{array}{l}\text { Core Knowledge } \\
\text { " } \text { "Assessment is gathering } \\
\text { information about the } \\
\text { health status of a patient" } \\
\text { and analyzing those data } \\
\text { (p. 10). }\end{array}$ \\
\hline - Synthesis & $\begin{array}{l}\text { Provide evidence- } \\
\text { based, clinically } \\
\text { competent care ( } p \text {. } \\
\text { 30). }\end{array}$ & $\begin{array}{l}\text { Liberal Education } \\
\text { • "...promotes critical } \\
\text { thinking” (p.7). }\end{array}$ \\
\hline
\end{tabular}


Table 4 (continued)

Cognitive Competencies for Professional Nursing Students

\begin{tabular}{|c|c|c|}
\hline $\begin{array}{c}\text { Competency type } \\
\text { cognitive }\end{array}$ & $\begin{array}{l}\text { Health professional } \\
\text { competencies* }\end{array}$ & $\begin{array}{c}\text { AACN baccalaureate nursing } \\
\text { essentials** }\end{array}$ \\
\hline \multirow{3}{*}{ - Evaluation } & $\begin{array}{l}\text { Demonstrate critical } \\
\text { thinking, reflection, } \\
\text { and problem-solving } \\
\text { skills (p. } 32 \text { ). }\end{array}$ & \\
\hline & $\begin{array}{l}\text { - Integrate population- } \\
\text { based care and } \\
\text { services into practice } \\
\text { (p. 34). }\end{array}$ & $\begin{array}{l}\text { Core Competencies } \\
\text { - "Critical thinking } \\
\text { underlies independent } \\
\text { and interdependent } \\
\text { decision making" (p.9). } \\
\text { - Assessment is } \\
\text { synthesizing data about } \\
\text { the health status of a } \\
\text { patient and making } \\
\text { judgments about nursing } \\
\text { interventions on the } \\
\text { findings, and evaluating } \\
\text { patient care outcomes" } \\
\text { (p. 10). }\end{array}$ \\
\hline & & $\begin{array}{l}\text { Core Knowledge } \\
\text { - "Illness and disease } \\
\text { management" (p. 13). }\end{array}$ \\
\hline
\end{tabular}

Note: "From "Recreating health professional practice for a new century," by E. H.

O'Neil and the Pew Health Professions Commission, 1998, The Fourth Report of the

Pew Health Professions Commission. Copyright 1998 by the Pew Health Professions

Commission. ${ }^{* *}$ From "The essentials of baccalaureate education for professional nursing practice," by American Association of Colleges of Nursing, 1998, Washington, DC. Copyright 1998 by American Association of Colleges of Nursing. 


\section{Affective Competencies}

All of the professional values described in the baccalaureate essentials: altruism, autonomy, human dignity, integrity, and social justice have been categorized within the affective domain. These professional nurse attributes are "the foundation for practice" (AACN, 1998, p. 8). Individuals should be committed to these values and beliefs and be "reflected in patterns of behavior" (p. 8). Accordingly, the highest level of the affective domain is the characterization by value set that "incorporates behavior which is consistent and predictive, including the personal, social and emotional patterns of adjustment" (Field et al., 1984, p. 287). This behavior occurs when a nurse "uses theory to change [their] own behavior during interactions with clients" (p. 287).

The core competency, communication (see Table 5), from the baccalaureate essentials is categorized in the affective domain at the responding level. Once students master this competency, they are able to interact "using basic communication techniques" (Field et al., 1984, p. 287) once they are practicing nurses. In addition, students who have achieved this skill are able to "adapt communication methods to patients with special needs" (O'Neil, 1998, p. 10) as this illustrates the active participation and motivation of the student. In addition, they are able to describe "interactions...verbally and in writing" (p. 287). Both of these skills are similar to those outlined by the AACN (1998).

Many of the health professional competencies are found in the affective domain. These competencies are crucial so that nursing students can address many of the social and civic issues as they begin practice upon completion of their undergraduate program. As nursing students progress in their education, they learn skills that guide 
their emotional development, as well as their attitude and values regarding social responsibility. Students who are able to provide culturally appropriate care to patients, improve the health of diverse populations, or partner with communities must have developed affective skills. The competencies and essentials outlined indicate the importance of the affective domain in nursing education.

Table 5

Affective Competencies for Professional Nursing Students

\begin{tabular}{|c|c|c|}
\hline $\begin{array}{l}\text { Competency type } \\
\text { cognitive }\end{array}$ & $\begin{array}{l}\text { Health professional } \\
\text { competencies* }\end{array}$ & $\begin{array}{c}\text { AACN baccalaureate nursing } \\
\text { essentials }\end{array}$ \\
\hline - Receiving & - None applicable & - None applicable \\
\hline - Responding & $\begin{array}{l}\text { Improve access to } \\
\text { health care for those } \\
\text { with unmet health } \\
\text { needs (p. 35). }\end{array}$ & $\begin{array}{l}\text { Core Competencies } \\
\text { - "Communication is a } \\
\text { complex, ongoing, } \\
\text { interactive process and } \\
\text { forms the basis for } \\
\text { building interpersonal } \\
\text { relationships.... [and] } \\
\text { includes listening, as well } \\
\text { as oral, nonverbal, and } \\
\text { written communication } \\
\text { skills" (p.10). }\end{array}$ \\
\hline - Valuing & $\begin{array}{l}\text { Practice relationship- } \\
\text { centered care with } \\
\text { individuals and } \\
\text { families ( } \mathrm{p} .35) \text {. } \\
\text { - Provide culturally } \\
\text { sensitive care to a } \\
\text { diverse society ( } \mathrm{p} \text {. } \\
\text { 36). } \\
\text { - Partner with } \\
\text { communities in } \\
\text { health care } \\
\text { decisions (p. } 37) \text {. }\end{array}$ & $\begin{array}{l}\text { Professional Values } \\
\text { - "Integrity is the acting in } \\
\text { accordance with an } \\
\text { appropriate code of } \\
\text { ethics and accepted } \\
\text { standards of practice" } \\
\text { (p.9). } \\
\text { - "Social justice is } \\
\text { upholding moral, legal, } \\
\text { and humanistic } \\
\text { principles" (p. 9). }\end{array}$ \\
\hline
\end{tabular}


Table 5 (continued)

Affective Competencies for Professional Nursing Students

\begin{tabular}{|c|c|c|}
\hline $\begin{array}{l}\text { Competency type } \\
\text { cognitive }\end{array}$ & $\begin{array}{l}\text { Health professional } \\
\text { competencies* }\end{array}$ & $\begin{array}{c}\text { AACN baccalaureate nursing } \\
\text { essentials*** }\end{array}$ \\
\hline & $\begin{array}{l}\text { - Contribute to } \\
\text { continuous } \\
\text { improvement of the } \\
\text { health care system } \\
\text { (p. 41). } \\
\text { Continue to learn } \\
\text { and help others } \\
\text { learn (p. 43). }\end{array}$ & \\
\hline - Organization & $\begin{array}{l}\text { Ensure care that } \\
\text { balances individual, } \\
\text { professional, } \\
\text { system, and societal } \\
\text { needs (p. 39). } \\
\text { Take responsibility } \\
\text { for quality of care } \\
\text { and health outcomes } \\
\text { at all levels (p. 41). }\end{array}$ & - None applicable \\
\hline $\begin{array}{l}\text { - Characterization } \\
\text { by value set }\end{array}$ & $\begin{array}{l}\text { Embrace a personal } \\
\text { ethic of social } \\
\text { responsibility and } \\
\text { service (p. 29). } \\
\text { Exhibit ethical } \\
\text { behavior in all } \\
\text { professional } \\
\text { activities (p. 29). } \\
\text { Work in } \\
\text { interdisciplinary } \\
\text { teams (p. 39). } \\
\text { Advocate for public } \\
\text { policy that promotes } \\
\text { and protects the } \\
\text { health of the public } \\
\text { (p. } 42 \text { ). }\end{array}$ & $\begin{array}{l}\text { Professional Values } \\
\text { - "Altruism is a concern for } \\
\text { the welfare and well } \\
\text { being of others" (p.8). } \\
\text { - "Autonomy is the right to } \\
\text { self-determination" (p.8). } \\
\text { "Human dignity is } \\
\text { respect for the inherent } \\
\text { worth and uniqueness of } \\
\text { individuals and } \\
\text { populations" (p.9). } \\
\text { Role Development } \\
\text { Member of a profession } \\
\text { who "embrace[s] life-long } \\
\text { learning, incorporate[s] } \\
\text { professionalism into } \\
\text { practice, and identif[ies] } \\
\text { with the values of the } \\
\text { profession" (p. 17). }\end{array}$ \\
\hline
\end{tabular}


Note: *From "Recreating health professional practice for a new century," by E. H. O'Neil and the Pew Health Professions Commission, 1998, The Fourth Report of the Pew Health Professions Commission. Copyright 1998 by the Pew Health Professions Commission. ${ }^{* *}$ From "The essentials of baccalaureate education for professional nursing practice," by American Association of Colleges of Nursing, 1998, Washington, DC. Copyright 1998 by American Association of Colleges of Nursing.

Psychomotor Competencies

There are no health professional competencies and only one baccalaureate essential categorized in the psychomotor domain (see Table 6). The core competency, technical skills, is categorized at the articulation level. It could potentially fit into the cognitive domain at the analysis level; however, the majority of skills listed by the AACN are psychomotor in nature. A few experiences that students typically participate in to achieve proficiency in technical skills are to "monitor and assess vital signs, including pulse and respiratory rate, [and] temperature... blood pressure" as well as "...manage wounds, including irrigation, application of dressings, and suture/staple removal" (AACN, 1998, p. 11-12).

Table 6

Psychomotor Competencies for Professional Nursing Students

\begin{tabular}{lcc}
$\begin{array}{c}\text { Competency type } \\
\text { cognitive }\end{array}$ & $\begin{array}{c}\text { Health professional } \\
\text { competencies* }^{*}\end{array}$ & $\begin{array}{c}\text { AACN baccalaureate nursing } \\
\text { essentials }\end{array}$ \\
\hline - Imitation & $\bullet$ None applicable & $\bullet$ None applicable \\
- Manipulation & - None applicable & - None applicable \\
- Precision & - None applicable & $\bullet$ None applicable \\
\hline
\end{tabular}


Table 6 (continued)

Psychomotor Competencies for Professional Nursing Students

\begin{tabular}{ccc}
\hline $\begin{array}{c}\text { Competency type } \\
\text { cognitive }\end{array}$ & $\begin{array}{c}\text { Health professional } \\
\text { competencies }^{*}\end{array}$ & $\begin{array}{c}\text { AACN baccalaureate nursing } \\
\text { essentials }^{* *}\end{array}$ \\
\hline$\bullet$ Articulation & $\bullet$ None applicable & $\begin{array}{c}\text { Core Competencies } \\
\text { "Technical skills" of the } \\
\text { baccalaureate nurse } \\
\text { require an" }\end{array}$ \\
& understanding and use of \\
& skills in a sophisticated, \\
& theoretical and analytic \\
& manner" $(p .11)$.
\end{tabular}

- Naturalization - None applicable - None applicable Note: *From "Recreating health professional practice for a new century," by E. H. O'Neil and the Pew Health Professions Commission, 1998, The Fourth Report of the Pew Health Professions Commission. Copyright 1998 by the Pew Health Professions Commission. ${ }^{* *}$ From "The essentials of baccalaureate education for professional nursing practice," by American Association of Colleges of Nursing, 1998, Washington, DC. Copyright 1998 by American Association of Colleges of Nursing.

What is Service Learning?

Service learning has multiple dimensions that should be present when implementing it into the curriculum. Service learning includes "both service to the community and learning [that is] tied to academic curriculum" (Billig, 2003, p. viii). In considering the concepts and practices of service learning, it is defined as ... a method under which students or participants learn and develop through active participation in thoughtfully organized service that is conducted in and meets the needs of a community and is coordinated with an... institution of higher education... and with the community, helps foster 
civic and social responsibility, is integrated into and enhances the academic curriculum of the student's program or the educational competencies of the community-service program in which the participants are enrolled, and includes structured time for the students and participants to reflect on the service experience (Norbeck, Connolly, \& Koerner, 1998, p.1).

The literature discusses several dimensions of service learning consistently. Those dimensions indicate that service learning is:

- Organized and coordinated to achieve specific learning outcomes (Astin, Vogelgesang, Ikeda, \& Yee, 2000; Batchelder \& Root, 1994; Cohen, \& MiloneNuzzo, 2001; Eyler \& Giles, 1999; Gray et al., 1999; Honnet \& Poulson, 1989; Kendrick, 1996; Osbourne, Hammerich \& Hensley, 1998).

- Coordinated with and meet the needs of the community as defined by the community (Bittle, Duggleby \& Ellison, 2002; Cohen, \& Milone-Nuzzo, 2001; Gugerty \& Swezey, 1996; Honnet \& Poulson, 1989).

- Foster civic and social responsibility (Eyler \& Giles, 1999; Giles \& Eyler, 1994; Gray et al., 1999; Kendrick, 1996; Markus, King \& Howard, 1993; Narsavage, Bachelor, Lindell \& Chen, 2003).

- Integrated into the academic curriculum (Eyler \& Giles, 1999; Gray et al., 1999; Hales, 1997; Kendrick, 1996).

- Structured reflection opportunities (Batchelder \& Root, 1994; Bittle, Duggleby \& Ellison, 2002; Eyler, 2002; Eyler \& Giles, 1999; Gray et al., 1999; Hales, 1997; 
Honnet \& Poulson, 1989; Mabry, 1998; Strage, 2000; Whitbourne, Collins \& Skultety, 2001).

Researchers agree that "service-learning is both a program type and a philosophy of education" (Giles, Honnet \& Migliore, 1991, p. 7). As a program type, it is an opportunity for students to provide services to the community while reflecting and studying content related to the service activity (Giles et al., 1991). As a philosophy of education, it is an opportunity for students to link social responsibility to learning in an "active and ...meaningful way" (p. 7).

Service learning should not to be confused with other services students might provide such as volunteerism or community service. These latter two activities are supported in higher education and students are encouraged to participate in them. However, service areas other than service learning are "not intended or designed to promote...learning and development" (Gray et al., 1999, p.5). Service learning in higher education meets the needs of the community, the student and it helps institutions "meet their own educational goals" (Jacoby, 1996, p. 20). Service learning is formally incorporated into existing academic courses with the expectation that students will achieve certain skills and advance their learning.

\section{What is the Educational Foundation of Service Learning?}

Experiential learning is the foundation from which service learning has developed. It "offers the foundation for an approach to education and learning as a lifelong process" (Kolb, 1984, p. 3). It has also "become widely accepted as a method of instruction in colleges and universities across the nation" (p. 3). According to Kolb, 
students learn when they gain knowledge from previous experiences and apply it to current and/or similar learning experiences.

Enthusiasm for service learning, which evolved from experiential education, started in full swing with the National and Community Service Trust Act of 1990 in which George H.W. Bush signed the initial legislation. Then President Clinton renewed its efforts during his term in office and it continues today (Jacoby, 1996) through the Corporation for National Service (CNS). There are other organizations whose purpose it is to encourage service learning, promote best practices, hold national conferences, and publish service learning resource materials. For example, Campus Compact is a "national coalition of college and university presidents who are committed to fulfilling the civic purpose of higher education" (Campus Compact, 2002, p. 2). Campus Compact serves as a resource for higher education faculty to enable them to better "integrate civic engagement into their teaching and research" (p. 2). Community-Campus Partnerships for Health (CCPH) is an organization that was developed out of the Health Professions Schools in Service to the Nation under the auspices of the Pew Health Professions Commission and "fosters partnerships between communities and health professions schools" (Seifer, 1998, p. 276). The National Society of Experiential Education (NSEE) is another organization that serves as a national resource for service learning.

Service learning is intended to produce better students and an active citizenry. Gray et al. (1999) believe service learning will help with the "perceived inadequacies in American...higher education" (p.1), and prepare students for the "responsibilities of living in a democratic society" (p.1). Campus Compact (1994) notes that service 
learning at Brevard Community College provides an opportunity for students to apply their classroom knowledge, "enhance personal growth and self-image...foster a concern for social problems which leads to a sense of social responsibility and commitment to public/human service" (Definitions of service learning, para. 3).

In the nursing curriculum, Childs, Sepples, and Moody (2003) indicate that service-learning courses provide a "unique opportunity for students to learn about communities, poverty, diversity, teamwork, at-risk populations, and their own biases and upbringing" (p. 185). As originally indicated in the Fourth Pew report by O'Neil (1998), Seifer and Vaughn (2002) follow by stating that "as national trends in health care delivery shift to community-based settings, the integration of service-learning into health professions education becomes an increasingly important issue for health profession educators, students, and communities" (p. 438). Sternas, O'Hare, Lehman, and Milligan (1999) further iterate that "all health professionals should be trained in working with persons from various cultural backgrounds, practicing, prevention, utilizing community resources, and working in teams with other professionals" (p.67). Service learning is the avenue many health professions educators use to develop students who are active citizens and socially responsible (Seifer \& Vaughan, 2002). "Service-learning experiences are increasingly part of the nursing curricula" (Sternas et al., p.66).

There are a few studies that focus more on critical thinking (Eyler, et al., 1997; Hesser, 1995; Sedlak, Doheny, Panthofer \& Anaya, 2003; Vogelgesang \& Astin, 2000), communication skills (Carter \& Dunn, 2002; Hesser, 1995; Osborne et al., 1998), and better understanding of course content (Hesser, 1995; Strage, 2000). Research that addresses the outcomes of service learning in the nursing curriculum focuses on much 
the same topics, but a few focus on additional areas such as understanding cultural diversity (Bittle, et al., 2002; Carter \& Dunn, 2002; Childs et al., 2003; Hales, 1997), one's own biases (Childs et al., 2003), and community awareness (Bittle et al., 2002; Sedlak et al., 2003). The results from these major research studies are discussed in the next section.

In addition to the societal and health problems that service learning may be able to address, scholars are also concerned about students' learning outcomes of such experiences. Much of the research focuses on a variety of course topics and examines whether service learning increases civic responsibilities. Civic responsibilities describe one's "commitment to serving the community, [and/or one's] intent to participate in volunteer work in the future" (Gray et al., 1999, p. 1). Several of the research studies find that service learning cultivates skills needed to better relate and appreciate people from different backgrounds (Kuh, 1993), shows positive changes in social responsibility and civic attitudes (Kendrick, 1996; Mabry, 1998), contributes to citizenship confidence Eyler, Giles \& Braxton, 1997), and increases attitudes regarding the need to serve others in need (Markus, Howard \& King, 1993).

\section{What are the Outcomes of Service Learning?}

The research literature reveals many different outcomes of service learning. The two major types of outcomes students achieve when they participate in service learning are: cognitive and affective (Gelmon, Holland, Driscoll, Spring \& Kerrigan, 2001). Outcomes from the psychomotor taxonomy are not discussed in the service-learning literature as these skills are typically not the focus of service learning. These skills are often obtained in other types of educational activities. 


\section{Cognitive Outcomes}

Service learning provides students with an opportunity to apply cognitive skills they have gained in the classroom in new situations in society. Researchers have used multiple methods to measure the cognitive outcomes of student participating in service learning such as self-report, course evaluation, general measures of critical thinking, general measures of creativity, and coding open-ended responses related to course content including problem solving protocols (Eyler \& Giles, 1999). However, cognitive outcomes are not "easily captured by traditional assessment instruments, which tend to test recall of factual content" (Steinke \& Buresh, 2002, p. 9). As a result, it is suggested that better definitions of cognitive outcomes be developed and that assessment measures should capture students' intelligent use of course content.

High quality service-learning projects increased cognitive outcomes and "predicted a more complex understanding of causes of and solutions to problems" in society (Steike \& Buresh, 2002, p. 9). From their 1999 study, Eyler and Giles state that critical thinking "allows students to identify, frame, resolve and readdress social issues..."; however, they go on to clarify that this ability is based on one's level of "knowledge ... and cognitive development" (p. 101). Students need that underlying knowledge before they can apply it to real life situations. It is the task of higher education to ensure students graduate with this ability. Eyler and Giles further state that service learning did help "students reach this important educational goal" (p. 101) when the experiences are an effective collaboration between the classroom and service environment. 
Carter \& Dunn (2002) emphasize the importance of collaboration between students and partners in the community. Students who participated in a diabetes management service-learning experience reported an increase in communication and collaboration with health care providers. This in turn led to a critical reflection on the part of students in that they were able to problem solve with the community partners in order to help the service-learning clientele overcome health barriers of their disease. Students were also able to examine and understand cultural differences as well as communicate better with those in the community.

Hesser (1995) surveyed and interviewed faculty who had incorporated service learning into their courses in order to determine their perceptions of student outcomes achieved by their undergraduates. Of the 48 faculty who participated in the study, $74 \%$ reported that they observed an increase either "very extensively" or "extensively" in students' "critical thinking/analytic skills" (p. 35), while more than $50 \%$ of the faculty indicated students improved their "problem-solving skills" at the same level (p. 35). Hesser indicates that these skills would typically be obtained in a liberal arts education where students gain an "awareness and a capacity for dealing with a broad range of knowledge....and commitment to life-long learning" (p. 35). Hesser contends that since faculty are in a better position to determine student critical thinking and analytical skill levels that the findings from his study "can be viewed as more valid and reliable..." ( $p$. 33) than other studies that use self reports from students.

Students self-reported in Vogelgesang and Astin's (2000) study that their critical thinking and writing skills increased when they participated in service learning independent of community service. A majority of students (75\%) self-reported that they 
learned as much or more through the service-learning experience than in a traditional classroom (Narsavage, Lindell, Chen, Savrin \& Duffy, 2002). In addition, a study in which Osborne et al. (1998) incorporated six different self-report survey instruments for both the control and experimental groups showed that service-learning students experienced a significant positive increase on cognitive complexities while the control group did not experience such growths. Cognitive complexity refers to the "degree to which a person feels he or she seeks out multiple explanations for the behavior of others" (p. 7).

Sedlak et al. (2003) describes the growth in critical thinking skills that occurred after a service-learning experience. Two themes developed from the content analysis of student journals using the critical thinking dimensions established by Paul (1993) (see Table 7). The first theme was a "development of a professional self-perspective" which focused on "caring for others and strengthening communication skills" (Sedlak et al., 2003, p.100). "Elements of reasoning" as well as "traits of reasoning" (p. 101) were found throughout student reflections. The second theme was "development of a community perspective" (p. 100) in which "abilities of reasoning" and "traits of reasoning" (p. 102) were found in the critical thinking dimensions of the model. They also increased their "self-confidence, self-esteem, and self-reflection" (p. 102) through the service-learning experience. 
Table 7

Paul's (1993) Critical Thinking Dimensions

\begin{tabular}{|c|c|}
\hline Reasoning & Examples \\
\hline Elements of reasoning & $\begin{array}{l}\text { - } \text { Identify problems } \\
\text { - Develop multiple points of view } \\
\text { - } \text { Identifying assumptions } \\
\text { - Recognizing } \\
\text { implications/consequences of } \\
\text { actions }\end{array}$ \\
\hline Abilities of reasoning & $\begin{array}{l}\text { - } \text { Compare analogous situations } \\
\text { - } \text { Develop perspectives } \\
\text { - } \text { Identify assumptions } \\
\text { - Evify issues } \\
\text { - } \text { Raise questions } \\
\text { - } \text { Generate solutions } \\
\text { - Evaluate actions }\end{array}$ \\
\hline Traits of reasoning & $\begin{array}{l}\text { - } \text { Affective attitudes } \\
\text { - } \text { Fair-mindedness } \\
\text { - } \text { Humility } \\
\text { - } \text { Courage } \\
\text { - Integrity } \\
\text { - Exploration of thoughts and feelings }\end{array}$ \\
\hline
\end{tabular}

Note: From "Critical thinking in students' service-learning experiences" by C. A. Sedlak,

M.O. Doheny, N. Panthofer and E. Anaya, 2003, College Teaching, 51, p. 101.

A pre-test given to both experimental and control groups in Eyler et al's. (1997) study illustrated a significant difference in issue identification skills. There were no significant differences between groups for political action skills, communication skills, critical thinking skills or tolerance. These findings are similar at the post-test stage in that there were no significant differences between groups for communication skills, critical thinking skills, and issue identification skills. Eyler et al. explain that it was disappointing not to find a significant difference between groups for critical thinking; 
however, they attempt to explain this by indicating that students may have not understood what was meant by the term critical thinking. They suggested that in order to determine if critical thinking was different between groups that more substantive material would need to be examined to extrapolate that data.

However, Markus et al. (1993) found significant differences between servicelearning and non-service-learning groups. Service-learning students indicated to what degree they felt they "learned to apply principles from this course to new situations" and are "performing up to my potential in this course" (p. 415). Statistically significant differences between service-learning and non-service-learning groups were found on these items in which students self reported: "I reconsidered many of my former attitudes", "I developed a greater sense of personal responsibility", and "I deepened my interest in the subject matter of this course" (Markus et al., p. 78). On all of these items, students who participated in service-learning courses reported significantly higher gains than students who did not participate.

When examining whether service learning contributed to understanding the course content, Hesser (1995) indicates that $76 \%$ of the faculty reported that students either "extensively" or "very extensively" do so (p. 36). This finding is similar to what students self-reported in the longitudinal study by Eyler and Giles (1999) in that students "believe that the service-learning experience added something unique to their understanding of what they were learning in the classroom" (p. 58). In another study, Narsavage et al. (2002) also confirm this finding regarding service learning. A majority of students "agreed they had learned new skills" (p. 459) while $72.5 \%(n=79)$ felt "they 
had gained a unique knowledge through the CETSL [community engagement through service-learning] experience" (p.459).

Steinke and Buresh (2002) indicate that the future development of cognitive outcomes in service learning will transform the education of students. The cognitive measures developed in the future will require understanding how students structure their knowledge in order to better assess objectively their self-reported gains in servicelearning experiences (Eyler \& Giles, 1999; Steinke \& Buresh, 2002). In addition, researchers will need to determine how students transfer knowledge from one experience to another as "knowledge transfer is an active, ongoing process requiring both a certain level of knowledge and active learning to complete" (Steinke \& Buresh, 2002, p. 10). However, "social and cultural context[s]" creates problems in assessing this knowledge transfer (p.11).

Cognitive scientists have developed Goal-Based Scenarios that provide a fit with service-learning pedagogy (Steinke \& Buresh, 2002). These scenarios help students practice skills and use course content knowledge in new and unique situations much like those experienced in service learning. These experiences set students up for "expectation failure" which are mistakes that are "inevitable in any complex task [and] allow[s] for learning" (p. 11). However, Steinke and Buresh indicate that this also gives faculty an opportunity to provide feedback on student reflections either in written form or in group discussions as feedback and reflection are keys to student learning.

\section{Affective Outcomes}

Service learning also provides students an opportunity to transform current perspectives and social attitudes regarding the society. Vogelgesang and Astin (2000) 
examined the importance of students participating in what they defined as "generic" community service versus service learning. Regarding the affective outcomes, the course-based service-learning experience significantly increased the students' "commitment to promoting racial understanding" as well as "commitment to activism" (p. 29-30). Giles and Eyler (1994) found that though there was not a significant increase in the post-test response to the statement "I can make a difference in my community" (p.332), there was a slight increase which they assert helps to illustrate a "strong sense of personal effectiveness" (p. 332) when students participate in service learning. Of the 72 undergraduates in the Giles and Eyler study, $75.4 \%$ self reported that they experienced a positive change regarding their "perceptions of how their views of service clients changed during [the] course..." (p. 334). The students' change in attitude regarding the clients served was based on their perception of their involvement and exposure to this client base via their service-learning experience. Similarly, Narsavage et al. (2002) found that students increased their understanding of people from different backgrounds than themselves.

In a service-learning study by Hales (1997), students in the sample group $(n=7)$ showed a trend toward increased commitment to service. Of these students, $85 \%$ indicated the course influenced both their "intent to serve others in need" and their "tolerance and appreciation for others" a "great deal" (p. 18). The trend toward increased commitment was not found in the control group. The author attributes these findings to a positive service-learning experience.

Markus et al. (1993) found similar results between pre- and post-test scores regarding changes in students' beliefs and values. For instance, in indicating the level 
to which "becoming involved in a program to improve my community" (p. 414) was important to them, students indicated a significant change between their pre- and posttest scores. Students also showed positive significant changes in their attitudes and values about the degree to which their participation in the service learning "increased or strengthened" (p. 415) their:

- intention to serve others in need.

- intention to give to charity to help those in need.

- orientation toward others and away from [them]selves.

- belief that helping those in need is one's social responsibility.

- belief that one can make a difference in the world ( $p$. 415).

The authors of this study indicate that there may be a few in the academic community that question whether these are important issues faculty should attempt to instill in students. However, they further indicate that preparing higher education students for the "responsibilities of citizenship...such effects are important" (p. 416).

Consistent with the Markus et al. (1993) as well as Giles and Eyler (1994) findings, Kendrick (1996) examined social responsibility and personal efficacy of students participating in service learning. At the end of the service-learning project, students felt it was important to volunteer to help those in need, give $3 \%$ of income to those in need, and to work toward equal opportunity for all. Kendrick's findings were also consistent with Markus et al. (1993) findings in that service-learning students 
responded more favorably than non-service-learning students regarding attitudes and values about one's social responsibility.

\section{Contribution of Reflection on Both Types of Outcomes}

Interviews conducted by Eyler and Giles (1999) reveal students who had high quality reflective opportunities in their service-learning experience had increased "complexity in analysis of both causes and solutions to social problems" (p. 75). These reflective opportunities allowed students to make connections between what they were learning in the classroom environment and what was naturally occurring in their servicelearning experience. These are the types of higher order cognitive connections faculty strive to achieve in student thinking processes. This reflective piece of service learning also promoted a "more realistic and detailed personal political strategy ..." (p. 81) that influenced a change in their affective outcomes.

Eyler (2002) suggests that faculty develop a reflection map to guide the reflection activities of students participating in service learning. The cycle of reflection presented is based on Kolb's (1984) work on experiential learning. Methods of reflection include role-play and discussion, journaling and presentations. The map has two of the dimensions of time and social context with three components each making a grid with nine cells. The map is intended to help "increase the power of community experiences for students" (p. 455) through reflection. Reflection activities should "...help students discover their own assumptions and expectations... [and] help them become aware of the differences in perspectives among their peers" (p. 455).

Based on a focus group interview responses by faculty, Hesser (1995) reports that in student papers, faculty were pleased by the "quality and level of analysis that 
was not there before ... the field study/service-learning component" (p. 36) was introduced. The written portion of this specific service-learning experience may not have been intentional, but it is reported that an increase in the ability of students to analyze material did result. This further supports Hesser's claim that faculty are a "valid proxy of student learning" (p. 37) to which researchers should pay attention.

Mabry (1998) found that students who reflected "in class at least weekly had significantly higher post-course personal social values" (p. 38) than those that reflected less often. Students' affective outcomes experienced a "significant positive change" ( $p$. 38) when they participated in ongoing and summative reflection during the course of the service-learning experience. Cognitive outcomes can also improve through reflective activities even if they are in a discussion atmosphere. As Mabry's study found, "student's learning can be enhanced by talking about their service-learning experiences with their site supervisor ... their instructor and other students" (p. 42). Students that make links between what they are "hearing and reading about in class and what they are doing in their service-learning placements" (p. 9) confirms the importance of reflection in the learning process (Strage, 2000).

What are the Principles of Good Practice for Service Learning?

"Principles provide essential benchmarks for developing practices; practice, in turn, serves to inform and refine principles" (Mintz \& Hesser, 1996, p. 26); however, each influences the other. Service-learning "principles [also] offer vision and guidance" (p. 50).

Mintz and Hesser (1996) believe service-learning principles can be examined by using the metaphor of a kaleidoscope with three lenses. The first lens represents 
"collaboration, which engages the partners to work together by sharing authority and resources to enhance each other's capacities to reach goals" (Mintz \& Hesser, p. 39). The second lens represents "reciprocity, which underscores that the partners are both teachers and learners, servers and those served" (p. 39). The third lens represents "diversity, which means that all three partners see differences as assets and that they employ those assets in service-learning endeavors" (p. 39). It is further noted that as one examines the principles of service learning by looking through the kaleidoscope one must "capture the intersection of the three lenses so that the most comprehensive assessment of the principles is attained" (p. 34).

There have been several lists developed that examine best practices for service learning whether by combining service and learning (Honnet \& Poulson, 1989), service learning as a pedagogy (Howard, 1993; Kendall \& Associates, 1990), or as a model for service learning (Schneider, 1998). Though each list is different in context, similarities exist and many individual principles fit into the dimensions of service learning found in the literature. The kaleidoscope metaphor offered by Mintz and Hesser (1996) to examine principles of service learning will guide the discussion of best practices in service learning.

Developing specific learning outcomes for students, which flow from the mission and vision of the institution, is a best practice principle commonly discussed in the literature (Honnet \& Poulson1989; Howard, 1993, Kendall et al., 1990). As this principle is examined through the kaleidoscope recommended by Mintz and Hesser (1996), the three lenses should be considered to get the most accurate picture. Collaboration in the development of learning outcomes involves the key stakeholders: faculty, students, and 
community members. During the assessment process, obtaining collaborative feedback regarding the experiences students have had in participating in service learning will help guide future learning outcomes. Reciprocity is important in this principle in that all participants are perceived as colleagues and must "reassess the realities of power and control over the learning and service goals" (p. 36). The final lens of diversity provides an opportunity for multiple perspectives and a variety of resources from which to improve student learning outcomes in service learning.

A second general principle that surfaces in the service-learning literature is the integration of service learning into the academic curriculum (Howard, 1993; Schneider, 1998; Sigmon, 1990). When service learning is integrated into the curriculum credit should be given for the demonstration of learning not for the performance of service (Howard, 1993). The collaborative lens of the kaleidoscope promotes a "mutually beneficial relationship... by sharing responsibility, authority, and accountability for achieving results" (Mintz \& Hesser, 1996, p. 34-35) while maintaining the academic rigor in service learning. When reciprocity is considered, the "expansion of the community of learners...enriches the outcomes" (p. 36). Diversity of the service-learning curriculum requires the integration of and "attention to cultural differences and commonalities, as well as to the links among power, privilege, prejudice, and oppression" (p. 38).

Providing an opportunity to foster civic and social responsibility is a third principle considered in the literature (Honnet \& Poulson, 1989; Howard, 1993; Kendall et al., 1990). For this principle to be most effective, society should consider the actions of the participants as important (Kendall et al., 1990). Through the collaborative lens, there is focus on community learning rather than individual learning, and as the reciprocity lens 
merges, learning is shared and group responsibility is promoted (Howard, 1993). As a result, students understand that they are a resource for one another which helps them build a commitment to civic and social responsibility (Howard, 1993). Considering the diversity lens in this principle is important because diverse service placements promote understanding of different social issues in society (Howard, 1993).

Encouraging community involvement in defining needs to be met is a fourth principle that surfaces in the literature (Honnet \& Poulson, 1989; Schneider, 1998; Sigmon, 1990). It is important to look through the collaborative lens when defining needs in service learning. Each stakeholder comes to the experience with different "interests, concerns and expectations" (Mintz \& Hesser, 1996, p. 35), and by collaborating to define the needs to be met each stakeholder has an opportunity to have concerns "heard, acknowledged and addressed" (p. 35). Examining what an institution can learn from the community requires also looking through the reciprocity lens of the kaleidoscope as the institution realizes the resources in the community. Continuing with the diversity lens, allows the participants to consider how "assets of the community and the academy complement one another in service-learning" (p. 41).

Critical reflection was also a best practice principle that emerged (Honnet \& Poulson, 1989; Howard, 1993). The collaboration lens demonstrates how participants share what they have gained through critical reflection throughout their service-learning experience. By implementing this principle into practice, faculty, students and the community will be able to reciprocate reflection and feedback which will continue to enhance and improve experiences in the service-learning program. The diversity lens 
illustrates the different types of reflection activities such as discussions, presentations and journals that can be implemented to achieve these improvements.

\section{Why assess service learning?}

Higher education institutions are increasingly incorporating assessment into the daily activities of academia. As a result, there is also an increased need to assess service learning. Gelmon et al. (2001) indicate that as "new programs and pedagogies" are introduced into higher education, they must "endure institutional examination to prove their value....and their contribution toward student learning" (p. 19). Faculty who have implemented the assessment process into their service-learning curriculum can use the data to guide their understanding of the impact of service learning on students. They can also use this information to improve their teaching and implementation of service learning in their courses.

It is also important to assess students' skills and their development in servicelearning programs and courses in order to inform key stakeholders such as students and community members of the benefits of this pedagogy. It also provides an opportunity to inform constituents how they have helped to "contribute to the student learning activities" since they may "play an important role in evaluating the work of the students, and in understanding student development in terms of knowledge of community factors and social responsibility" (Gelmon et al., 2001, p. 19).

Finally, Hesser (1995) indicates that it is the "faculty's professional responsibility to evaluate the learning in every course" (p. 35) they teach and be accountable for the learning that has or has not taken place. As a result, the cyclical process of assessment is the best way to enable faculty to develop learning outcomes; identify and 
create methods to measure those outcomes; design appropriate experiences leading to the outcomes created; and report, discuss, and use the results of the assessment to improve student learning.

\section{Definitions of Key Terms}

\section{- Assessment}

The "process of gathering and discussing information from multiple and diverse sources in order to develop a deep understanding of what students know, understand, and can do with their knowledge as a result of their educational experiences; the process culminates when assessment results are used to improve subsequent learning" (Huba \& Freed, 2000, p.8).

- Service learning

...a method under which students or participants learn and develop through active participation in thoughtfully organized service that is conducted in and meets the needs of a community and is coordinated with an elementary school, secondary school, institution of higher education, or community-service program, and with community helps foster civic and social responsibility, is integrated into and enhances the academic curriculum of the student's program or the educational competencies of the community-service program in which the participants are enrolled, and includes structured time for the students and participants to reflect on the service experience (Norbeck et al., 1998, p.1). 
- Student learning outcomes

"Capture the knowledge, skills, and values that graduates of an institution have in common" (Palomba, 2001b, p. 15) and often describe what students will know or be able to do upon completion of the course.

- Cognitive domain consists of a hierarchy of knowledge, comprehension, application, analysis, synthesis and evaluation based on Bloom's (1956) taxonomy.

- Affective domain consists of a hierarchy of receiving, responding, valuing, organization, and characterization by value set (Krathwohl et al., 1964).

- Psychomotor domain consists of a hierarchy of imitation, manipulation, precision, articulation, and naturalization (The University of Mississippi, 2003c).

- Direct assessment measures

Intended to allow students to demonstrate what they know and include "projects, products, paper/theses, exhibitions, performances, case studies, clinical evaluations, portfolios, interviews, and oral exams" (Huba \& Freed, 2000, p. 11).

- Indirect assessment measures

Intended for students to reflect on what they know and include questionnaires, interviews, and focus groups (Palomba \& Banta, 1999).

- Commercially and nationally developed instruments

Developed by an organization where the "reliability and validity have already been addressed" (Palomba \& Banta, 1999, p. 99) for the instrument.

- Locally developed instruments

Developed by the faculty and they "will closely match the local curriculum as well as local issues and concerns" (Palomba \& Banta, 1999, p. 100). 
- Reliability

Refers to "the consistency, precision, and dependability" of the measurements implemented in the assessment process" (Erwin, 1991, p.59).

- Validity

Addresses the "worth, or applicability, of these measurements for one's stated objectives" (Erwin, 1991, p.59). 


\section{Chapter Three}

\section{Research Design}

The purpose of this study was to determine how service-learning experiences were assessed in health professions programs in order to determine if this type of pedagogical practice was useful in advancing student learning. It was difficult to determine how many health professions programs actually implement service learning across the curriculum. In addition, there were few research studies that have formally investigated this topic. As a result, a qualitative research design was warranted and a case study approach was implemented.

\section{Qualitative Research Design}

When considering a definition for qualitative research, Strauss and Corbin (1990) indicate that it is "any kind of research that produces findings not arrived at by means of statistical procedures or other means of quantification" (p. 17). They identify the skills a researcher should have in order to successfully conduct qualitative research. One must be able to "step back and critically analyze situations, to recognize and avoid bias, to obtain valid and reliable data, and to think abstractly" (p. 18).

After completing a synthesis of sources, Aloi (2004) identified seven characteristics of qualitative research. The characteristics are:

- "Qualitative researchers are primarily concerned with process, in addition to outcomes or products, they are interested in how things occur" (p. 79).

- "Qualitative researchers are interested in understanding what the participants in the study are thinking and why they think what they do" (p. 79-80). 
- "The process of qualitative research is inductive; the research builds abstractions, concepts, hypotheses, or theories rather than testing existing theory" (p. 80).

- "The product of qualitative research is richly descriptive; words and pictures rather than numbers are used to convey what the researcher has learned" ( $p$. 80)

- "The qualitative researcher is the primary instrument for data collection and analysis" (p. 80).

- "The natural setting is the direct source of data, usually necessitating fieldwork" (p. 80).

- "Ideally, the design of a qualitative study is emergent and flexible, responsive to the changing conditions of the study in progress" (p. 80).

There are several types of qualitative research in which investigators may participate such as ethnographies, phenomenological studies, case studies, grounded theory, life histories, or conversational analyses (McMillan, 2000; Strauss \& Corbin, 1990). In order to identify which type(s) to implement, the investigator should consider the reason for conducting qualitative research. Strauss and Corbin (1990) offer such reasons for consideration: "conviction of the researcher based upon research experience", an adherence to scientific discipline orientation, as well as the "nature of the research problem" (p.19). In general, some research studies "naturally lend themselves more to qualitative types of research" than others (p. 19).

The qualitative research method is often criticized for its lack of rigor, but McMillan (2000) defends qualitative research by indicating that this method is "no less 
'scientific' than quantitative methods" (p. 252). Creswell, Clark, Gutmann and Hanson (2003) further state that qualitative research has "become an accepted and legitimate form of inquiry in the social sciences, and researchers of all methodological persuasions recognize its value in obtaining detailed contextualized information" (p. 211). McMillan (2000) indicates that credibility is the "primary criterion for evaluating qualitative studies" (p. 272), and is defined as the "extent to which data, data analysis, and conclusions are believable and trustworthy" (p. 272).

Case Study Research

Yin (1994) indicates that "case studies are the preferred strategy when 'how' or 'why' questions are being posed" (p. 1) and that a case can range from an individual, event or entity as a unit of analysis. Patton (2002) iterates that the "purpose [of the case study approach] is to gather comprehensive, systematic, and in-depth information about each case of interest" (p. 447).

This study implemented a multiple-case design. Yin (1994) indicates that such a design is typically implemented when "independent innovation occur at different sites" (p44). Institutions identified as best practice models for service learning guided the case selection in this study. As a result, each site was the "subject of an individual case study" (p. 44), and the study, as a whole, used a multiple-case design. It is suggested that each case selected "serve a specific purpose within the overall scope of inquiry" ( $p$. 45).

This study investigated how assessment was implemented in health professions service-learning undergraduate and graduate courses. It was necessary to include schools that implemented service learning across the curriculum rather than schools 
that only implemented one or two service-learning courses within the programmatic curriculum. By utilizing institutions that implemented service learning across the health professions curriculum, this study obtained information regarding the process of assessment and yielded a fuller understanding of the assessment phenomenon. In addition, by implementing a case study approach in this research an important description was obtained about what the faculty did when implementing service learning across the curriculum, and what they believed was most important when assessing these learning experiences.

\section{Strengths and Limitations}

There is concern regarding case study research that it cannot be generalized. However, Yin (1994) uses the analogy of conducting an experiment and that "scientific facts are rarely based on single experiments" (p. 10) as there are "multiple set[s] of experiments" (p. 10). As a result, when multiple-cases are utilized in the qualitative research design it "is often considered more compelling, and [the] overall study is therefore regarded as being more robust" (p. 45). Yin also reminds researchers that case studies rely on analytical generalization not statistical results.

Triangulation is an important component of qualitative research as it allows an investigator to use "different methods of gathering data... [and] compares the findings of different techniques" (McMillan, 2000, p. 272). Tellis (1997) indicates that case study is known as "a triangulated research strategy" (Introduction, para. 6). In this study there were multiple sources of evidence to triangulate the data collected, which also helped to "confirm the validity of the processes" (Introduction, para. 6). Detailed information about triangulation is presented in the data collection section of this chapter. 
Reliability and validity are also concerns when collecting data during a case study. Yin (1994) offers three principles when "establishing construct validity and reliability of a case study" (p. 90).

- Use multiple sources of evidence (p. 90).

- Create a case study database (p. 94).

- Maintain a chain of evidence (p. 98).

If these three principles are implemented in a case study design, it will allow the researcher to "move from one portion of the case study to another, with clear crossreferencing to methodological procedures and to the resulting evidence" (p. 99).

Research Methods

\section{Site Selection}

Schneider (1998) examined 27 institutions that were nominated as best practice models for service learning, as "nominated by community service and service-learning experts" (p.1) in the field, in order to "get a pulse on what is happening nationally" (p.1) in service learning. A variety of institutions were nominated and on average approximately 50 service-learning courses were incorporated into the curriculum of these institutions each year. Schneider's intent was to outline themes that seemed to "grasp the mainstays of each program" (p.1) though each theme may not have been present at each institution. Schneider identified 13 "themes of success" (p.1) in model service-learning programs. These themes include:

- "Have a vision and well-defined mission" (p. 1) where these serve as the guide in the planning and development of the service-learning program. 
- "Capitalize on what you do well and do it with quality" (p. 2) while also developing other sections of the program.

- "Support and leadership are important ingredients" (p. 2) in order to gain a variety of resources to develop a successful service-learning program.

- "One person can make a difference" (p. 2) and often in successful servicelearning programs an individual's persistence and patience made a difference in the program.

- "Service-learning [sic] is found in every discipline" (p. 2) to include the major disciplines at an institution as well as professional schools.

- "Roles and rewards for faculty" (p. 3) were important because faculty played an integral role in the development and integration of service-learning, and support and rewards need to be offered to encourage this continued effort.

- The degree of "complexity" (p. 3) and variety of service options offered was intentional in order to include faculty, students and the community.

- "Student support and leadership" (p. 3) because they were the foundation of service learning.

- "Agency and community involvement" (p. 3) was critical because service learning was a joint venture and shared responsibility.

- "Cutting edge work" (p. 4) in service-learning programs may include implementing innovative approaches such as service scholarships.

- "Defined outcomes" (p. 4) were critical in order for the identified outcomes to be assessed appropriately. 
- Service-learning "programs age well" (p. 4) and those that were institutionalized were well established while newer programs were successful because of support and development.

- "Keep an eye on the national, state, and local scenes" (p. 4) in order incorporate new initiatives into the service-learning program.

For this new research study, the researcher analyzed these 27 institutions using public information from each institution's website to determine which had health professions programs. In addition, community colleges were excluded. From the remaining institutions, seven incorporated service learning across the undergraduate curriculum (see Table 8). Within these seven institutions, three were doctoral/research universities-extensive, two were doctoral/research universities-intensive, one was a master's college and university I, and one was classified as a baccalaureate college general (see Table 8) (The Carnegie Foundation for the Advancement of Teaching, 2000).

Table 8

Best Practice Models for Service Learning

\begin{tabular}{|c|c|c|}
\hline Institution & Location & $\begin{array}{c}\text { Carnegie } \\
\text { classification }\end{array}$ \\
\hline Alverno College & Milwaukee, WI & $\begin{array}{l}\text { Baccalaureate Colleges } \\
\text { General }\end{array}$ \\
\hline Valparaiso University & Valparaiso, IN & $\begin{array}{l}\text { Master's Colleges and } \\
\text { Universities I }\end{array}$ \\
\hline University of San Diego & San Diego, CA & $\begin{array}{l}\text { Doctoral/Research } \\
\text { Universities-Intensive }\end{array}$ \\
\hline $\begin{array}{l}\text { Indiana University, Purdue } \\
\text { University-Indianapolis }\end{array}$ & Indianapolis, IN & $\begin{array}{l}\text { Doctoral/Research } \\
\text { Universities-Intensive }\end{array}$ \\
\hline
\end{tabular}


Table 8 (continued)

Best Practice Models for Service Learning

\begin{tabular}{lll}
\hline \multicolumn{1}{c}{ Institution } & \multicolumn{1}{c}{ Location } & \multicolumn{1}{c}{$\begin{array}{c}\text { Carnegie } \\
\text { classification }\end{array}$} \\
\hline Georgetown University & Washington, DC & $\begin{array}{l}\text { Doctoral/Research } \\
\text { Universities-Extensive }\end{array}$ \\
University of Michigan & Ann Arbor, MI & $\begin{array}{l}\text { Doctoral/Research } \\
\text { Universities-Extensive }\end{array}$ \\
University of Utah & Salt Lake City, UT & $\begin{array}{l}\text { Doctoral/Research } \\
\text { Universities-Extensive }\end{array}$ \\
\hline
\end{tabular}

The researcher talked with program coordinators over the phone to gather information about service-learning courses and to determine interest in participation. The researcher sent multiple follow up emails to program coordinators to gain their approval to conduct this study at these seven institutions; however, only one Carnegie classified Doctoral/Research University Extensive institution agreed to participate in this study. As a result, the researcher sought out additional leads in order to select institutions for this study. A multi-state consortium that trains health professions faculty in higher education to "integrate the teaching methodology of service learning into health professions schools curricula" (Consortium website, 2005) provided approximately 12 additional institutions for the researcher to contact. From this list, one Doctoral/Research University Intensive Carnegie classified institution agreed to participate. However, the researcher was still short one institution for this study. The program coordinator from the health professions consortium institution recommended several other institutions for possible inclusion. Upon contacting these additional programs, one Doctoral/Research University Extensive Carnegie classified institution 
agreed to participate in this study. Once the researcher received permission to conduct the study at each of the three institutions, interviews were conducted in Spring 2005. The regional geographic location of each of these institutions was not part of the selection process.

Sampling Procedures

McMillan (2000) indicates that "based on the researcher's knowledge of the population, a judgment is made to include those cases that will be information-rich" ( $p$. 110). Patton (2002) states, "information-rich cases are those from which one can learn a great deal about issues of central importance to the purpose of the inquiry....[and] will illuminate the questions under study" (p. 230). Once selected, these cases are considered a purposeful sample and are "studied in depth" (McMillan, 2000, p. 110).

Purposeful sampling in case studies is a design strategy and is "aimed at insight about a phenomenon of interest, not empirical generalization from a sample to a population" (Patton, 2002, p. 40). This sampling procedure allows cases to be "selected purposefully to permit inquiry into and understanding of a phenomenon in depth" (p. 46). Patton (2002) offers a case sampling strategy for purposeful sampling that will be implemented in this study. "When entire programs or communities are the unit of analysis, the process and effects described for the typical program may be used to provide a framework of reference for case studies of 'poor' or 'excellent' sites" (p. 236). Health professions programs are the unit of analysis in this study and those institutions that were representative as best practice models in Schneider's (1998) study provided the framework of reference for the case study sample. 
Key informants were selected from each case study site in order to conduct interviews. Patton (2002) indicates that key informants are knowledgeable about the area being studied and are able to provide insights that help the researcher "understand what is happening and why" (p. 321). Key informants are also able to "provide detailed information about a group's past and about contemporary happenings and relationships as well as everyday nuances" (Fraenkel \& Wallen, 2000, p. 510). As a result, the key informants for this study consisted of those faculty who were currently, or within the 2004-2005 academic year, implementing and assessing service learning across the curriculum.

Initiating Contact and Institutional Approval

In order to initiate contact with the potential institutions, the researcher developed a short telephone interview protocol (see Appendix D). Phone interviews with program coordinators helped to confirm that service learning continued to be implemented across the curriculum. The results of this telephone interview further guided the actual selection of individual cases for this qualitative research study. The health professions programs that had the highest number of faculty engaged in service learning were ultimately selected. The researcher rank ordered each institution according to the telephone interview results, so that if a specific program declined to participate the next best case was selected.

The dean of the nursing program at each case study site was contacted to request approval to conduct this study at each respective institution (see Appendix A). From each of the case sites selected, a letter from the nursing dean granting permission for a site visit and participation was obtained and submitted to the Institutional Review 
Board for the Protection of Human Subjects (IRB) of West Virginia University. A sample letter of agreement drafted by the researcher was included in this letter sent to the institution from which permission was being requested (see Appendix B).

Further discussions regarding the institutions included in this study utilize fictitious names. Following Aloi's (2004) sampling procedure, a key contact person, such as the health professions program coordinator, was selected from each institution. This individual was requested to nominate individuals who currently, or had recently taught service-learning courses for interviews. Approval was obtained from these individuals at each of the case study sites. The researcher originally intended to interview about 12 full-time health professions faculty from each site to include a total of three sites. At Alpha University and Beta University, the nursing program coordinators nominated faculty to participate. However, this process could not be followed at Gamma University. One interview was scheduled at Gamma University with the intention of scheduling additional interviews upon visiting the institution. The researcher was able to interview two additional faculty before being advised by the program coordinator that neither she nor the other faculty was able to release names or contact information for any Gamma University faculty. As a result, the researcher was only able to obtain three interviews at Gamma University.

The researcher originally intended to include undergraduate service-learning courses in this study. However, because there were insufficient numbers of participating faculty at the undergraduate level, graduate level health professions courses were included and those faculty interviewed. In addition, the original intention of the researcher was to include institutions that were identified as best practice service- 
learning institutions. However, because all but one of the institutions identified as best practice did not agree to participate in this study other institutions were included. These institutions were not identified as best practice institutions, but were found to incorporate service learning across the health professions curriculum.

\section{Data Collection}

In this study, the interview questions and the list of documents that were analyzed evolved from the literature. Table 9 illustrates how each set of interview questions and documents addressed the research questions $(R Q)$ for this study. The researcher developed several interview questions to address each research question. For example, five interview questions addressed research question 1 (see Appendix $E$ for complete interview protocol).

Table 9

Relationship between Interview Questions, Documents and Research Questions.

\begin{tabular}{ccl}
\hline $\begin{array}{c}\text { Research } \\
\text { questions }\end{array}$ & $\begin{array}{c}\text { Interview } \\
\text { question }\end{array}$ & \multicolumn{1}{c}{ Documents } \\
\hline RQ 1 & $9-13$ & $\begin{array}{l}\text { Assessment plans, assessment reports, course } \\
\text { syllabi, institutional website documentation }\end{array}$ \\
RQ 2 & $14-17$ & $\begin{array}{l}\text { Assessment plans, course syllabi, institutional } \\
\text { website documentation }\end{array}$ \\
RQ 3 & $18-23$ & Course syllabi \\
RQ 4 & $24-26$ & Assessment reports \\
RQ 5 & $27-31$ & Assessment reports \\
\hline
\end{tabular}

Zucker (2001) indicates, "data collection and analysis occur as an iterative process, wherein the researcher moves between the literature and field data and back 
to the literature again" (p. 3). In this study, data was collected from a variety of sources such as case study interviews and document analysis.

\section{Documents}

Obtaining information from a variety of documents is relevant in this case study as it can be used to "corroborate and augment evidence from other sources" (Yin, 1994, p. 81). For this study, documentation included:

- Assessment plans

- Assessment reports

- Accreditation reports

- Course syllabi

- Department minutes from meetings

- Institutional website documentation

This documentation provided useful information regarding the assessment practices of the health professions faculty and was utilized to compare and contrast the interview responses of participating faculty. Assessment plans provided information regarding programmatic outcomes that guided the development of course level outcomes for service-learning courses. Assessment reports provided information about student achievement of the student learning outcomes and illustrated the manner in which this data was reported to stakeholders. Course syllabi provided the researcher with information about the specific intended learning outcomes faculty identified for students as well as the methods by which students were assessed in order to determine the outcomes achieved. The manner in which faculty addressed changes or adjustments in 
service-learning courses were found in the minutes of curriculum committee meetings and advisory board meetings.

A review of different documents has its strengths and weaknesses in case study research. Yin (1994) outlines four strengths of document information. Documents are considered "stable" because they "can be reviewed repeatedly" (p. 80). Since the document is not "created as a result of the case study," it is "unobtrusive" (p. 80). Documents often reveal the "exact names, references and details of an event" (p. 80) and cover a broad range of time, events and settings.

Yin (1994) also outlines four weaknesses associated with using documents. Yin reports that retrieving relevant documents to the case study may be difficult. It is important to make sure all appropriate documents are obtained; otherwise, "biased selectivity" becomes a concern during data collection. Bias may continue to play a role in the documentary information in that the author of the document may have been biased in writing it. The documents may have been "written for some specific purpose and some specific audience other than those of the case study being done" (p. 82). A final weakness Yin discusses is that of access to the appropriate documents. The researcher's access to important documentation may be "deliberately blocked" and access denied (p. 80).

There were several proactive actions that the researcher incorporated into this study in order to overcome some of the weaknesses identified by Yin concerning documents. Documents were requested early in the study when making contact with the health professions programs. This request was included in the initial letter requesting permission to conduct the study (see Appendix A) as well as to each individual (see 
Appendix C). Requesting the information early and reiterating the request in subsequent contact with the individual faculty in the program reminded participants of crucial documents needed for this study. In addition, identifying specific documents for analysis in these communications also helped to overcome the biased selection of documents.

\section{Interviews}

Yin (1994) identifies case study interviews as "one of the most important sources" of information (p. 84). Interviews have an advantage over surveys in that they allow for probing. "The interviewer can probe...for clarity or for more detailed information when needed" (Johnson \& Turner, 2003, p. 305). The case study literature indicates that interviews can be standardized and open-ended in nature (Johnson \& Turner, 2003; Patton, 2002; Yin, 1994). In these types of interviews each respondent will answer the same questions in the same sequence (Johnson \& Turner, 2003).

Johnson \& Turner (2003) as well as Yin (1994) offer lists of strengths and weaknesses in the use of interviews in case study research. At the onset, Yin (1994) indicates interviews provide direct focus on the topic at hand. If the question is not direct enough interviews allow the interviewer to probe further on topics of concern (Johnson \& Turner, 2003). As a result, the interview provides insight and obtains indepth information on the case study topic (Johnson \& Turner, 2003; Yin, 1994).

There are a few limitations in using interviews. Yin (1994) indicates bias may enter the interview equation by "poorly constructed questions" (p. 80). In addition, a concern also arises when an interviewee offers information during the interview that the interviewee believes the interviewer is expecting or looking for in a response (Yin, 
1994). As a result, questions must not lead the interviewee to a certain answer. A pilot study was conducted to address these concerns.

Anonymity is also a concern for those participating in interviews. In order to overcome a possible low perception of anonymity, a clear statement was included in the interview protocol for the faculty (see Appendix E) to ease participant's minds. Individual participants were not identified by name in reporting the results of this research. In addition, the researcher made every attempt to avoid including leading questions.

\section{Data Analysis}

Analysis of interview data was ongoing in this study. The researcher requested permission to record the interviews, and all participants agreed. The researcher transcribed the interview recordings after the conclusion of the interview. In addition, course syllabi were also analyzed and other program documents were reviewed by the researcher.

The majority of data gathered from the open-ended interview questions required qualitative analysis. "Qualitative analysis of data involves the non-numerical organisation [sic] of data in order to discover patterns, themes, forms and qualities found" in the data collected for a study (Labuschagne, 2003, Qualitative Analysis, para. 1). The analysis of the qualitative data obtained for this case study will require a constant comparative method of analysis as described by Strauss and Corbin (1990). This type of analysis involves the "making of comparisons" and "asking of questions" ( $p$. 62) about the data as it is obtained. 
Yin (1994) suggests several analytic techniques to analyze qualitative data, which will be used in this study. Creswell (1994) indicates that in order to analyze the large amounts of qualitative data gathered the data must first be reduced and interpreted in some manner. To accomplish that task, Patton (2002) suggests the development of a "manageable classification or coding system" (p. 463). One technique suggested by Yin (1994) is the use of a "matrix of categories and placing the evidence within such categories" (p. 103) as well as "tabulating the frequency of different events" (p. 103).

The conceptual framework described in chapter two served as the framework in which data from open-ended questions in the interviews as well as data from documents was categorized. The documents obtained for this study were analyzed using a document protocol (see Appendix F). The purpose of the document protocol was to guide the analysis of the documents in order to obtain information regarding the research questions for this study.

The development of a coding system helps to identify patterns, and categorical themes (Patton, 2002). Once the information obtained in both the open-ended questions of the interview and documents were coded, the themes and patterns were analyzed. The data coded from this study was analyzed similar to the procedure implemented by Aloi (2004) where the researcher "interpreted the data, selectively categorized findings, systematically developed themes, and utilized quotes to demonstrate key points" (p. 93). For course syllabi analysis, the researcher analyzed the learning outcomes and reported percentages across categories. 


\section{Pilot Study}

Fraenkel and Wallen (2002) indicate that it is important to conduct a pilot study in order to detect and remedy any potential problems before the research is conducted. As a result, a pilot study was conducted for this study. The main objective was to refine the interview protocol regarding clarity of questions asked as well as to determine the length of the interviews in order to improve the data collection of this study. In addition, the pilot study provided the novice researcher an opportunity to practice interviewing techniques, take field notes during the interviews as well as transcribe recorded interviews.

The researcher conducted a pilot study during November 2004 after receiving IRB approval from West Virginia University. Initially, the pilot study was to be conducted at an institution similar to the majority of institutions nominated as best practice institutions for service learning. However, this was not possible because a similar institution was not conveniently located for inclusion. As a result, the pilot study was conducted at a Christian College with a Carnegie classification of Master's II located in Southwestern Pennsylvania.

Pilot Study Results

The researcher scheduled the interviews with one department chair of nursing and two faculty in the nursing program. However, as the interview process began with the department chair, she advised the researcher that she was unable to adequately answer the questions presented in the interview protocol. As a result, administrators were excluded from the sample since it was determined that they would refer the researcher directly to the faculty in order to answer the interview protocol questions. 
The two faculty who were interviewed discussed the same required course. The first participant was interviewed in person, but did not grant permission to be audiorecorded. The second participant was interviewed over the telephone. As a result, an audio-recording of this interview was not obtained as well. However, both participants were able to offer useful feedback regarding the question order and possible redundancy of several questions in the protocol.

Both mentioned the redundancy of several questions in the protocol that addressed the third research question. For example, both instructors mentioned that the questions 'Do students participate as individuals in service-learning courses? What is the rationale for this?' and 'Do students participate as teams in service-learning courses? What is the rationale for this?' are too similar to be separate questions. They advised if students did not participate as individuals they would indicate how students did participate in service-learning courses. The researcher decided not to combine these questions. If the interviewee addressed both individual and team work when asked the initial question, then the second question was not asked.

In addition, both advised they felt that the questions 'What types of servicelearning projects and/or products have nursing students produced at service-learning sites?' and 'What are examples of individual and team projects and/or products?' also in response to RQ3 were redundant. Those questions were combined into the question 'What types of service-learning projects and/or products have students produced at service-learning sites? What are examples?'

In addition to the interview protocol feedback, participants were asked about the duration of the interview. Each interview lasted between 45 to 60 minutes. The 
participants felt that this was an adequate amount of time in order to appropriately answer the interview questions. Furthermore, all pilot study participants read the cover letter in order to provide feedback regarding the letter's clarity. They reported the cover letter was clear and concise. No changes were made to the cover letter.

Documentation from the pilot study institution was obtained during the person-toperson interview with the first participant. Documents such as a self-study report, systematic program evaluation plan, course syllabus, course description from the campus catalog, as well as information regarding the campus service-learning initiative were gathered at this visit.

\section{Background of the Researcher}

At the time of this study, the researcher is a graduate research assistant for West Virginia University in the College of Human Resources and Education. Prior to this position, the researcher was a research assistant at West Virginia University's Health Sciences Center working on a case study examining the correlation between local social environment and heart disease and stroke. The researcher's main responsibility was collecting and analyzing documents. As a result of the researcher's prior experience conducting case study research, she was aware of and addressed the issue of bias in her research. In an attempt to reduce bias that might be introduced, the researcher heavily utilized the assessment and service learning literature in the development of the conceptual framework and research questions for this study. The researcher has a Master's degree in Educational Leadership from West Virginia University. 


\section{Chapter Four}

\section{Case Study One: Alpha University}

Alpha University was a fictitious name for this case study institution and was created to ensure the anonymity of study participants and their institution. The discussion of Alpha University begins with information regarding the background of the institution, a discussion of service learning at this particular university, and provides demographic data about the participants. The researcher then addressed each research question and concluded with a summary of findings for this case. Institutional Background

Classified by the Carnegie Foundation (2000) as a Doctoral/Research Extensive institution, Alpha University was the flagship institution of the state and was accredited by Northwest Association of Schools and Colleges. The total enrollment for Fall 2004 was approximately 30,000 of which $79.0 \%$ were undergraduate and $21.0 \%$ were graduate students. Eighty-five percent of these students were resident students and approximately 3,500 students lived on-campus. Male students made up $55 \%$ of the total enrollment and female students made up $45 \%$ of the total enrollment for the Fall 2004. In addition, a total of about 7,000 graduate $(72.0 \%)$ and baccalaureate $(28.0 \%)$ degrees were awarded for the 2003-2004 academic year at Alpha University. (Who We Are, institutional website, 2005).

The Alpha University mission statement indicated that faculty and staff, welcomes students who are committed to learning and who conform to high academic standards. The right of free inquiry is zealously preserved; diversity is encouraged and respected; critical examination and creativity are prompted; and 
intellectual integrity and social responsibility are fostered (Who We Are, institutional website, 2005).

The mission also encouraged faculty, staff, and students to "contribute time and expertise to community and professional service, to national and international affairs and governance, and to matters of civic dialogue" (Who We Are, institutional website). During the 2003-2004 academic year, an estimated 4,500 students participated in service learning at Alpha University. These students contributed an estimated 130,000 hours of service during the same academic year (Alpha University Service-Learning Annual Report, 2003-2004).

Service Learning at Alpha University

Alpha University was nationally ranked for the 2003-2004 academic year for its service-learning program. The main mission of the Service-Learning Center was to "foster lifelong service and civic participation by engaging the university with the greater community in action, change, and learning" (Alpha University Service-Learning Center brochure). The university's service learning recognition of high quality was "part of a new initiative designed to highlight programs within higher education that had been shown to enhance learning" (Alpha University Service-Learning Annual Report, 20032004). A study conducted in 2001 of 348 Alpha University's Service-Learning students showed "95\% felt they learned something valuable from diverse populations through service-learning"; "77.5\% reported service-learning improved their understanding of the subject"; and "66\% reported service-learning made them study harder" (Alpha University Service-Learning Center brochure). 
Alpha University's Service-Learning Center brochure included nine criteria a course must meet in order to obtain the service learning designation. The brochure listed the following criteria:

- Students provided needed service to individuals, schools, or other community agencies;

- Service experience related to subject matter of the course;

- The class provided method(s) to think about what they have learned through services and how it related to the subject of the class;

- The course offered a method to assess learning derived from service—credit was given for learning...not service;

- Service recognized the needs of service recipients and offered an opportunity for them to be involved in the evaluation of service;

- Service was aimed at the development of the civic education of students even though they may be focused on career preparation;

- Knowledge from the discipline informed the service experiences with which students were involved;

- The class offered a way to learn from other class members as well as the instructor;

- Course options ensured that no student was required to participate in service that created a religious, political, and/or moral conflict for the student.

Faculty were also provided with a handbook to guide them in the process of developing (Phase I), implementing (Phase II), and evaluating (Phase III) a service-learning course 
(see Table 10). In addition, a faculty review committee assisted faculty in designing the service-learning course.

At Alpha University, when faculty initially planned their courses (Phase I), they sought to accomplish four activities (see Table 10). The first activity was to initiate community partner contact in which "selecting, developing and maintaining strong relationships with community partners is critical to the success of service-learning" (Alpha University Service-Learning Center, Service-learning in the Curriculum: A faculty guide, 2002-2003). When selecting community partners the guide offered three questions for faculty to consider:

- Does the agency's mission effectively fit with the educational goals of the course?

- Can the agency effectively accommodate the students who choose to be involved there?

- Can the staff accommodate students [sic] schedules; can they handle an array of student projects?

The faculty guide further outlined that when placements were effective for each stakeholder a more positive learning experience would occur.

The second activity was to identify and train service-learning assistants. These assistants were trained and identified by the university's service-learning center; however, the assistants "cannot be expected to help with responsibilities related to content of the course, only to facilitate the service-learning process" (Alpha University Service-Learning Center, Service-learning in the Curriculum: A faculty guide, 20022003). Tasks outlined for service-learning assistants included: "initiating and maintaining contact with the agency partners; placing students at agencies; facilitating 
reflections; reading and evaluating journals; and communicating frequently with faculty" (Alpha University Service-Learning Center, Service-learning in the Curriculum: A faculty guide, 2002-2003).

Creating a plan was the third activity completed in order to implement a servicelearning course. This activity included course level and departmental transition. At the course level, agencies were reminded by mid-semester that the service-learning experience was nearing an end in order to help avoid logistical and managerial problems for agencies. At the departmental level, sustaining the service-learning experience was the intent. As a result, faculty and departments were encouraged to include budget lines for service-learning assistants, provide clerical support to promote ongoing communication and coordination between the community agency and the department, as well as create a community database to track agencies and contact personnel.

Another part of the development phase was to produce an evaluation plan. Suggested methods for this evaluation included: "pre and post surveys that assess student attitudes and/or cognitive growth on course content....[and an] analysis of students' reflection responses" (Alpha University Service-Learning Center, Servicelearning in the Curriculum: A faculty guide, 2002-2003). Finally, in the course development stage, faculty were encouraged to develop a dissemination plan where results from the assessment process were shared "within the discipline and in the service-learning field through articles in peer-reviewed journals and refereed conferences" (Alpha University Service-Learning Center, Service-learning in the Curriculum: A faculty guide, 2002-2003). 
The fourth and final activity in the course development phase was to provide a community orientation/fair. In this activity, faculty were encouraged to provide community agencies information about the course through a community fair. This was an opportunity for community agencies to learn more about the course and provided an opportunity to network with one another.

At Alpha University, when faculty initially planned their course implementation (Phase II), there were four activities they sought to accomplish (see Table 10). For the first activity in the course implementation, it was recommended that faculty invite community agencies to their class. This activity allowed community agencies to describe their agency as well as potential activities to students. The second activity encouraged faculty to create and maintain a database. This database assisted faculty in monitoring students, events and progress of the course. Faculty were also encouraged to maintain contact with the community agency. Through this contact, faculty were able to address problems as they arose with the agency. The fourth activity the faculty completed was conducting ongoing reflection. It was recommended that faculty remember three points when integrating reflection into a course: "determine the instructional purposes of reflection.... consider multiple reflection methods, depending on the instructional objective...incorporate basic dimensions or characteristics of the reflective component." (Alpha University Service-Learning Center, Service-learning in the Curriculum: A faculty guide, 2002-2003).

The final phase (Phase III) in the development of a service-learning course at Alpha University included course evaluation (see Table 10). The faculty guide indicated, "assessing the impact of service-learning courses at all levels is critical" 
(Alpha University Service-Learning Center, Service-learning in the Curriculum: A faculty guide, 2002-2003). Again, several assessment methods were listed for faculty to consider such as Likert-type surveys, focus group interviews, and examination of written reflection journals.

In this phase, faculty were recommended to use the university service-learning center's course evaluation in order to document student impact. In addition the servicelearning center was also recommended to assist faculty in the development of methods in order to assess 'students' cognitive understanding of course content, civic behavior and personal growth" (Alpha University Service-Learning Center, Service-learning in the Curriculum: A faculty guide, 2002-2003). The service-learning center was also recommended as a source for methods to assess community impact. It was suggested that faculty also "revisit their motivation and determine if the course did, in fact, accomplish the intended objectives which they expressed in their course proposal" as well as met the goals of the department (Alpha University Service-Learning Center, Service-learning in the Curriculum: A faculty guide, 2002-2003).

Table 10

Service-Learning Course Development, Implementation and Evaluation at Alpha University

\begin{tabular}{|c|c|c|c|}
\hline Phase & Activity & Personnel & When/how much time \\
\hline \multirow[t]{2}{*}{$\begin{array}{l}\text { Course } \\
\text { Development }\end{array}$} & $\begin{array}{l}\text { Initiate community partner } \\
\text { contact }\end{array}$ & $\begin{array}{l}F C^{a}\left(S L A^{b}, F^{c},\right. \\
\left.S^{d}, S L C^{e}\right)^{g}\end{array}$ & $\begin{array}{l}\text { Semester prior to } \\
\text { class: } 1 \mathrm{hr} \text { max at } \\
\text { each site }\end{array}$ \\
\hline & $\begin{array}{l}\text { Identify and train service- } \\
\text { learning assistants }\end{array}$ & FAC (SLC) & 1 day + ongoing $1 \mathrm{hr}$ \\
\hline
\end{tabular}


Table 10 (continued)

Service-learning Course Development, Implementation and Evaluation at Alpha University

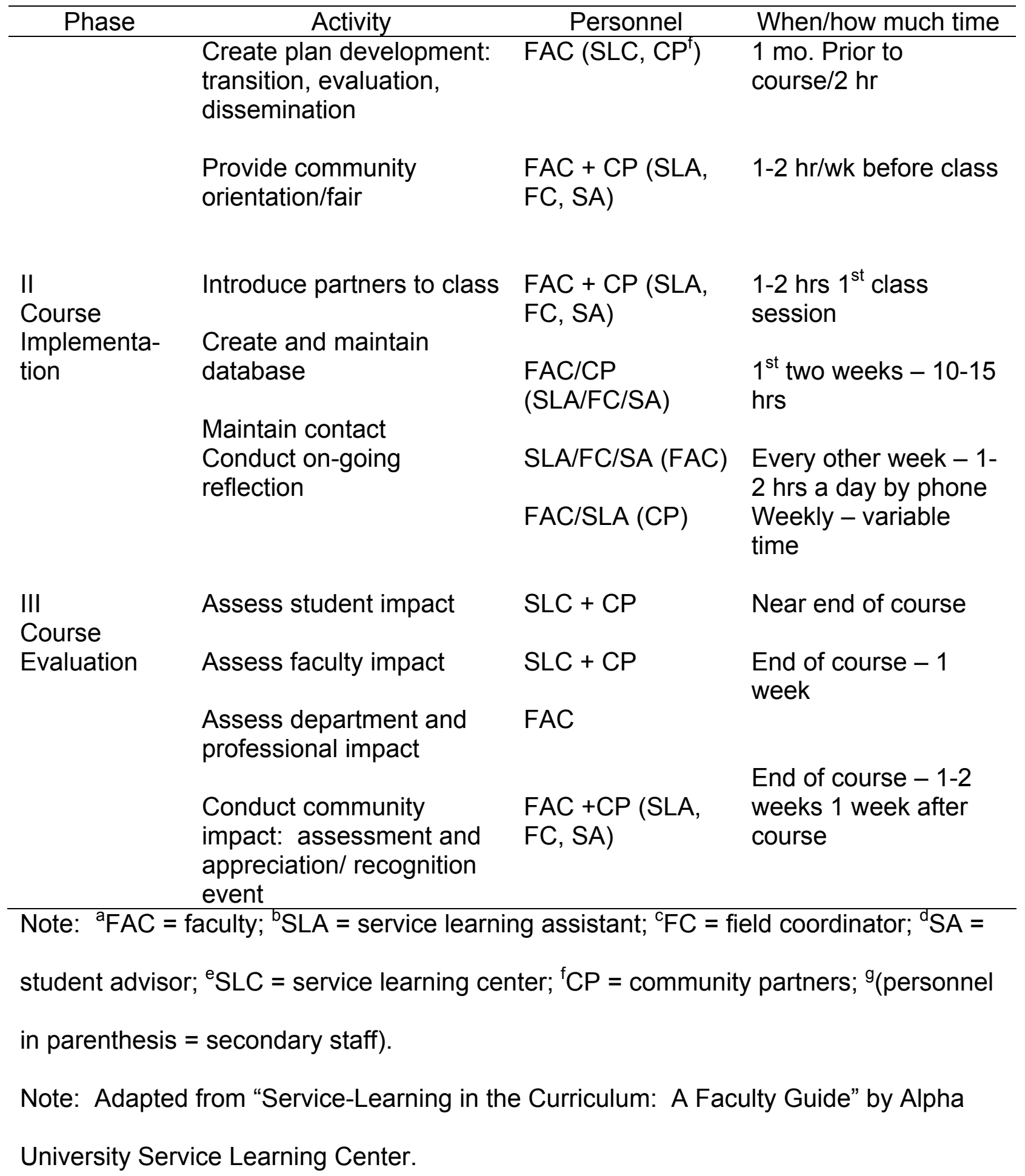


In the Spring 2005 semester, Alpha University's service-learning center added several new features to the service-learning program: full-time or half-time ServiceLearning Coordinators (SLCs) and a service-learning database. The Service-Learning Coordinators "serve as liaisons between teachers, community partners, and students." Full-time SLCs are expected to work approximately 90 hours per semester and are compensated $\$ 1,000.00$. The service-learning database "eases the [course] creation process, as well as assists teachers, students, and community partners with management and communication" (Journal of the Center for Teaching \& Learning Excellence at Alpha University, Spring 2005).

Study Participants

Seven health professions faculty were interviewed at Alpha University for this study. They were recommended by the program coordinator based on their involvement in implementing service learning into their course(s). The researcher obtained permission from each participant to be interviewed and audio-recorded for this study.

Several demographic characteristics of the participants were collected for this study. The majority of the participants were female $(85.7 \%)$ and held the rank of associate professor (42.9\%). The ranks of assistant professor and full professor represented the same percentage of participants (28.6\%). In addition, the majority $(85.7 \%)$ of the participants incorporated service learning in upper division junior and senior level courses (see Table 11). Six of the seven courses the participants taught were required courses and the majority (71.4\%) had a course enrollment between 40 and 60 students. 


\section{Table 11}

Demographic Characteristics of Study Participants

\begin{tabular}{lcc}
\hline \multicolumn{1}{c}{ Gender of participants } & $\mathrm{N}$ & $\%$ \\
\hline Male & 1 & 14.3 \\
Female & 6 & 85.7 \\
Total & 7 & 100.0 \\
& & \\
\hline \multicolumn{1}{c}{ Rank of participants } & $\mathrm{N}$ & $\%$ \\
\hline Assistant Professor & 2 & 28.6 \\
Associate Professor & 3 & 42.9 \\
Full Professor & 2 & 28.6 \\
Total & 7 & 100.1 \\
$\quad$ & $\mathrm{~N}$ & $\%$ \\
\hline \multicolumn{1}{r}{ Level of course } & 0 & 0 \\
Freshman and Sophomore & 6 & 85.7 \\
Junior and Senior & 1 & 14.3 \\
Graduate & 7 & 100.0 \\
Total & & \\
\hline
\end{tabular}

The participants indicated in the interviews that there were multiple ways of identifying service-learning sites for the students. Many of the participants indicated that the sites were selected based on those with which the faculty were familiar either collectively or individually. For example, a female assistant professor stated, "the faculty that [sic] teach in this program collectively decide on potential sites" while another female associate professor indicated that she selects sites that she has a "personal connection with." There were several other ways sites were selected for service-learning students. For example, in one program students were encouraged to follow the same site through their junior and senior semesters. The male full professor said that some agencies in the community contacted them for students and said, "we would love to have a student do a project" at our agency and students were offered the opportunity to work on a project identified by the agency. 
Faculty utilized multiple types of service-learning sites. The majority $(85.7 \%)$ of the faculty identified non-profit organizations as sites in which students had opportunities for service learning (see Table 12). Elementary schools were the next type identified by the largest number of faculty $(57.1 \%)$. State and county health departments, foundations, and hospitals and clinics were also sites the faculty identified. The miscellaneous site category included wellness homes; psychiatric centers; and high-risk telephone lines where students would answer questions regarding high risk topics like HIV and AIDS. The Alpha University Annual Report indicated "hundreds of community schools and organizations benefit from partnerships with the servicelearning program each year" (2003-2004).

Table 12

Number of Faculty who Utilize Specific Types of Service-Learning Sites

\begin{tabular}{lcc}
\hline \multicolumn{1}{c}{ Type of site } & N & $\%$ \\
\hline Non-profit organizations & 6 & 85.7 \\
Schools & 4 & 57.1 \\
State and county health departments & 3 & 42.9 \\
Foundations & 3 & 42.9 \\
Hospitals and clinics & 3 & 42.9 \\
Miscellaneous sites & 3 & 42.9 \\
\hline
\end{tabular}

The distance students traveled to the service-learning sites varied. There was no set radius students had to remain within to participate at service-learning sites. Most of the sites were located in the valley near the institution. One female associate professor indicated "some of them [sites] are across the street." Many of the students commuted to Alpha University making travel distance and times to the service-learning sites vary from student to student. As a result, students were also given the option of choosing a "site in their own community," or somewhere in the state or region. As the male full 
professor iterated, "they can go all over the place, but the majority of them stay local because of travel costs and things like that."

Participants were also asked about the number of hours students were required to spend at service-learning sites per semester. The typical number of hours discussed by the participants ranged from 20 to 30 hours per semester. Two of the participants mentioned that it did not matter how many hours students devoted to the servicelearning project per semester. A female associate professor stated, "if it takes them three hours to set up the fair that's fine, if it takes 300 so be it. It's their choice." The male full professor indicated that the service-learning course he teaches is a "truly adult learning course....[where] we don't have a punch in clock for them. We've also minimized class time."

Participants were asked to explain the assessment process for the college and institution. All respondents said they were not aware of a formal process. However, two professors cited the service-learning course evaluation provided by the university's service-learning center as an example of assessment. The researcher reviewed the actual evaluation form and discovered that nine items address cognitive outcomes and two items addressed affective outcomes (see Table 13). The Likert-scale response on the evaluation form included: strongly disagree, disagree, somewhat disagree, somewhat agree, agree, and strongly agree to each statement. 
Table 13

Outcomes Identified from Alpha University's Service-Learning Course Evaluation

\section{Cognitive outcomes}

I have developed my leadership skills in this class.

I have a better understanding of diverse groups and issued related to diversity.

I have developed my skills to work collaboratively with others.

I learned to be a good citizen by working with the community.

I better understand course content through the service activities in this class.

I reflected in class on what I learned during this course.

I learned from other class members as well as from the instructor.

I will use information from this course in the future.

I used knowledge from the field/discipline to help guide my service experience.

\begin{tabular}{l}
\hline \multicolumn{1}{c}{ Affective outcomes } \\
\hline I think the recipients of service have something valuable to offer to my \\
learning. \\
I believe it is my responsibility to help solve social problems.
\end{tabular}

The participants also mentioned several other service-learning center evaluations such as faculty service-learning evaluations, and community partner service-learning evaluations. Upon review of these evaluation tools, the researcher found that none of them addressed student learning outcomes.

Intended Learning Outcomes for Service-Learning Courses

The development of learning outcomes for service-learning courses was closely tied to the overall course objectives at Alpha University. Several faculty mentioned service learning as a teaching pedagogy implemented in order to achieve course 
outcomes. Three of the seven faculty members interviewed indicated that there were no differences between service-learning courses and other courses. A female associate professor indicated, "service learning is a method of teaching and learning as opposed to an outcome in and of itself," and followed by stating that "the outcome of service learning is really to achieve the outcomes of the course itself." Another female associate professor indicated, "the objectives, or what the student is expected to learn, are the same as the objectives for the course." The sentiment was continued by a female assistant professor by her indication that the service-learning course outcomes were the same intended learning outcomes and were tied directly to the course content. Other faculty members stated that the only difference in service-learning courses from other courses was that they were more service or community oriented and they offered an opportunity for real learning experience in the community where the students will ultimately practice professionally. Faculty discussed the differences in course orientation and experiences, but did not mention any differences in the intended student learning outcomes.

Faculty at Alpha University indicated a wide range of intended learning outcomes for the students of service-learning courses; however, the majority of the examples given for student learning outcomes were cognitive. A few examples of the cognitive outcomes identified by faculty were for students to be able to: articulate content, understand populations, understand research principles, understand research in nursing, understand community, explore leadership, and negotiate action plans with community agencies. Social responsibility and civic engagement were two affective outcomes mentioned by faculty. 
Upon review of the course syllabi for the faculty interviewed, the researcher found that the majority $(89.8 \%)$ of the course objectives resided in the cognitive domain with a few $(10.2 \%)$ in the affective domain and none in the psychomotor domain (see Table 14). Regarding the psychomotor taxonomy, a female associate professor indicated "they [the students] want to perform nursing psychomotor tasks, but we deliberately place them where they can't..." She followed by indicating that the psychomotor tasks were typically implemented in strictly clinical courses with close supervision because of licensure issues.

Table 14

Taxonomy Totals in Course Syllabi

\begin{tabular}{lcc}
\hline Taxonomy & $\mathrm{N}=49$ & $\begin{array}{c}\text { \% of } \\
\text { outcomes }\end{array}$ \\
\hline Cognitive & 44 & 89.9 \\
Affective & 5 & 10.2 \\
Psychomotor & 0 & 0.0 \\
\hline
\end{tabular}

The majority $(79.5 \%)$ of student learning outcomes found in the cognitive domain were represented within the comprehension (27.3\%), application (22.7\%) and analysis $(29.5 \%)$ levels while fewer than $20 \%$ of the outcomes identified represented the highest two levels of the cognitive taxonomy (see Table 15). Three of the five, or $60 \%$, of the affective outcomes identified in course syllabi were at the valuing level. The two remaining affective outcomes were at the two highest levels within this domain (see Table 15). 
Table 15

Breakdown by Taxonomy in Course Syllabi

\begin{tabular}{lcc}
\hline \multicolumn{1}{c}{ Taxonomy } & $\mathrm{N}$ & \% of outcomes \\
\hline Cognitive & 1 & \\
$\quad$ Knowledge & 12 & 2.3 \\
Comprehension & 10 & 27.3 \\
$\quad$ Application & 13 & 22.7 \\
$\quad$ Analysis & 5 & 29.5 \\
$\quad$ Synthesis & 3 & 11.4 \\
$\quad$ Evaluation & 44 & 6.8 \\
Total cognitive & & 100.0 \\
outcomes & $\mathrm{N}$ & \\
\hline$\quad$ Taxonomy & & \% of outcomes \\
\hline Affective & 0 & 0.0 \\
$\quad$ Receiving & 0 & 0.0 \\
$\quad$ Responding & 3 & 60.0 \\
$\quad$ Valuing & 1 & 20.0 \\
$\quad$ Organization & 1 & 20.0 \\
$\quad$ Characterization by & & \\
$\quad$ value set & 5 & 100.0 \\
Total affective & & \\
outcomes & &
\end{tabular}

Faculty identified their course-level learning outcomes, but the university curriculum committee within the college reviewed and approved those course outcomes. Two faculty mentioned that once the curriculum committee in the college approved the course outcomes they were reviewed by the university's service-learning center in order to receive formal service-learning recognition. The final faculty member simply indicated that the course outcomes for a service-learning course evolved from the program curriculum and that each individual faculty member was responsible for the development of the course outcomes.

The involvement of the community and students in the development of student learning outcomes at Alpha University was not commonly practiced. All faculty 
interviewed indicated that they did not involve students in any way when developing the course outcomes for service-learning courses. In addition, none of the faculty involved the community when developing these outcomes; however, four of the faculty did meet with community agencies in order to determine a match between the course outcomes and the agency need. One female assistant professor stated,

I think the best way I can explain that is when I contract with a partner we look at the course objectives, discuss how their agency might be able to meet those objectives, and then design or discuss potential projects and activities for the students to accomplish those.

\section{Assessing Learning Outcomes in Service-Learning Courses}

A number of people were involved in assessing student learning at Alpha University (see Table 16). First and foremost, faculty identified themselves as the main individuals responsible for assessing the learning outcomes of service-learning courses. Students were also important in this process and in one instance a female full professor indicated "the faculty, the community agency, and in some situations their peers, and in all situations the students themselves" assessed outcomes.

Table 16

Types of Individuals Involved in Assessing Student Learning

\begin{tabular}{lcc}
\hline \multicolumn{1}{c}{ Individuals involved } & $\mathrm{N}=18$ & \% of responses \\
\hline Course faculty & 5 & 27.8 \\
Students & 4 & 22.2 \\
Service learning coordinator & 3 & 16.7 \\
Community agency & 2 & 11.1 \\
Service learning center & 2 & 11.1 \\
Peers & 1 & 5.6 \\
Dean's office & 1 & 5.6 \\
\hline
\end{tabular}


Service learning coordinators were also discussed as individuals included in the assessment process; however, based on the job description of the service learning coordinator obtained from the university's service learning center, the role of the coordinator is more of a facilitator. Faculty may request a service-learning coordinator in order to "facilitate a consistent service-learning experience for faculty, students and community partners." (Alpha University, Service-Learning Coordinator Job Description). One of the ways the service-learning coordinators provided assistance was to "distribute and collect community partner and course evaluations." These coordinators were trained by the service-learning center at Alpha University and they were typically undergraduate or graduate students.

Obtaining feedback at the end of the semester from both students and community members was the most frequent manner in which these groups were included in the assessment of student learning outcomes. Five of the seven, or $71.4 \%$, of the faculty identified final feedback at the end of the semester as the manner in which outcomes were assessed by the community and students. A female associate professor indicated that she seeks feedback by using a tool that was a service-learning partner evaluation of the written project and it asks for them [the community agency] to use a Likert scale to evaluate.... about six categories.... looking at did they [the students] approach the audience correctly and [if] the content [is appropriate] and will it actually be used [by the community agency].

Faculty discussed a multitude of assessment methods for grading or to offer formal feedback to students. The most widely mentioned method was the final project 
and upon examination of course syllabi this was confirmed; however, the weight of the project on the overall course grade varied among courses (see Table 17). The service portion of course grades ranged from $11.5 \%$ of the grade in one course to $50 \%$ of the course grade in another while still another course syllabus indicated the service portion of the course as pass/fail. A female associate professor explained the final project as a process where

They [the students] initiate the topic, they come up with a plan for what they think they are going to do and provide that to the faculty.... Then they come up with an outline and ultimately a rough draft. In each one of those, I give them written feedback on their tools

and once the project is finished and submitted a grade was awarded.

Table 17

Weight of Service-Learning Project on Overall Grade

\begin{tabular}{lc}
\hline \multicolumn{1}{c}{ Project title } & Weight on grade \\
\hline Community project & Pass/Fail \\
Project completion & $11.5 \%$ \\
Service project & $20 \%$ \\
Service-learning written project & $30 \%$ \\
Term project & $50 \%$ \\
\hline
\end{tabular}

Group reflections, journals, weekly discussions were several other ways that faculty received feedback from as well as gave formal feedback to students. A female assistant professor indicated that

they [the students] submit journals at both midterm and final and in general the feedback that I give on each journal is about a half a page of written feedback. 
Grading, we try to make this a significant enough part of the course that they take it seriously, but grade it in such a way that it is not stressful.

She went on to explain that the

journal is the primary thing that is graded and there are criteria related to that....

It's worth ' $X$ ' number of points, if they miss any of the criteria then they are docked a percentage of the points if they hit all the criteria they get all the points. The researcher evaluated the course syllabi for examples of criteria implemented for reflection or journals. Two of the course syllabi did not mention reflections or journals at all. Of the remaining course syllabi that listed reflections and/or journals as an activity, only three course syllabi listed criteria for these activities and the criteria listed varied from course to course. For example, one of those course syllabi indicated the criteria for the reflection were that students would "discuss, share and analyze their service-learning experiences as they relate to course content" (Alpha University health professions service learning course syllabus). In another course, students were advised that they would reflect in class via writing assignments or class discussions where they would "share their learning in more detail with each other" (Alpha University health professions service learning course syllabus). In a final example, another course implemented the ABCDs of reflection: How were you Affected by way of feelings or emotions?; How was your Behavior activated?; How was your Cognition or thinking validated or changed?; What various types of Diversity did you experience in your placement?

Final poster presentations were also a method in which students were graded in the service-learning course. A female associate professor stated 
At the end of the class they present their service in a poster format appropriate for the discipline of nursing. So it has fairly structured components. It has background and justification, problems or needs statement, and goals and actions, outcomes and implications and recommendations.

\section{Optimizing Student Learning and Development in Service-Learning Courses}

In order to optimize student learning, participation as individuals or as teams in service-learning projects was highly variable. Five of the seven faculty interviewed indicated that this practice depended on where students were placed in an agency, in what type of agency they were placed as well as the project itself. A male full professor indicated, "They're there to learn as individuals, but they are going out with other people." Upon the researcher's investigation of the course syllabi, only two faculty indicated how students would participate in the service learning experience. One required students to choose a project individually or as part of a group. The other indicated that "whenever possible, these projects should be completed in small groups" (Alpha University health professions service learning course syllabus).

The projects and products faculty discussed were as varied as the activities and assignments students were expected to complete. In addition, students were able to choose from a list of service projects in the course syllabi or they chose their own projects. Organizing charitable contributions, developing health education programs, developing health information materials for distribution to at-risk populations, organizing a community conference, completing a needs assessment of the community, conducting intervention in a community based on the needs assessment, and 
evaluating the intervention completed in the community were several of the product and projects the faculty discussed.

An evaluation of the course syllabi revealed a list of potential service-sites with projects that could be completed at each site. For example, one project site was identified as a family support center where students could choose projects to complete such as: working in a crisis nursery, participate in the completion of various projects needed in the domestic abuse safe house, educational and developmental activities for both parents and children and after school programs. Another course syllabi indicated that 'We have selected some service sites for you, and we'll discuss these on the first day of class. For some of you, this will be a continuation of previous service projects."

Faculty identified many assignments and activities in which students participated in service-learning courses. The majority identified was either health related or education related. Examples of health related activities identified by the faculty and described in the Alpha University College of Nursing's Academic Service-Learning in the Undergraduate Curriculum report (2005) included: health fairs where students "organize, market and coordinate a health fair covering topics most relevant to the diverse...population...[in the area]"; health literacy activities where students developed "pamphlet[s] or packet[s] made for clients on reliable, trustable resources on alternative treatments for cancer"; hospice respite care where students "help terminally ill patients and their families find dignity in death"; and in home care in order to "improve the quality of life of senior citizens."

Education related activities identified by the faculty and described in the Alpha University College of Nursing's Academic Service-Learning in the Undergraduate 
Curriculum report (2005) included: teaching an intervention to school age children where students discussed "health issues with students.... [and work] with students to create a project related to health education"; conducted research where students "synthesize research based on a questionnaire regarding nutrition"; developed newsletters where students created "nutritional/health newsletters for elementary school children and their families to create a 'bridge' between in-class health education and the learning in the home"; and educational campaigns for legislative lobbying where "leadership skills developed will be asset evaluation, task allocation and project development" while students also developed "educational resources aimed at health care professionals..." in the legislature.

The course syllabi revealed that a female associate professor of an advanced nursing course separated the course activities into categories such as exercises including: self assessment where students identified their own leadership base; "shark bait" where students developed their nursing citizenship by answering a variety of questions after reading course materials; interviewing preparation where students were able to prepare for future job interviews; mentoring where students reflected on their future role as mentors; performance review where students were able to practice this activity with family members or close friends; risk-taking and review where students completed an activity to help them understand themselves regarding failure and success in order to improve their leadership abilities; delegation and conflict where students learned how these activities were regulated; and professional organizations where students were introduced to the roles professional organizations had in order to 
promote and regulate the profession. The exercise portion of the course activities represented $30.8 \%$ of the course grade.

Another category outlined in the associate professor's course syllabus was interview activities. For this activity, students were required to "identify three different nurses in the same or different organization holding the same or different positions in the line of authority" and interview them using the interview protocol provided (Alpha University health professions course syllabi). Once the interviews were conducted, students were expected to analyze the interviews in order to reflect on the differences and similarities among the responses. The interview activities portion of the course represented $23.1 \%$ of the course grade.

The final activity listed in the associate professor's course syllabus was service activities. Students were required to complete a project, which allowed students to "develop leadership skills, while providing service for a selected setting and population" (Alpha University health professions course syllabi). Students were also required to complete two annotated articles, which needed to be applied in some manner to the service project. Students were also required to complete a group evaluation where all group members were rated on their individual contribution on the collaborative project activity. The final activity for the service project was a poster presentation by the group and was evaluated using a poster evaluation tool. Items included in the tool for poster evaluation were name of project, personnel, setting, background, specific goals, specific actions, results and impacts, conclusions, implications, appearance, readability, creativity, innovation, communication, independence, and time management. The service portion of the course activities represented $46.2 \%$ of the course grade. 
Another course provided students the opportunity to complete a service project worth $20 \%$ of the course grade. The service project was broken down into four parts. First, students were required to choose to complete the project as individuals or as a group. Second, students selected a service site for the project, which was worth $5 \%$ of the project grade. Third, students documented progress in completing the research project at midterm, which was also worth $5 \%$ of the project grade. Finally, students submitted a polished draft of an abstract as well as complete a poster presentation for the final $10 \%$ of the research project grade.

Participating in reflections was another assignment and activity that six of the seven faculty regularly incorporated into their service-learning courses. Four types of reflection activities were offered as examples: one-minute papers where students were given an opportunity to respond personally to a specific question in 60 seconds; group reflections; journals; and a "get off the fence" reflection activity in which students stood up in a group, were given an issue and then chose a side of the issue and moved to that side of the classroom.

The frequency of these reflections varied widely. In some, faculty required reflections in each class session or each week while other instructors required them every other week two to four times per semester, or once at the end of the semester. The course syllabi did not provide any additional information on the issue of reflection either by type or frequency. Typically in the course syllabi if reflection was included it was simply listed as an activity or assignment to be completed by the student. Achieved Student Learning Outcomes in Service-Learning Courses

Faculty talked more about what learning outcomes were achieved by their 
students than they did in their discussion regarding initial intended learning outcomes. Several outcomes from their initial responses were repeated such as: social responsibility, civic engagement, understanding populations, communication and leadership. New outcomes were added in the response to this question by the faculty. A female assistant professor stated

What I hope was achieved, again I go back to the same two things first in terms of the affective objective would be to have an increased sense of who they are as people.... I guess sort of the bridge between affective and cognitive is knowledge of their code of ethics and scope of practice that help them see the difference between having an opinion and being a nurse.

Another female assistant professor indicated that she "hears [from students] an increased sense of understanding of diverse populations and social issues and health care issues which impact them [students]." A female full professor stated that "values development was another. I felt like we were preparing more ethical, empathetic nurses."

The follow-up question regarding how they know students have met these outcomes provided a variety of answers as well. The method that received the highest number of responses was reflections. A female assistant professor stated that "I think through journaling and reflections sessions I can evaluate..." student understanding of the outcomes. Other tools faculty mentioned they used to determine if students met the intended outcomes were course assessment tools, agency feedback, and faculty observations. 
Faculty responded differently regarding what learning outcomes students did not achieve. A female assistant professor indicated it was "difficult to tie some of the content directly into the course, or some of the course content into the site.... [and as a result,] students aren't getting equal observation of the course concepts." Another female assistant professor indicated that she cannot "generalize [to] the whole class in regards to not meeting course outcomes." However, she identified two students who feel the service learning portion of the course was a "real waste of time" and as a result, she didn't feel they completely grasped the entire "cognitive piece [though] it seems they got the affective" piece. A female associate professor stated "I will tell you that...l'm not counting on the service-learning experience being responsible for meeting any of the objectives of the course" while another female associate professor stated "I think they've achieved the outcomes I wanted them to so I can't say that there's any that I am aware of that they don't achieve." A female full professor stated, "I guess some outcomes that didn't consistently get achieved were just the recognition of the value of service not just to the community, but to the individual."

Faculty members used the assessment data results to determine if students had reached the intended learning outcomes. A female associate professor indicated, "My expectation is that they will produce a product that meets the needs of their agency, and if they do that, I feel that they've met the learning outcomes." A female assistant professor indicated that the assessment methods are reviewed by myself and other service-learning faculty to either make curricular changes within a specific course, assignment changes, and to do a 
better job of sit selection. It helps me understand if I have them in a site that is demonstrating what we need to demonstrate.

\section{Using Assessment Data and Results To Enhance Service-Learning Courses}

Faculty mentioned four ways assessment results were used in order to enhance a service-learning course. The first way described to enhance the service-learning course was to make curricular changes. For example, a male full professor indicated that a service-learning orientation was added to the course based on feedback obtained from the students, which he indicated enhanced the service-learning experience. A female assistant professor indicated, "Specifically, that data [obtained from students] would then be used to make those curricular changes to seek out other sites which may be more effective, to change processes in terms of course operations and scheduling."

A second enhancement to the course was to make more effective agency selections. For example, a female associate professor stated when students and community agencies can't make a connection, students were reassigned as quickly as possible to reduce the chance of the student getting too far behind in course work. The last two ways faculty discussed to enhance the service learning courses were to increase course effectiveness and change teaching style. A female assistant professor stated, "... basically what I do is take the data, take the feedback and really listen to the negative stuff and see where I can deal with that effectively in the course, and so it changes the way I teach."

Faculty also used the assessment results to improve student learning. A female assistant professor indicated that she used assessment results to redesign "different kinds of related service-learning activities." Another way to improve student learning 
was identified by a female associate professor when she indicated that she would more fully integrate reflection throughout her course. Another female associate professor indicated that she could "give them more verbal examples and suggestions...[of things] to avoid based on what other students have had problems with... and hopefully [it] improves their learning."

The majority of faculty $(85.7 \%)$ interviewed at Alpha University indicated they shared assessment data and results at college faculty meetings. Only one faculty member had no knowledge of data sharing with internal stakeholders. In addition to sharing information at the college faculty meetings, a female full professor identified press releases in the college as well as the university hospital newsletters as means to share assessment data and results. As far as sharing assessment data and results with external stakeholders, $28.6 \%$ stated that they were not sure results were shared outside of the college at all. Providing informal verbal feedback to community agencies was the manner in which $42.9 \%$ of the faculty shared assessment results with external stakeholders. In addition, no faculty were aware of any use of assessment results from service-learning courses for accreditation purposes.

The majority $(71.4 \%)$ of the faculty felt the assessment process was achieving its goals. When asked to explain, faculty gave a variety of answers. For example, a female assistant professor stated, "...I think we are able to currently evaluate how things are going and we have because of those evaluations made fundamental changes in the way we operate service learning here." A female associate professor offered a positive response and indicated the program was achieving its assessment goals and explained, "...assessment is not service learning specific. My assessment is meeting 
the objectives of the curriculum..." Finally, a female full professor indicated that since there were multiple service-learning courses in the college each faculty taught and assessed the outcomes in their own unique way.

The majority $(57.1 \%)$ of the faculty felt the service-learning experience was achieving its goals. A female assistant professor who agreed stated, "I think if I gave the students a test right now they would be able to identify how cognitively it relates to at least [one] dimension of public health." A male full professor stated,

...the students are doing tremendous service and fabulous projects that have been a measurable direct benefit to our community and many of the projects are really clear benefits to communities or agencies that are serving a population in the community and are valued because of the reflections and evaluations. However, a female associate professor iterated that the success of service learning depended on whether service learning was treated as an add-on component to a course. She stated, "...I think you have to commit to service learning as a method of teaching content not a nice thing to do for the community."

Faculty identified several challenges associated with assessing service learning. In addition to being time consuming, which was a response identified by $42.9 \%$ of the faculty, a female assistant professor indicated that with a "crammed curriculum" placement of service-learning courses was difficult. In addition, she stated in servicelearning courses assessment

gets sort of scattered over the map where as in a classroom you can give a test [and] everyone is starting with the same knowledge base and the same 
experiences to influence that knowledge, but with service learning all of their experiences are different so assessing is really hard.

A female associate professor advised, "Assessing these outputs are longitudinal design problems that we continue to address with one-time measures and methods."

Faculty identified several benefits associated with assessing service learning as well. A female assistant professor stated that one benefit was "definitely for ongoing improvement of the program and to impact more critically student's learning." Another female assistant professor indicated that knowing what the students were saying and listening to them regarding the appropriateness of activities was a benefit of assessment. A male full professor also identified obtaining community feedback as a benefit of assessment in that the community provides critical information regarding student progress in their on-site work.

\section{Summary}

The assessment of service-learning courses at Alpha University began with the proposal to have individual courses qualify as service-learning courses. In this process, faculty were required to develop a plan implementing the three phases of servicelearning course development: course development, course implementation and course evaluation.

Faculty developed course outcomes based on programmatic goals. The majority of these outcomes resided in the cognitive taxonomy while fewer were located in the affective taxonomy and none in the psychomotor taxonomy. Typically students and community partners were not involved in the process of course outcome development. 
Faculty implemented a variety of methods to assess student learning outcomes in the service-learning courses. These methods were used for both grading and to offer formal feedback to students. Course faculty and students were the most often identified individuals as those included in the assessment of student learning outcomes; however, community partners were identified as a source for course feedback at the end of each semester.

Students participated in a multitude of course activities and assignments and produced many project and service-learning products. These activities allowed for students to enhance their leadership, research, and community health skills. Faculty who required reflection activities from their students reported that their undergraduates increased their cognitive and affective outcomes which optimized student learning.

There was no clear process provided for sharing of the assessment data with either internal or external stakeholders. The only sharing of results occurred internally at faculty meetings; however, it was identified that these meetings often guided the decisions as to whether or not to alter courses. No direct connection surfaced regarding accreditation and the outcomes in service-learning courses. However, the assessment data collected by the faculty interviewed was utilized in making course adjustments as needed to enhance and improve student learning. 


\section{Chapter Five}

\section{Case Study Two: Beta University}

Beta University was a fictitious name for this case study institution and was created to ensure the anonymity of study participants and their institution. The discussion of Beta University begins with information regarding the background of the institution, a discussion of service learning at this particular university, and provides demographic data about the participants. The researcher then addressed each research question and concluded with a summary of findings for this case. Institutional Background

Classified by the Carnegie Foundation (2000) as a Doctoral/Research Intensive university, Beta University was accredited by North Central Association of Colleges and Schools. The total enrollment for Fall 2004 was approximately 17,000 of which $77.0 \%$ were undergraduate, $19.0 \%$ were graduate students and $4.0 \%$ were doctoral/ professional graduates. In-state students represented $93.4 \%$ of the total enrollment for the same time period. Male students made up $42.1 \%$ of the total enrollment and female students made up 57.9\% of the total enrollment for the Fall 2004 (About MWU, institutional website, 2005).

The Beta University mission statement indicated that the faculty and staff will be a catalyst for educational excellence....meeting the need for an educated citizenry dedicated to lifelong learning and service. To those ends, [BU] will provide: access to scholarship and learning; economic and technological development; leadership in health, education, and human services; cultural enhancement, and international understanding while fostering collegial involvement and 
responsibility for continuous improvement of education and research (About BU, institutional website, 2005).

Service learning at Beta University

There was no institution wide service-learning center at Beta University; however, there was a Healthy Communities Center (HCC) that was established in 1991 and housed in the Department of Community Health in the School of Medicine. The main mission of the office was to develop "community-academic partnership[s] committed to improving the health and well-being of the community, educating its health professionals and serving as a force for change" (Healthy Communities Center About Us, institutional website, 2005).

The community advisory board of the HCC, which "represents community and academic constituents... [and] provides programmatic oversight and direction" (Healthy Communities Center History, institutional website, 2005) adopted the following six strategic initiatives in November 2004:

- Develop strong partnerships and expand existing ones among community, educators and providers.

- Educate students and providers to improve health care service delivery.

- Support and encourage community advocacy and programs that empower community members to become active participants in improving their own health and the health of the community.

- Conduct and disseminate program evaluation and community based participatory research. 
- Diversify and increase the funding base that supports Center programs and activities.

In order to meet the strategic initiative to educate students and providers to improve health care service delivery, $\mathrm{HCC}$ identified the following three goals:

- Continue to develop health professions school curricula and expand faculty development programs to support service-learning, multi-professional community-based clinical training, and community-based participatory research.

- Expand continuing education and continuing medical education opportunities for community and academic partners, providers, and community members.

- Assess the extent to which education efforts of students and providers have improved health care delivery in the community.

The Multi-professional Community Based Primary Care course at Beta University helped meet this strategic initiative and was a service-learning course. It was designed for upper-division undergraduate and graduate students from a variety of health professions related majors such as nursing, medicine, social work, physician assistants and professional psychology.

The course starts students in the classroom learning about team practice, health promotion and disease prevention and community resources for the first half of the quarter, then places them, working as multi-professional teams, in the community through service-learning projects with health and human services agencies in the second half of the quarter (Healthy Communities Center Education, institutional website, 2005). 
The HCC also sponsored a one-day campus conference in the Fall 2004. This service-learning workshop was geared toward those faculty who were just getting started in service learning as well as those who were experienced as service-learning instructors. In addition, administrators planning to integrate service learning were also encouraged to participate. Experts in service learning such as Dr. Barbara Holland and Edward Zlotkowski were invited keynote speakers.

The service learning workshops were geared for faculty who were beginning to develop their courses and taught instructors how to: promote a foundation for learning by appropriately designing service learning courses as well as develop a syllabus that incorporates service learning. Topics covered for experienced service-learning faculty included reflecting on the quality of service learning experiences and completing a formal evaluation. Topics covered for administrators included reviewing models for success and institutionalizing service learning. All participants were encouraged to attend two keynote addresses that focused on why service-learning experiences should be created and how such experiences could be designed with successful community partnerships.

\section{Study Participants}

Five health professions faculty were interviewed at Beta University for this study. They were recommended by the program manager based on their involvement in implementing service learning into their courses. The researcher obtained permission from each participant to be interviewed and audio-recorded for this study.

Several demographic characteristics of the participants were collected for this study. All of the participants were female. Participants who held the rank of clinical 
instructor represented $40 \%$ of the sample while the remaining $60 \%$ held the rank of associate professor. In addition, the majority (87.5\%) of courses, for which syllabi were obtained, incorporated service learning in upper-division junior and senior and graduate level courses (see Table 18). Four of the eight courses in which syllabi were obtained were required courses. All of the courses had enrollments of more than 20 students. Although five faculty were interviewed, some taught multiple service-learning courses and a total of eight courses were examined.

Table 18

Demographic Characteristics of Study Participants

\begin{tabular}{lcc}
\hline \multicolumn{1}{c}{ Gender of participants } & $\mathrm{N}$ & $\%$ \\
\hline Male & 0 & 0.0 \\
Female & 5 & 100.0 \\
Total & 5 & 100.0 \\
& & \\
\hline \multicolumn{1}{c}{ Rank of participants } & $\mathrm{N}$ & $\%$ \\
\hline Clinical Instructor & 2 & 40.0 \\
Associate Professor & 3 & 60.0 \\
Total & 5 & 100.0 \\
$\quad$ & $\mathrm{~N}$ & $\%$ \\
\hline \multicolumn{1}{c}{ Level of course } & 1 & 12.5 \\
Freshman and Sophomore & 5 & 62.5 \\
Junior and Senior & 2 & 25.0 \\
Graduate & 8 & 100.0 \\
Total &
\end{tabular}

Three of the five faculty interviewed team taught a multi-professional communitybased service-learning course. In addition, two faculty interviewed taught separate sections of the same service-learning course. As a result, five faculty were interviewed and eight service-learning course syllabi were analyzed from Beta University.

The participants indicated, in the interviews, that there were multiple ways of identifying service-learning sites for the students and that they were primarily selected 
based on those with which the faculty were familiar individually. For example, a clinical instructor stated, "I just have a lot of good community partnerships that I have worked with over the years" while another clinical instructor indicated that she identified the sites and made contact with the community agency herself. There were several other ways sites were selected for service-learning students. An associate professor stated the Healthy Communities Center "was founded...for the purpose of establishing community activity partnerships that would facilitate community-based education and service learning so we identify sites by essentially contacting potential sites and sometimes sites contact us." Another associate professor indicated that "those things are already identified and I think that the organizer of the course...locates and organizes those sites..."

Faculty utilized multiple types of service-learning sites. The majority $(80.0 \%)$ of the faculty identified both public and parochial schools as sites in which students had opportunities for service learning (see Table 19). Non-profit organizations were the next type identified by the largest number of faculty (40.0\%). Departments of Health and Human Services, hospitals, clinics, and church affiliated organizations were also sites the faculty identified. An associate professor indicated that Beta University and the HCC worked with 75 organizations to provide service-learning experiences for students. Table 19

Number of Faculty who Utilize Specific Types of Service-Learning Sites

\begin{tabular}{llc}
\hline \multicolumn{1}{c}{ Type of site } & N & $\%$ \\
\hline Non-profit organizations & 2 & 40.0 \\
Schools & 4 & 80.0 \\
Departments of Health and Human Services & 1 & 20.0 \\
Hospitals and clinics & 1 & 20.0 \\
Church affiliated organizations & 1 & 20.0 \\
\hline
\end{tabular}


The distance students traveled to the service-learning sites varied. There was no set radius students had to remain within to participate at service-learning sites. Most of the sites were located in the valley near the institution. One associate professor indicated more than half of the students commuted to Beta University making travel distance and times to the service-learning sites vary from student to student.

Participants were also asked about the number of hours students were required to spend at service-learning sites per quarter. A clinical instructor indicated, "It depends on the faculty teaching [and] what the service is.... It would be real hard to say a certain number because it varies quite a bit." Another clinical instructor advised that each student was required to complete "80 clinical hours" in the community health course, but that "any or all of those can [meet the] service-learning" course requirement. An associate professor stated that in her course "It's not a hard and fast requirement. It's a variation of between 15 to 30 hours depending on how they [the students] work that out."

The researcher examined the course syllabi regarding number of hours required at the service-learning site. In one course, students are advised "This quarter students will be engaging in six hours of service learning. Three classes will not meet to provide the time back for this experience" (Beta University, health professions course syllabus). No other course syllabi examined specifically outlined class release time to allow students to complete their service-learning requirements.

Participants were asked to explain the assessment process for the college and institution. A clinical instructor advised that "at the university level l'm sure there is a 
university curriculum committee" that handles the assessment of the learning objectives, but she was not clear on the procedures for that process. One associate professor who served on the North Central Association of Colleges and Schools subcommittee for Beta University advised that in her college the main assessment method was the use of grades; however, clinicals were graded as pass/fail. She followed by indicating that when students "do service learning they do it as part of their clinical; therefore, it is pass/fail." In addition, she indicated that faculty assessed students' critical thinking skills through written assignments. Instructors provided in-depth feedback on these assignments.

Another associate professor indicated "three different assessment procedures [take place]...in any service-learning course." She identified a "pre- and postassessment" of students "which is primarily a knowledge and attitude assessment." She also mentioned 'faculty assessment of the students'...knowledge and skills acquired and whatever requirements there are for the course." Finally she indicated, "community partners...[assess] students in terms of their contributions, their level of professionality, [and]...ease with which the students fit into the community organization's situations."

The researcher examined the pre- and post- assessment tools and found that a variety of information was gathered. Initially on the pre-test, students were asked for demographic data such as age, race, ethnicity, and discipline. Students were also asked for information regarding their service-placement such as the setting of the experience, length of experience, where prior placements had been, and locations of previous volunteer experience. A set of fifteen affective Likert-scale responses followed 
(see Table 20) and ranged from strongly agree to strongly disagree for each statement.

Finally, a set of eight affective Likert-scale responses addressing attitudes regarding post-graduation work activities followed (see Table 21). These responses ranged from very willing to very unwilling.

Table 20

Pre- and Post-Knowledge and Attitude Assessment of Affective Outcomes

As a result of this clinical/training experience:

I feel well prepared to practice my profession in a community similar to the community in which my placement is located.

I feel comfortable providing services to people from different ethnic and racial groups than my own.

I believe students should volunteer their time helping people without resources.

Upon graduation, I would like to work in settings where health care professionals are underrepresented.

Upon graduation, I would like to work in a setting with patients/clients of various cultural backgrounds.

Upon graduation, I would be interested in working on a multidisciplinary team (e.g. psychologist, physician, social worker, nurse practitioner, etc.).

I believe that health care professionals have a responsibility to volunteer for community service activities.

I believe that health care would be improved by the increased practice of multidisciplinary health care teams.

I believe that health care professionals should always try to incorporate the patient/client's health beliefs/practices when planning treatment.

I feel that I can have a positive impact on the community in which I work by volunteering my time.

It is important for me to be involved in a program to improve the community.

Learning by doing is a necessary component for adequate training of health care professionals. 
Table 20 (continued)

Pre- and Post- Knowledge and Attitude Assessment of Affective Outcomes

As a result of this clinical/training experience:

I believe it should be mandatory for health care professional students to participate in community service.

I feel that it is important to consider a wide range of health care beliefs/practices (such as nontraditional practices) when planning treatment for my client/patient.

I believe that there are valid alternative health care beliefs/practices that may differ from traditional health care practices.

\section{Table 21}

Pre- and Post-Knowledge and Assessment of Attitudes Toward Post-Graduation Work Activities

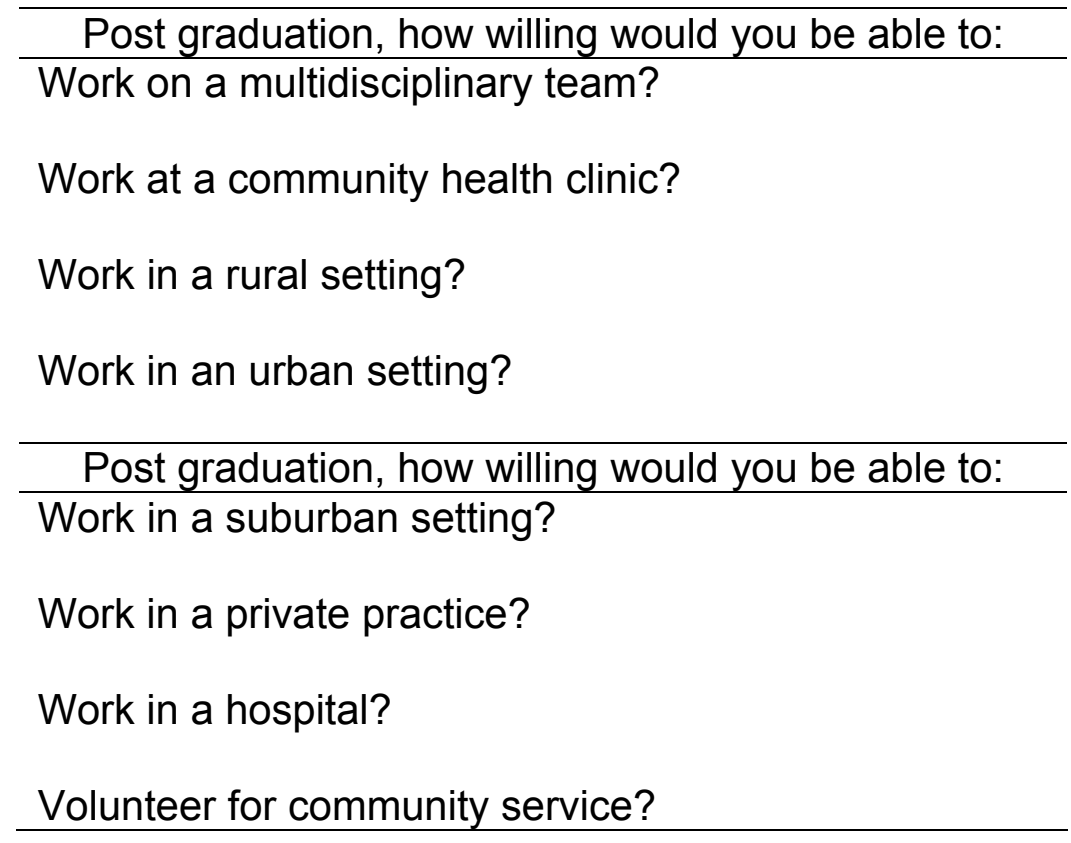

The researcher also analyzed the post-test and found some similarities and differences. The demographic data was deleted from the post-test. The exact same affective items found on the pre-test were also found on the post-test. However, nine cognitive items were added to the post-test (see Table 22). Students were asked to 
respond to these nine items regarding their "knowledge and understanding" before and after their service-learning placement using a Likert-scale ranging from no knowledge or understanding to extensive knowledge or understanding.

Table 22

Outcomes Identified from Service-Learning Course Evaluation

\begin{tabular}{lll}
\hline My knowledge/understanding of... & $\begin{array}{l}\text { Before this } \\
\text { placement }\end{array}$ & $\begin{array}{l}\text { After this } \\
\text { placement }\end{array}$ \\
\hline
\end{tabular}

The types of community resources available for the population with whom I worked.

How health care delivery systems (e.g. managed care) impact my work in the community.

The health care needs of the community in which I served.

The responsibilities of other professionals in a multidisciplinary team.

The barriers to receiving health care in the community that I served.

The impact of socioeconomic status on health and illness.

How my placement site is perceived in the community.

How to work with clients/patients who have various levels of health care knowledge.

What the terms "community resources" and "community service" mean.

The post-test concluded with four open-ended items. The first requested information regarding the types of reflection activities the students participated in during the service-learning course and offered examples such as "journaling, discussions, final integration paper, Q\&A sessions, etc." The second addressed the area of formal orientation for students at the service site and requested a description of the orientation 
activities. The third item focused on whether students believed they acquired new skills or enhanced existing skills and if so, students were requested to describe how this was done. Finally, the fourth item concentrated on whether students felt as if they received unique knowledge from the service experience.

Intended Learning Outcomes for Service-Learning Courses

The development of student learning outcomes for service-learning courses was closely tied to the overall course objectives at Beta University. A clinical instructor advised, "everything is based on the course objectives, which is of course based on the characteristics of the graduate and accreditation." Another clinical instructor indicated, "the curriculum committee sets the...objectives [and] the instructor sets the strategy to get those outcomes accomplished."

In a team taught junior level course, an associate professor indicated that a group of faculty determined the course outcomes. She stated, "we have a planning meeting, a meeting the first week of the quarter, a meeting at midterm and a wrap up meeting." However, she further indicated that "if you audited every syllabus here you wouldn't find the verbiage the same," in regard to the "requirements related to activities like service learning," and with that she included in her syllabus that students will be "engaging in part of our service-learning program [as] part of the clinical hours." In addition, she stated rhetorically, "If I didn't use the word service learning would it make a difference? Part of me says I don't think it would."

In order to involve the community in the development of student learning outcomes, an associate professor stated "we start developing a relationship [with community agencies]...about six months [prior to the service-learning experience] on 
average ... to learn about the services provided and [to give] the community partners [an opportunity] to learn about the things that we do." She further indicated that once this information was gathered, both the community and academic partners worked together to determine what service objectives provided the best fit for the course in order to meet the community agency's needs because "once we establish a community site it is somebody that we have a commitment to continually work with in some context."

An associate professor stated that service learning was not implemented across the university curriculum as other teaching and learning pedagogies such as writing across the curriculum. She further advised that service learning was embedded in clinical courses for health professions students and that "almost all of our clinical courses are team taught....[and the] team usually decides" the intended learning outcomes for the course.

When distinguishing service-learning courses from other courses, an associate professor indicated, "service-learning courses... have service-learning objectives where we deliberately combine learning objectives from the discipline and a service objective from a [community] service partner." She further stated, "community and academic partners plan together what the service-learning objectives will be for the course..." Further displaying the community-based nature of service learning at Beta University, a clinical instructor indicated, for her course, service learning was, "integrated into [it, and] I would say that it is community based because it is a community health class."

A clinical instructor advised that the only difference she identified between service-learning courses and other courses was the affective outcomes students experienced. She stated, 
...any time you put a student in a situation that is outside their comfort zone they are going to have emotions about it. They are going to have feelings about it, and we do a lot of reflection, which is the critical thinking piece of the experience. An associate professor continued this sentiment when she indicated,"...other courses often don't involve civic engagement....Other courses focus more on learning activities as opposed to both the learning and the service."

Faculty at Beta University indicated a wide range of intended learning outcomes for the students of service-learning courses; however, the majority of the examples were cognitive. Faculty expected students to be able to understand: research, the care of children in a variety of settings, how to access to resources in communities, and the service-learning organization in which they were serving. Affective outcomes such as appreciate the diversity of populations, appreciate community reciprocity, and appreciate meeting a community need were also mentioned.

Upon review of the course syllabi collected from the faculty interviewed, the researcher found that all of the course objectives resided in the cognitive domain with no outcomes listed in either the affective domain or the psychomotor domain (see Table 23). The majority $(79.3 \%)$ of the student learning outcomes found in the cognitive domain were represented within the comprehension (22.0\%), application (42.7\%) and analysis $(14.6 \%)$ levels while fewer than $13 \%$ of the outcomes identified represented the highest two levels (synthesis and evaluation) of the cognitive taxonomy (see Table 23). 
Table 23

Breakdown by Taxonomy in Course Syllabi

\begin{tabular}{lcc}
\hline Taxonomy & $\mathrm{N}=82$ & $\begin{array}{c}\% \text { of } \\
\text { outcomes }\end{array}$ \\
\hline Cognitive & & \\
Knowledge & 7 & 8.5 \\
Comprehension & 18 & 22 \\
Application & 35 & 42.7 \\
Analysis & 12 & 14.6 \\
Synthesis & 5 & 6.1 \\
Evaluation & 5 & 6.1 \\
Affective & 0 & 0.0 \\
Psychomotor & 0 & 0.0 \\
\hline
\end{tabular}

Assessing Learning Outcomes in Service-Learning Courses

A variety of people were involved in assessing student learning at Beta University (see Table 24). Faculty predominantly identified themselves as the main individuals responsible for assessing the learning outcomes of service-learning courses. A clinical instructor advised that for the multi-professional community-based course "each discipline specific faculty is responsible for grading" even though a group that a faculty was working with might include multiple disciplines. For example, she stated she was responsible for giving "grades to all of the nursing students...even though they are not on my team because... [the students] have specific questions that they have to answer each week based on readings and experiences."

Table 24

Types of Individuals Involved in Assessing Student Learning

\begin{tabular}{lcc}
\hline $\begin{array}{c}\text { Individuals } \\
\text { involved }\end{array}$ & $\mathrm{N}=7$ & $\begin{array}{c}\% \text { of } \\
\text { responses }\end{array}$ \\
\hline Course faculty & 4 & 57.1 \\
Students & 2 & 28.6 \\
Community faculty & 1 & 14.3 \\
\hline
\end{tabular}


Students were also part of this process and an associate professor indicated, "they [the students] completed a survey at the end of the course...." where they have an opportunity to “...talk about what they've learned, how they've changed as a result of the service-learning project." Another associate professor described this survey as a "pre post attitude and knowledge test." Another associate professor indicated that students "are involved in the team meeting where they provide input" at the end of the quarter.

Faculty discussed several assessment methods for grading or to offer formal feedback to students. However, the main methods identified were journaling and/or reflection activities. One clinical instructor advised that journals were a great method for feedback. She stated,

I respond to every one now that they can email it so nicely because I can read it and respond to it right away, and I tend to respond to every one...sometimes I ask them more questions, sometimes they have done a really good job and I tell them that.

An associate professor indicated "the strategies that we use primarily are of course the written responses on their reflective activities, and then we have post conferences where we just sit and we talk and we provide feedback in those situations."

The researcher reviewed the course syllabi for examples of questions that students were to address in their journals and/or reflections. One of the course syllabi did not indicate reflections or journals as a method of assessment for grading or formal feedback at all; however, the clinical instructor for this course offered samples of what 
she considered good journals. In these journal responses, students were required to indicate the clinical objective they met that week, at what service site the activity was completed, total hours spent at service site for the week, and cumulative hours for the quarter.

Of the remaining course syllabi that listed reflections and/or journals as an activity, five course syllabi listed various questions about service-learning activities. For example, in a sophomore level course, students were given a list of ten points to include in the reflection:

- Explain, in detail, what you did in your service learning activity.

- What did you gain from this experience? (i.e. you learning)

- What do you believe the agency, activity, client gained from your involvement? (i.e. service)

- How did this experience relate to health promotion/disease prevention?

- Discuss the relational aspects of your experience.

- Explain and analyze any problems/concerns you had in this experience.

- Did you find this a rewarding experience? How? If not, why?

- What would you say was the high point of your experience? Explain.

- How would you evaluate the activity/activities you participated in? Explain.

- Please rate your experience on a scale of 1-5 with five being excellent.

Students could also add additional information beyond this list of items.

In the multi-professional course, reflections were separated into two categories: team and discipline specific, which required students to respond to items as it related to 
their discipline. The first two weeks of the course included the discipline specific reflection items including:

- When you reflect on your future as a licensed professional, discuss what you think your role should be in regard to multi-professional practice.

- In a multi-professional team, who should assume a leadership role and why?

- How can each health professional contribute to the agency you will be working with?

- How do you think this agency contributes to the well being of the clients/community?

The final weeks were team reflections and included the following items:

- Reflect and discuss the team process that took place at today's meeting.

- Discuss the importance of grant writing for a health professional.

- Teams function in different styles, discuss how the roles emerged for your group (i.e. Leader, Listener, etc.). In your team how are these roles emerging?

- What is your role in the team?

- As a result of the "In The Streets" exercise, discuss the barriers or facilitative factors to obtaining the required service(s) you encountered.

- Discuss the range of emotions you experienced during this exercise.

- What impact will participating in this course have on your future practice as a health professional?

- Last week you reflected on barriers to services for the underserved, what can be done to eliminate these barriers? 
- Having been in this course for seven weeks now, reflect on your future as a licensed professional, discuss what you think your role should be in regard to multi-professional practice. Has it changed since week one? In what way?

- In your multi-professional team, who assumed the leadership role and why?

- What is your responsibility as a citizen and a professional to addressing barriers to services and unmet needs in the community?

- How can you take what you have learned about the population/agency you have served and help improve the quality of their lives?

- How can you facilitate outreach to this population?

The course syllabi further indicated that students were to submit these responses to their discipline faculty, the multi-professional team faculty, and the community faculty.

In addition to reflection activities, faculty identified final presentations, writing projects and direct faculty observations as ways in which to grade and offer formal feedback to students. Students prepared team presentations for the multi-professional course at the end of the quarter. Each team member was required to participate and the intention of the presentation was for students to creatively highlight their servicelearning project.

Two of the upper-division courses incorporated written papers where one was worth $5 \%$ of the grade and the other was worth $20 \%$ of the grade. One course syllabus indicated the purpose of the writing assignment was to "sharpen critical thinking, problem solving, and communication skills as a basis for life long learning" (Beta University health professions course syllabus). The other course was similar in that the course syllabus indicated the writing assignment was intended to "enhance critical 
thinking skills, encourage exploration of professional literature, and incorporate written communication" (Beta University health professions course syllabus).

Upon examination of course syllabi other methods were identified; however, several courses merged clinical and service-learning courses thus blurring the line of what were service learning activities and what were not. The weight of the servicelearning activity on the overall course grade varied among courses. The service portion of course grades ranged from $9.0 \%$ of the grade in one course to $50 \%$ of the course grade in another while still another course syllabus indicated the service portion of the course as pass/fail.

Optimizing Student Learning and Development in Service-Learning Courses

In order to optimize student learning, participation as individuals or as teams in service-learning projects was varied. Two of the five faculty interviewed indicated that students participated both as individuals and as teams. Instructors offered several reasons for this practice: it depended on the activity at the agency, the service need of the agency, and the agency size. An associate professor who indicated her students participated as teams advised the rational "is that the community partner's service need is usually more than any one individual could provide them." Another associate professor offered another rationale by stating, "health professionals are never operating independently. They are always operating as a team even if the team is only themselves and a patient."

The team projects and products faculty discussed were similar to the activities and assignments students were expected to complete. Faculty identified either health related or education related products and projects students were required to complete. 
Examples of health related activities identified by the faculty included: health fairs where students developed health education stations at health fairs for school age children, vision screenings, health physicals, assessment of a community, hands on intervention, and evaluation of services. Education related activities identified by the faculty included: information sessions with the elderly population from the community, grant writing for service agencies, informational CDRoms, and health related marketing brochures.

The researcher analyzed the course syllabi and there was little leeway in what students were permitted to do for their service-learning project. One course syllabus indicated, "you will be participating in special activities as directed by your clinical instructor." Another course outlined, "each section of the course has been assigned to assist at a community event." The multi-professional course was the exception in that the syllabi indicated "community partners will be invited to class to present information about their agency/organization to students....Students will be asked to identify their top two choices of agencies" at which point they were divided among the agencies in multiprofessional teams.

Participating in reflections was another assignment and activity that faculty incorporated into their service-learning courses. Three types of reflection activities were offered as examples: on-site reflections with community agency faculty, guided reflections where "faculty use specific questions to tie back into the content" as described by a clinical instructor. In addition, the frequency of these reflections did not vary at all. Each faculty required reflections each week. 


\section{Achieved Student Learning Outcomes in Service-Learning Courses}

Faculty revisited many of the intended learning outcomes they discussed when they advised what learning outcomes their students achieved. Several outcomes from their initial responses were repeated such as students' enhanced their communication, interpersonal, and research skills. Team building or collaboration was also mentioned as an outcome achieved by the students. A clinical instructor advised students "rely on each other's expertise which is really interesting. Sometimes team building is something that they have learned a lot about in a service-learning course." Another clinical instructor advised that students collaborate with multiple groups of people to accomplish the service-learning project.

The follow-up question regarding how they know students have met these outcomes provided a variety of answers as well. An associate professor indicated all of the student learning outcomes were achieved because she had "over 4,000 records of pre and post attitude and knowledge evaluations and products that students produced and interviews we've done with students following it and feedback from the community partners." Another associate professor identified reflections as a method she utilized to determine if students achieved the outcomes. She stated, "based on the students' reflection notes and the feedback that's on the forms....more of the affective outcomes were achieved" while a clinical instructor indicated that student "reflections or their verbal communications will also indicate that they have met" the learning outcomes.

Faculty responded differently regarding what learning outcomes students did not achieve. Two of the five faculty indicated that all of the student learning outcomes were achieved while an associate professor advised her team was continually surprised at 
two affective outcomes that were typically not met during the service-learning course. She stated "We expect them to come away with a sense that they can have a positive impact on the community in which they work." She followed by indicating on the preand post-test students did not perceive they had a positive impact on the community because they consistently showed a stronger disagreement after the service-learning experience than agreement. However, in order to improve this problem she advised the faculty team has "over the years tried to build into the class some orientation discussion" that reminded students that this experience will be one of the first times you are in a situation outside of a clinical setting or working with people different from yourself and you may not find that you are feeling particularly competent in this arena so pay attention to what it is you need to learn.

The associate professor also reported that students did not "feel comfortable providing services to people with different ethnic and racial groups than my own" even though they hoped students would feel comfortable. To improve this outcome, she advised the team faculty "built into the course...a health place module and [outlined] the differences in cultural beliefs and practices" to help students remember these issues as they entered the service-learning experience. Although faculty implemented changes to improve the course, the associate professor advised both areas have gotten better, but they have remained areas where students felt "less competent at the end of the service experience." 
Faculty members also found information from student evaluations provided insights regarding students' perceptions about their achievement of intended learning outcomes. A clinical instructor advised that when students completed the student evaluation at the end of the quarter, if I am still reading things like...this was a waste of my time or I don't understand anything I did; then I know I have failed [and] it wouldn't have mattered what service-learning objective I wrote, they didn't get it.

An associate professor indicated that the quality of the mini-grant students wrote guided the determination if students reached the intended learning outcomes. She stated students "have to work together which is one of the objectives [and they have to work] together in multidisciplinary teams" in order to create a unique and different mini-grant proposal as well as implement the proposal. If they completed the project, then the student learning outcomes were achieved. Faculty who implemented a pre- and postknowledge and attitude assessment analyzed the significant changes from the beginning of the course to the end of the course in order to determine if student learning took place. An associate professor advised, "we do statistical analysis and so we come up with whether or not there are significant changes in the context of what we hoped."

\section{Using Assessment Data and Results To Enhance Service-Learning Courses}

Faculty indicated assessment results were used to improve course effectiveness. A clinical instructor stated that as a team it was decided, "whether we're doing [servicelearning well, and] if we can do it better." An associate professor advised that since reflection activities were completed weekly, faculty had an opportunity to "respond to the students... and ask additional questions and get the students to continue to learn about 
whatever issues...they are learning about" by making adjustments. Another associate professor indicated that the use of student feedback assisted in enhancing the course. She advised, "we asked the students at the end of the quarter whether we should keep these activities [and] they say, 'Keep these activities' [because] they perceive that they were beneficial ...[and] worth their time." Another clinical instructor advised, "Once I have established a service-learning opportunity or experience in a course, I don't change it based on the feedback. I don't want to change that kind of experience"; however, she did indicate that if students "reached proficiency faster" she would adjust a specific activity within the service-learning experience.

Faculty also used the assessment results to improve student learning. A clinical instructor advised, "all you have to do is have one bad experience where you just never go there again.... one negative experience... with a community partner and...I don't invite them back." Another clinical instructor indicated she would scale a servicelearning project back if it appeared students were not learning, but followed by stating, "I don't know that l've ever had to go back and restructure something and make it a more enriching experience." An associate professor indicated that she thought by giving them [students] feedback weekly through their journaling, by having discussion in the midst of the course while they are involved in the class, and having them to continue to pay attention to the issues that come up in the field gave her opportunities to improve student learning and development.

All faculty at Beta University indicated they shared assessment data and results for the service-learning courses with a variety of groups. Only one associate professor had no knowledge of data sharing with internal stakeholders; however her guess was 
that "they are shared for the course to continue to go forward." She further advised that several health professions faculty at Beta University "had an article or two...produced as a result of service-learning classes." A clinical instructor advised that she generates a "course report at the end of the quarter and forwards it to the course coordinator." However, she was not sure what the course coordinator did with the information or to whom it was reported. In addition, she was not aware of how or if the assessment data was reported to external stakeholders. Another associate professor indicated that the assessment results are shared within the college via the "assessment committee, which looks at activities done in every course as well as the overall program." She further advised that she sent community partners a thank you note. In addition, she would "summarize some of the comments students have made about the experience." Finally, an additional associate professor identified "articles in newspapers... articles in peer reviewed journals...reports at faculty meetings and during recruitment of students for the course next year" as well as "through meetings of my community advisory board" where she shared service-learning assessment results both internally and externally.

Three of the five faculty were not aware whether assessment results for servicelearning courses were used for accreditation. A clinical instructor advised that her college had just gone through accreditation and stated, "we have a lot of good community sites and contract with community agencies...and have some service learning, but they weren't really pinpointing that...eventually they will, but they didn't do it this time." An associate professor from the same college advised that the accrediting body is looking for "linkages with your community...[and] when you do service learning it 
fits very well with those standards that are considered characteristics of a healthy college."

Most of the faculty interviewed felt the assessment process was achieving its goals. When asked to explain, faculty gave a variety of answers. For example, a clinical instructor stated, "I think the assessment process is achieving its goals in that learning is taking place and good products are occurring because of it." However, she countered by indicating that it was "not well defined....I don't know if I have the right goals, I don't know that I articulate them well and I don't know if I evaluate them well. All I know is that I partner well, I accomplish stuff and in that learning takes place and I provide service." Another clinical instructor advised that assessment "could be done better and more widely or more broadly." An associate professor offered a positive response when she stated, "it is a comprehensive assessment through which we get data and feedback from multiple stakeholders that inform the work that we continue to do educating students."

Four of the five faculty felt the service-learning experience was achieving its goals. A clinical instructor advised that since they had good partnerships with the community, they were able to provide a variety of service-learning experiences for the students. She stated if the students "didn't benefit [from the experience she] wouldn't do it," but she went on and stated that when she heard them and saw them make statements such as "It's the best thing I've done...I know why I want to help people" it provided fuel for the faculty to continue. An associate professor advised that the service-learning activities "broadened the traditional experience that they would have had otherwise." Another associate professor indicated she based her idea of success 
on the "continued willingness on the part of the community participants to be a part of the educational process of the students." An additional associate professor believed students reached her student learning outcomes because they reported "that they learned so much that it was a really fun class and they recommend other students take it....I think they learn, they serve and they have fun at the same time."

Faculty identified several challenges associated with assessing service learning. A clinical instructor advised service learning was not systematic throughout Beta University and was not well defined. As a result, she identified "an overlap between what is volunteering and what is clinical hands on stuff versus what is learning....I think that it's kind of hard to get at professional growth and development of nurses with a service-learning strategy." An associate professor indicated that identifying "everybody's role and responsibility and supervision and evaluation" was difficult, and it had "to be taken seriously and the students have to understand that it is not a typical evaluation process and that the evaluation will be at multiple levels." Another associate professor indicated her concern that students felt "comfortable saying that they didn't like" the service-learning experience when they were given the opportunity to offer feedback regarding their experiences. Another clinical instructor advised she felt service-learning courses "should be assessed more and better," but that she was not in a position of authority to make that happen.

Faculty identified several benefits associated with assessing service learning as well. An associate professor identified the emotional paycheck as a benefit and the reciprocal nature of the service. She stated the students were providing a service to the community, and learning course content while at the same time the community staff 
were providing a service to the institution and they were also learning from the students. Another associate professor indicated,

students really do enjoy it, but I guess that we have to take their word for it as we attempt to measure and assess the outcomes. Basically, we are going on the feedback they give which is almost always very positive.

\section{Summary}

The Healthy Communities Center at Beta University initially wanted to develop strong relationships among community partners, educators, and providers while educating health professions students by developing service-learning opportunities. As a result, health professions faculty incorporated service-learning experiences for the health professions students; however, these experiences were sometimes part of a clinical course instead of a stand-alone service-learning health professions course.

Several of the courses that incorporated service learning into the curriculum were team taught and the student learning outcomes were developed by groups of faculty. In some instances, community agencies were involved in the development of service objectives; however students were not. Based on interviews, faculty felt the outcomes resided in mostly the cognitive and affective taxonomies. However, upon evaluation of course syllabi, it was determined that all of the course objectives were in the cognitive taxonomy alone.

The main assessment method faculty implemented to assess student learning outcomes in the service-learning courses was reflection activities. Faculty used this method to grade students and offer them formal feedback. Faculty were the main individuals responsible for assessing their students' learning outcomes. 
Students participated in many course activities and assignments. These activities helped students enhance their communication, research, and collaborative or team building skills. Faculty who required reflection activities from their students reported that their students increased their cognitive and affective outcomes, which optimized student learning.

A process to share assessment results both internally and externally existed, however, it was not clear that each faculty member was aware of the process. Course assessments were reported to the course coordinator who reported aggregated information to a curriculum committee within the college. Newsletters, peer reviewed journal articles, faculty meetings, community advisory board meetings, and student recruitment materials were other methods implemented for sharing assessment results both internally and externally. 


\section{Chapter Six}

\section{Case Study Three: Gamma University}

Gamma University was a fictitious name for this case study institution and was created to ensure the anonymity of study participants and their institution. The discussion of Gamma University begins with information regarding the background of the institution, a discussion of service learning at this particular university, and provides demographic data about the participants. The researcher then addressed each research question and concluded with a summary of findings for this case. Institutional Background

At the time of this study, Gamma University was classified by the Carnegie Foundation (2000) as a Doctoral/Research Universities Extensive, and was accredited by North Central Association of Colleges and Schools. The total enrollment for Fall 2004 was approximately 9,000 of which $40.0 \%$ were undergraduate and $60.0 \%$ were graduate students. Resident students made up $52.9 \%$ of the population for the Fall 2004. Male students made up $54.5 \%$ of the total enrollment and female students made up $45.6 \%$ of the total enrollment for the Fall 2004 . In addition, a total of approximately 2,500 graduate $(70.0 \%)$ and baccalaureate $(30.0 \%)$ degrees were awarded for the 2004-2005 academic year at Gamma University. (Degrees awarded, institutional website, 2005).

The Gamma University mission, vision and values statement indicated that it will, ...serve society as a leading independent center for undergraduate, graduate, and professional education, for research that adds to society's store of knowledge and addresses its priorities, and for active, responsible world and 
community citizenship. The students, faculty, staff, volunteers, alumni, and other friends who constitute the university community pursue and exemplify this mission through their teaching, research, professional activities, and public service, all marked by a commitment to continuous learning" (Mission, Vision and Values, institutional website, 2005).

Gamma University considers itself to be a service-oriented institution "dedicated to civic leadership" and they "seek individually and collectively to transform society by preparing our students to improve the human condition and by directing the benefits of discovery toward a better society" (institutional website, 2005).

Service Learning at Gamma University

At Gamma University, the Partnership Center was established in 2003 in an effort to build stronger community relationships, and its purpose was to "strategically align its activities with the university's vision by providing infrastructure support to the campus community and developing mutually beneficial, academically centered partnerships with the external community" (Gamma University in the Community, institutional website, 2005). The Partnership Center evolved from the Office of Community Service that was started in 1993 as a community relations unit. At that time, the purpose of the office was to overcome "a lack of information about the university's community activities, both internally and externally....[and to] establish dialogues and relationships" between the university community and the local community (institutional website, 2005).

At the time of this study, based on the self-study report for accreditation at Gamma University, the Partnership Center identified several goals to achieve in the 
future. Four of the goals focused on developing partnerships or cooperative efforts with other departments in the university to build service opportunities, service events, and employee service programs as well as to build local and regional service relations. Another goal addressed the development of an infrastructure for community service related programs. In order to focus on program effectiveness, another goal identified the need to develop assessment tools and metrics. In addition, the creation of an advisory committee for the Center was also considered. The intended purpose of this committee was to have representatives from each school who were aware of the community relations activities within their own school and were able to share that information throughout the university.

Based on the university's self-report for accreditation, each academic unit incorporated academic community relation activities, which provided opportunities for students to connect or interact with the local community. Medical students who participated gained important knowledge and skills, while they contributed to the community in general. In addition, they were able to explore knowledge and skills areas that included: "health education and promotion, health care in clinical settings, health policy and research" (Gamma University in the Community, institutional website, 2005). In addition, freshman through junior year nursing students developed skills and knowledge in areas such as "health screening[s], health teaching, [and] family follow-up" (institutional website, 2005) in required community seminar courses. Senior year nursing students were required to enroll in a capstone public heath course where they explored concepts in the community such as "epidemiology, ethics, informatics, and global health issues" (institutional website, 2005). By integrating the curricular-related 
service opportunities students had an opportunity to experience the reality of learning in the community.

Two faculty from the school of nursing at Gamma University adapted a servicelearning manual for their own faculty from another Carnegie classified Doctoral Research University-Extensive institution. The Service-Learning Manual identified effective practices to incorporate service learning and the faculty closely followed this manual as they created their own service-learning experiences. The manual advised, "Successful learning and effective community contributions depend upon a dynamic inter-relationship among the faculty-student-community agency and a well-integrated package of assessment, syllabus, orientation, implementation, reflection, and evaluation" (Gamma University, School of Nursing, Service-Learning Manual, 2001). The manual further described the components of a well developed service-learning course which included:

- Preparation which links service learning "to specific learning outcomes and preparing students to perform the activities. Students are provided with a clear sense of what is to be accomplished and what is to be learned during the service learning activity."

- Development of the syllabus in which service learning was not "presented as a mere sidebar to the course; rather, the syllabus should explain why this kind of service is a part of the course. This requires instructors to think about the explicit connections between their course and departmental objectives; between the university's mission and the community's expectations; and 
perhaps most importantly, between their goals and the students' expectations."

- Orientation and training where faculty "talk about the service experience on the first day of the course"; "invite agency or community representatives to visit the class"; "address student concerns, fears, and expectations regarding the service experience"; and "prepare students with the appropriate skills and brief them on their responsibilities regarding communication, follow-through and professionalism."

- Contracting and supervision in which faculty "provide a timeline" to students for benchmarking purposes; "have a back-up plan for students with special needs"; and "contact the community partner(s) at least once a semester to seek feedback and visit the service site(s) to gain first-hand exposure to the experience."

- Facilitated critical reflection where "students come to understand the meaning and impact of their efforts [, and] they link what they have learned about themselves and the academic disciplines to what they have done in service to others."

- Outcome evaluation where the purpose was to "measure the effects of a program against the goals it sets out to accomplish and to improve future programming."

The manual also indicated that the final element of service learning, outcome evaluation, included students, faculty, and community agencies. In addition, the assessment tools for students should incorporate "both quantitative and qualitative" 
methods while the "faculty and community feedback is quantitative." No rationale was provided for this statement about assessment tools.

Study Participants

Three health professions faculty were interviewed at Gamma University for this study. The researcher obtained permission from each participant to be interviewed and audio-recorded for this study.

Several demographic characteristics of the participants were collected for this study. All of the participants were female and the ranks represented were clinical instructor, associate professor and assistant professor. In addition, two of the participants incorporated service learning at the graduate level (see Table 25).

Although three faculty members were interviewed, seven course syllabi were obtained for examination by the researcher and all were required courses.

Table 25

Demographic Characteristics of Study Participants

\begin{tabular}{lcc}
\hline \multicolumn{1}{c}{ Gender of participants } & $\mathrm{N}$ & $\%$ \\
\hline Male & 0 & 0 \\
Female & 3 & 100.0 \\
Total & 3 & 100.0 \\
& & \\
\hline \multicolumn{1}{c}{ Rank of participants } & $\mathrm{N}$ & $\%$ \\
\hline Clinical Instructor & 1 & 33.3 \\
Assistant Professor & 1 & 33.3 \\
Associate Professor & 1 & 33.3 \\
Total & 3 & 99.9 \\
$\quad$ & & \\
\hline \multicolumn{1}{c}{ Level of course } & $\mathrm{N}$ & $\%$ \\
\hline Freshman and Sophomore & 3 & 42.9 \\
Junior and Senior & 2 & 28.6 \\
Graduate & 2 & 28.6 \\
Total & 7 & 100.1 \\
\hline
\end{tabular}


The participants indicated in the interviews that there were multiple ways of identifying service-learning sites for the students. The clinical instructor stated that the selection of sites occurred at a more "administrative level" and that the university's service learning office "also identify sites." The assistant professor indicated, "the ones that were most consistent...[were identified] either through networking or them calling me or someone I knew. I really didn't have to go out to look for them." In addition, she stated another way service-learning sites were selected was if "we were providing a service that would not otherwise be received or not easily [received] by those clients." The associate professor stated that the "community advisory board...[conducted] a needs assessment" in the community to help identify agencies.

Faculty utilized several different types of service-learning sites. The most frequently described service-learning site was the local school system, both public and private. The local department of public health and a substance abuse treatment facility were other sites participants identified.

The distance students traveled to the service-learning sites varied. There was no set radius students had to remain within to participate at service-learning sites. Most of the sites were located near the institution. The clinical instructor advised that the site she mainly utilized was "only a couple miles away" in the inner city.

Participants were also asked about the number of hours students were required to spend at service-learning sites per semester. The typical number of hours discussed by the participants ranged from 12 to 15 hours per semester for undergraduates and approximately 8 hours were required for graduate students. The associate professor advised, "fifteen hours per course is a nice requirement. It means they have to go and it 
has to be spread out. They can't just do a week of it. They have to do an hour a week." The clinical instructor advised that each semester during the "freshman, sophomore, junior year...[students] are required to do 12 hours." The number of hours required for a service-learning course was confirmed in the community chapter of the university's selfstudy report for accreditation. The report described the hourly requirement for service learning in the freshman through junior year which indicated, "students are enrolled in a required community seminar...that includes a twelve-hour commitment for service in the schools" (Gamma University in the Community, institutional website, 2005).

Participants were asked to explain the assessment process for the college and institution. The clinical instructor was not aware of how the assessment process worked at either the institutional or the school level. However, she postulated that the development of the process occurred at an administrative level in which she was not a part. In the school of nursing, she believed the assessment process might start at the program directorship level.

The associate professor indicated that there was "a mandated student evaluation of the course that is given anonymously" at the end of the semester. The data were collected and reported back to the faculty member. If problems in the course occurred, the program director met with the individual course faculty and discussed options for changes to the course. However, if formal changes were required to the course, it required the approval from the faculty curriculum review committee. After completing the faculty review process of the course where changes were warranted, it only affected the first page of the course syllabus. The reason that changes only affected the first page was due to the fact that this was where the common course information, which 
passed through curriculum review, was contained such as the course name, number, credit hours, instructor, description and objectives. She further advised that if the course problem resided only in the service-learning experience or the manner in which the objectives were achieved, it was resolved between the course faculty member and the program director. Changes in teaching pedagogy did not warrant the full review process of the curriculum committee because these modifications occurred at the discretion of the instructors.

The assistant professor stated, "There is no institutional wide assessment process.... this institution does not have any policy" regarding their expectations concerning the assessment of service learning. She further advised that at the school level the BSN program had just recently implemented assessment while the MSN program "developed an assessment process that then was used for all courses." This assessment process was developed as a direct result of a grant received to incorporate service learning. After Institutional Review Board (IRB) approval was received, students who gave informed consent completed a "quantitative survey." The data collected from these surveys was shared within the university community, at national conferences and published in peer-reviewed articles.

The researcher analyzed the quantitative grant supported survey that was given to all graduate students before and after their service-learning placement. The first section of the survey requested informed consent from students in order to allow the results to be shared within and outside the school. Other information obtained in the first section was course and semester identifiers. The next section asked students to rate their level of agreement based on a Likert-scale where the responses included: 
strongly agree, agree, disagree, and strongly disagree. The items addressed both cognitive and affective outcomes (see Table 26).

Table 26

Outcomes Identified from Gamma University's Service-Learning Survey

\section{Cognitive outcomes}

Service-learning helped me understand how internal and external factors affect the ability of an agency to meet community needs.

Service-learning helped me understand the challenges/barriers faced by the individual in the community in accessing health care.

Service-learning helped me better understand my role as a resource to the community.

Service-learning helped me better understand the community as a resource to me.

The information presented to me in class and an agency orientation was sufficient for me to begin in the service-learning project.

Service-learning in this course enriched classroom discussion with my peers.

\section{Affective outcomes}

The service I provided through this class influenced my career plans and goals for the future.

I feel the service I provided through this class was beneficial to the community.

I feel I would have learned more if there were no service-learning requirement in the course.

This course made me more interested in community service than before.

As a result of this experience, I have a more diverse and inclusive view of my community.

The final section of this survey focused on students' pre- and post- cognitive responses to the service-learning placement (see Table 27). Students were asked to respond to the nine items regarding their "knowledge and understanding" before and 
after their service-learning placement using a Likert-scale ranging from no knowledge or understanding to extensive knowledge or understanding.

Table 27

Outcomes Identified from Gamma University's Service-Learning Survey

\begin{tabular}{ccc}
\hline My knowledge/understanding of... & $\begin{array}{l}\text { Before this } \\
\text { placement }\end{array}$ & $\begin{array}{c}\text { After this } \\
\text { placement }\end{array}$ \\
\hline
\end{tabular}

The types of community resources available for the population with whom I worked.

How health care delivery systems (e.g. managed care) impact my work in the community.

The health care needs of the community in which I served.

The responsibilities of other professionals in a multidisciplinary team.

The barriers to receiving health care in the community that I served.

The impact of socioeconomic status on health and illness.

How my placement site is perceived in the community.

How to work with clients/patients who have various levels of health care knowledge.

What the terms "community resources" and "community service" mean.

Faculty used a qualitative evaluation tool to obtain students' perceptions and attitudes regarding the service-learning course. The faculty developed a series of openended questions that they asked students. The faculty utilized a list of items to either conduct focus groups with students or faculty requested students provide written responses to the list of open-ended items. Sixteen cognitive and affective items were included in this qualitative tool (see Table 28). Three additional items requested, 
"Would you recommend this experience to someone else?"; "How can we improve upon this experience?"; and "Is there anything else you would like to share?" The researcher also examined the faculty evaluation tool as well as the community feedback tool, but these did not include an assessment of the student learning outcomes.

Table 28

Qualitative Evaluation of the Service-Learning Course

What did you learn about yourself?

Cognitive outcomes

What did you learn about the health care system/nursing?

What did you learn about the community agency?

What did you learn about the community you served?

What did you learn about society?

What needs did the clients have?

Describe how this service learning added to your academic experience.

Did you identify any other areas of the agency that may be useful for servicelearning projects in the future?

What contributions did you make to meeting the needs of the agency?

\section{Affective outcomes}

What expectations or myths did you have prior to the experience?

What was the most positive/fulfilling aspect of your experience?

What was the most frustrating aspect of your experience?

What was the most surprising aspect of your experience?

Did this experience change your ideas of, or approaches to, caring for people?

Did you feel useful in completing the project at this agency?

How did it affect your personal life? 
Intended Learning Outcomes for Service-Learning Courses

The development of learning outcomes for service-learning courses was tied to the implementation of service learning as a teaching pedagogy at Gamma University. The assistant professor advised service learning "...is one teaching methodology of many that allow the students to meet course objectives or in this case clinical objectives.... It was just another strategy." She also stated that as a result of grant funding, her course "had a service objective, a learning objective and a service-learning objective." The researcher was directed to an article co-authored by the associate professor. Upon examination of the article, the researcher found that service learning was presented as an "alternative method of instruction that facilitates two learning outcomes." The two outcomes the researcher identified were "awareness of one's attitudes and abilities, and community learning with regard to social, cultural, and economic issues .... [and for] students to identify the value of a 'life of engaged, democratic citizenship'."

The clinical instructor advised that the learning outcomes were different based on the level of the service-learning course. She further stated that as students progress through the service-learning courses the outcomes expand from the individual to the family to the community so they are showing a progression of the students' ability to focus on the individual and then on the family and then on the community. By the time they are juniors they should be working in more community-based settings.

Faculty indicated a wide range of intended learning outcomes for the students of service-learning courses; however, the majority of the examples were cognitive. A few 
examples of the cognitive outcomes that students should be able to achieve included: describe population and socioeconomic characteristics, identify unmet health care needs, and understand community and its resources. Citizenship and awareness of one's attitudes and beliefs regarding social, cultural and economic issues were two affective outcomes mentioned by faculty.

Upon review of the course syllabi collected from the faculty interviewed, the researcher found that all of the course objectives resided in the cognitive domain with no outcomes articulated in either the affective domain or the psychomotor domain (see Table 29). The majority (60.0\%) of the student learning outcomes found in the cognitive domain were represented within the application (28.0\%), analysis (16.0\%), synthesis (4.0\%), and evaluation (12.0) levels while $40 \%$ of the outcomes identified represented the lowest level of the cognitive taxonomy, knowledge (see Table 29).

Table 29

Breakdown by Taxonomy in Course Syllabi

\begin{tabular}{lcc}
\hline \multicolumn{1}{c}{ Taxonomy } & $\mathrm{N}=25$ & \% of outcomes \\
\hline Cognitive & & \\
Knowledge & 10 & 40.0 \\
Comprehension & 0 & 0.0 \\
Application & 7 & 28.0 \\
Analysis & 4 & 16.0 \\
Synthesis & 1 & 4.0 \\
Evaluation & 3 & 12.0 \\
Affective & 0 & 0.0 \\
Psychomotor & 0 & 0.0 \\
\hline
\end{tabular}

Faculty identified several ways in which service-learning outcomes were developed. The clinical instructor advised that the programmatic curriculum committee determined the course-level learning outcomes. She stated, "all of the courses have to 
go through a curriculum review committee process and once they are finalized they meet all of the objectives." The assistant professor advised until she had the grant she didn't have any specific service-learning outcomes developed. However, she indicated that she identified the goals with the community partners in order to determine how each partnership would contribute to the learning outcomes. The associate professor indicated that the community agency and the faculty member met in order "to determine the needs." She also advised that the learning outcomes developed were typically a "mutually defined project to meet the community needs."

The faculty indicated that student involvement in the development of student learning outcomes was not practiced. The clinical instructor stated, "I don't know that the students are involved very much at all." The assistant professor similarly indicated, "No, they weren't really" involved. However, though students were not involved in the development of the course student learning outcomes, the associate professor indicated they were involved in identifying projects that they completed for the service-learning course. She explained, "the student, the faculty and the agency meet first" to examine projects that met a community need "and then the student and the agency decide" on the project. She further explained, "The faculty can be part of that if necessary, but we found that it works well if we do the upfront work and then let the student and the agency work it out so the student really buys into the project." Assessing Learning Outcomes in Service-Learning Courses

Several people were involved in assessing student learning (see Table 30). For the most part, faculty identified themselves as the main individuals responsible for assessing the learning outcomes of service-learning courses. The associate professor 
referred to faculty, students and community agencies when she stated, "We have all three doing the evaluation." The clinical instructor advised the faculty who were "coordinating a particular site are involved in the assessment of outcomes."

Table 30

Types of Individuals Involved in Assessing Student Learning

\begin{tabular}{lcc}
\hline Individuals involved & $\mathrm{N}=9$ & \% of responses \\
\hline Course faculty & 3 & 33.3 \\
Program director & 1 & 11.1 \\
Students & 3 & 33.3 \\
Community agency & 2 & 22.2 \\
\hline
\end{tabular}

Faculty discussed several assessment methods for grading or giving formal feedback to students. Reflections and journaling were identified as typical methods. The clinical instructor implemented reflections as a way to offer and receive feedback from students. "For me" she stated, "they have to do three clinical reflections from their service-learning experience" and those reflections should have been in accordance with the three course objectives. The associate professor advised that the undergraduate students participated in "guided journaling," but journaling at the graduate level was a non-graded activity; however, it was used as a method in which to give feedback to students throughout the service-learning experience because the graduate students "can share and reflect on what is happening in their service learning.... it's used for sort of a discussion board." The assistant professor identified a journal activity she called the "What? So what? Now what?" approach where students were required to "explain a critical incident and then also [identify] whether they met their learning objectives for the day." 
The researcher analyzed the course syllabi for examples of criteria implemented for journaling and/or reflection. All seven of the course syllabi indicated written reflection as an assessment method; however, only one syllabus identified guidelines for the journal. In this course syllabus, there were two types of journals students were expected to complete. They were described as a pre-experience and post-experience journal.

The pre-experience journal was to be "prepared prior to the experience" and students were expected to include four items in the entry. The items included: "briefly discuss how you prepared for the experience"; "note several points you learned"; "note at least three objectives you have for your professional and/or personal growth during this experience"; and "note your thoughts and concerns as you prepare for the experience."

Students submitted the post-experience journal the same day they completed their clinical experience. The syllabus described four items students were required to consider in their post-experience journal:

- Take time to reflect on the experience before you begin to write.... Faculty will look for evidence of critical analysis of the experience that indicates application of preparation activities, class content and readings. This is not just a review of the events of the day.

- WHAT? Summarize your experience. Describe key events relating to your practice, personal reactions to the experience, client-related events, and the setting. 
- SO WHAT? (Analysis). Discuss the extent to which, and how you met your objectives for the experience"; "analyze the events noted under What? In terms of concepts examined in preparing for the experience, class, readings, etc. - what factors/influences were in play?"; "compare/contrast your experiences with other experiences in this course"; "describe insights you had about public health and/or how information covered in class this week related to this experience"; and "Oh well...reflect on how things went if you were not able to do you planned experience.

- NOW WHAT? (Implications). How will this experience affect your practice in the future?"; "If you were in this situation again, what, if anything, would you do differently?"; and "What should be done about the issues you raised in [SO WHAT?] (i.e. changes in how care is provided in that setting, health cares system, funding of health care, etc.).

The course syllabus indicated that the journal experiences provided "essential opportunities for student-instructor communication, post experience reflection, and evaluation."

There were other methods discussed by the faculty to give formal feedback to students. The clinical instructor advised, "They have a series of assignments.... [and] requirements... [to complete] to get a satisfactory grade." Several of the assignments she mentioned included: completion of twelve hours of service, assigned readings, and participation in class discussions. She also advised that though she taught the freshmen service-learning course, the senior level service-learning course required 
students to complete a community project, course presentation on the project or students participated in a health fair.

Upon further analysis of the course syllabi, four of the courses were assessed on a pass/fail basis. A linked series of freshman, sophomore and junior level servicelearning courses identified three methods of assessment: field experience project, written reflection, and completion of field experience. However, there was no descriptive information regarding these assessments listed in any of the course syllabi. A separate junior level service-learning course was also identified as a pass/fail course.

Another freshman level service-learning course only identified a reflection paper as the method of assessment for the service-learning experience. This paper made up $20 \%$ of the course grade and students were required to "articulate a personal understanding of some of the issues of health care, caring and nursing, using examples from life experiences, clinical experiences, and class readings and discussions."

The two graduate course syllabi offered a more in-depth outline regarding the weight of "each learning experience." For example, the weight of the poster presentation was relatively similar in each course and ranged from $10.0 \%$ to $12.5 \%$ of the total course grade. Excluding other non-service-learning course assignments, service-learning experiences again were similarly weighted and ranged from $10.0 \%$ to $15.0 \%$ of the total grade.

Both of the required graduate courses were required, taken in sequence and incorporated a poster presentation in the service-learning experience. The first sequential course indicated the poster presentation depicted the elements and results of a community needs assessment students completed in a community health course the 
prior semester. In addition, the students outlined the planning model designed and implemented during their service-learning experience in this course. The following course's poster presentation requirements incorporated the theme "Service Learning in Action" and elements of the posters included: contact information for the community agency, details of the negotiated community project, Gantt chart that illustrated the service timeline and activities, and the student's evaluation of the learning experience. Optimizing Student Learning and Development in Service-Learning Courses

In order to optimize student learning, participation as individuals or as teams in service-learning projects varied. The clinical instructor indicated that students signed up for the course as individuals, and "they get an individual grade, but they are kept in some group activities." She further advised that there was no educational rationale for working in either teams or as individuals, but that "students have had safety concerns so sometimes they prefer to meet here as a group and work on a project." The assistant professor advised students "never did anything as individuals. We don't have the luxury... because the way I conceptualize it students have to be supervised by...a clinical instructor, so we could never do a one-on-one." The associate professor indicated, "There is no set rule." She advised that how students participated really depended on the need of the community. She gave an example where "you might have five students... and one of them will take one project and then two or three will take another project depending on the need."

The team projects and products faculty offered as examples were similar to the activities and assignments students were expected to complete. The products and projects discussed were identified as either health related or education related. The 
examples of health related activities identified by the faculty only included health screening activities. The types of health screenings included: blood pressure screenings, cholesterol screenings, blood sugar screenings, scoliosis screenings, vision and hearing screenings. Education related activities identified by the faculty included the development of: health education resource manuals based on the needs of the clinic, instructional hand washing posters, health related PowerPoint presentations for classroom teachers, proposals for health awareness programs, and HIVIAIDS curricula.

An evaluation of a graduate course syllabus revealed a list of potential servicesites with activities that could be completed at each site. For example, one project site was identified as a mobile health unit where the purpose was to "improve the health of child-bearing women and children" and students completed activities by providing health screenings, health counseling, case findings, referrals and immunizations when needed. Another project site identified in this course syllabus was a private, gender segregated school where graduate students provided vision, hearing and posture screening according to the state health department guidelines as well as within the socio-cultural context of the school. A third site identified in the same syllabus was an alcohol and chemically dependent rehabilitation center where students provided health education for the women in a residential facility.

Participating in reflections was another assignment and activity that faculty incorporated into their service-learning courses. The clinical instructor required students to complete a total of three reflections throughout the semester, and they were typically guided in nature by the prompts that the instructor provided. For one reflection, students were able to "just reflect on the experience." In another, students 
were requested to "describe a cultural, ethnic and socioeconomic characteristic of the community in which they are working." The third reflection required students to "describe the association between at least one population characteristic and health care outcomes." As a result of these three reflections, students were able to address the course objectives.

The assistant professor also required students to complete three reflections throughout the semester; however she utilized poster presentations for graduate students that focused on their reflections, but undergraduate students completed daily journaling. The assistant professor advised that students complete a pre- and postjournal reflection after each clinical and the approach she used was called "What? So What? Now What?" Students summarized the service-learning experience in the "What?" section, analyzed the experience in the "So What?" section, and identified implications for practice in the "Now What?" section.

Achieved Student Learning Outcomes in Service-Learning Courses

Faculty discussed a variety of intended learning outcomes their students achieved. The clinical instructor indicated that since the semester wasn't over she wasn't sure about the achievement of all the course objectives; however, she stated if I look back at the three course objectives, one of those is to just get out into the community and see what some of the characteristics of community are, and if the objective is to raise their awareness or help them identify or describe the characteristics of the community, I think they have accomplished that. 
She followed by indicating that based on her observations the students were learning because they were in the community actually interacting with the population and participating in learning activities.

The assistant professor stated the students were "meeting the clinical objectives and meeting course objectives" and that these outcomes were identified in "their own reflections in their journals.... And also [through] course evaluations." She followed by stating,

I use course evaluations to determine if they [students] found these experiences to be good learning experienced for them to meet the course objectives.... a student can meet a learning outcome, but they may not feel it was a good learning experience.

The associate professor identified the student evaluations as the method in which she determined students met the learning outcomes. The outcomes she identified students met included understanding the "resources, the healthcare system, or the healthcare needs" of a community. These outcomes were different from the learning outcomes she identified earlier in that they were cognitive in nature and she originally identified affective outcomes such as personal learning and growth.

Two faculty responded similarly regarding what learning outcomes students achieved. Both the clinical instructor and the assistant professor felt the students achieved all of the learning outcomes identified. The clinical instructor stated, if you go back to those three course objectives they are able to identify and describe the population characteristics that may have an effect on healthcare outcomes, the general characteristics of the community in which they are 
working, and an unmet health care need. So, I think they do meet these specific course objectives.

The assistant professor advised, "They couldn't pass the course unless they met all the clinicals. So they did meet them."

However, the associate professor identified one outcome she felt students consistently had difficulty achieving. She indicated "The main problem area was for students [coming from] acute care settings when we moved them into the communities helping them see the relevance to the acute care" nurse. She followed by indicating that there had been a miscommunication between the faculty and the community agency on the role the acute care nurses would play. She further explained that the issue was eventually resolved when students were able to help "design the advance curriculum...[for those students who] wanted more ambulatory care."

Faculty members were not clear regarding how they used the assessment data results to determine if students had reached the intended learning outcomes. The assistant professor stated, "students are responsible for keeping their clinical evaluations" as a method to self-report achievement of the learning outcome. She indicated as students participated in the service-learning course, they identified objectives they met through the experience. She further explained that students "had to journal about their experience.... [and] had to have an example of how they met it." However, the clinical instructor identified the completion of a student self-evaluation and course evaluation to accomplish this task. The associate professor indicated the method to determine if students reached the intended learning outcomes was 
quantitative in nature referring to the grant supported survey implemented for the service-learning course.

\section{Using Assessment Data and Results To Enhance Service-Learning Courses}

Faculty mentioned several ways in which they used the results from their assessments to enhance and improve the service-learning course. The clinical instructor stated that faculty met "at the beginning and end of the semester....to look at the students' feedback from the course evaluations. We talk about problems encountered, challenges, [and] how we can accommodate that." She further noted that this information was utilized to make adjustments to the course and to the learning outcomes. She followed by stating "I think they have made substantial changes this particular academic year in response to feedback [from students] from the past years."

The assistant professor believed that she used information obtained from students to enhance and change to the course. She stated, "the students and the instructors would gather together and we would do an informal discussion. We went through every... activity they had done" and based on that feedback adjusted the course appropriately. Student journals, course evaluations and clinical evaluations were also methods the assistant professor utilized to determine what adjustments needed to be made in order to improve student learning. She advised she would also "go back and meet with the [program] director and talk about what sites went well, what sites didn't. We were constantly doing that." As a result, site changes often required project changes in which students participated thus improving and enhancing the learning and development of the students. 
The associate professor noted that the community advisory board reviewed the courses at the end of each semester. The advisory group, which was made up of faculty, offered

suggestions for how we can change it, and the changes are not just for our end. Changes occur at the agencies to where they say we really didn't make the most of these students' skills because they don't always understand what the students were capable of doing.

The associate professor provided meeting minutes of the community advisory board for five of the monthly meetings. The researcher analyzed the meeting minutes and discovered suggestions for assessment improvement and course enhancement. Faculty discussed how much of the service-learning course grade was appropriate to be allocated to service-learning activities. One instructor advised that there were not hard and fast guidelines, but that other faculty members who had incorporated service learning into their course typically allocated between $5 \%$ and $30 \%$ of the course grade to the service-learning activities. In order to enhance the clinical experience for students in another undergraduate program, it was decided that one credit of service learning would be added to the course. However, in order to institute service learning into the course, the committee realized that planning for this was required them to develop strategies linking the service experience with course objectives. In a graduate course, the minutes revealed that the qualitative and quantitative data suggested that integrating service-learning into the course was appropriate and should be added to the same course the following semester. In another graduate course, a community advisory board member suggested that it would be helpful if students were able to leave 
additional copies of the products produced with the community agencies they worked with and further suggested the possibility of seeking funding for such a project.

The faculty identified several ways in which assessment data was shared both internally and externally. The clinical instructor advised that assessment results were "discussed at faculty meetings." According to the associate professor faculty met within the school and held "brown bag lunches" where faculty would present on what their students were doing and shared information. In addition, she stated, "we report...mostly quantitative" data to the institution's Office of Community Service such as the number of people or clients served by the service-learning experience. The assistant professor conducted workshops in conjunction with the Office of Community Service in which there were "speakers or instruction on different aspects of service learning....and l've presented on my research." Both the associate and assistant professor have published their research on service learning in peer-reviewed articles in order to share assessment results externally.

The faculty gave different answers that addressed whether or not the assessment process was achieving its goals. The clinical instructor stated, "I don't know that I can fully answer that because I don't participate in all levels of the assessment process." However, she further indicated that for her course the process was working. The associate professor believed the assessment process was achieving its goal because they collected outcome data and we've published what we've been doing. We have a process that is ongoing and we've gotten part of the process and buy in from people: the 
students, the stakeholders, and faculty.... We've got the structure in place, we've got the tools, we've got the process.

The faculty interviewed felt that the service learning experience in the program was fulfilling its goals. However, the clinical instructor identified a challenge to the experience. She advised "some of the freshmen were very reluctant to go out into the communities because of safety issues." However, in order to overcome this challenge, students were encouraged to travel to the community agency site "with a buddy or a partner and not to go alone." The clinical instructor also believed students were meeting the course objectives by being out in the community. In addition, she indicated that as the students were out in the community they were able to get a better sense of the "health disparities [and] educational disparities" that help them gain a "better sensitivity of what community they are coming from.... It raises their awareness and their ability to identify and describe the characteristics of the population. So, for those reasons, I think it is achieving its goals." The assistant professor wanted to "see the program...do more service learning...but as you know it is very challenging...[because] not every faculty member is ready to take it on or to see the value" of service learning. She stated her course was meeting the service learning goals she envisioned and that a successful program or service learning experience would be one in which students met the learning objectives for that experience and it should help them meet the learning course objective...there should be a definite link between the course objective and the service learning assignment or project...it should also meet community identified needs. 
The associate professor asserted that the service learning goals had been met and that "it's made a difference... because students have been able to identify the impact that they are having on the community, but also have learned from the community." She stated, "I think the reflection pieces that we do help us to really get at that affective part" of the service learning experience.

Faculty identified several challenges associated with assessing service learning. The clinical instructor indicated the importance of including the community in the assessment process. She wasn't aware if that was a common practice in the program, but stated

I would think that would be an invaluable part of the process getting the input of the key people in the community whether it is individual schools, or school administrators or school district administrators and getting their initial input but also their input throughout each phase of the process.

The assistant professor indicated,

it is important to look at the process and outcomes at both ends.... The students met the learning objectives, but the process did not go well for the students....you have to look at the learning side, the service side and you have to look at each from the process and outcomes.

The associate professor indicated that developing these service-learning experiences "take a lot of time" to organize. She explained that "we started with focus groups... but it was really important to design that evaluation right from the beginning and change things" such as the "number of hours that students were involved." 
The faculty members all felt that service learning was a worthwhile endeavor. The clinical instructor advised

It's been an enjoyable experience for me actually getting out into the inner city schools because I hadn't done that...it has been a growth experience for me and I hope for most of my students... [as well as] raising consciousness about health and education experiences on the part of the students.

The assistant professor stated she is "very committed to service learning." She indicated service learning

is not a good fit necessarily for every course and for every faculty member, maybe not even for every student necessarily. I do think that the faculty member has to be strongly committed to it and see the value in it.

The associate professor explained "I think we will see more of a move on the part of the university to tap how our students' knowledge can benefit the community, but also the community help teach our students." She also stated institutions that value research should focus on service learning "as a scholarly endeavor and that's where evaluation gives you that. You can't publish if you don't have outcomes. You can't have outcomes if you don't value evaluation in a scholarly way."

\section{Summary}

The implementation of multiple approaches of assessing student learning such as qualitative and quantitative methods was emphasized by the faculty. The importance of assessing service-learning courses was further illustrated in the faculty adapted Service-Learning Manual. It advised of the importance to include the key stakeholders: students, faculty, and community agencies in the process. 
The course outcomes faculty identified resided in the cognitive taxonomy while fewer affective outcomes were reported and none in the psychomotor taxonomy. Analysis of course syllabi revealed all course outcomes resided in the cognitive taxonomy. Students were not involved in the process of developing course outcomes, but were involved in the development of projects and products they produced with community agencies.

Faculty implemented a variety of methods to assess student learning outcomes in the service-learning courses. These methods were used for both grading and to offer formal feedback to students. Course faculty were the most often identified individuals as those included in the assessment of student learning outcomes.

Students participated in several course activities and assignments and produced service-learning products. These activities allowed for students to enhance their understanding of community characteristics, community resources as well as unmet health care needs. Faculty who required reflection identified it as a method by which to offer and receive feedback from students regarding their learning and experiences during the service-learning course.

Sharing assessment data with internal stakeholders often took the form of faculty workshops in conjunction with the university's service-learning office or in the form of "brown bag lunches" within the school. Faculty interviewed who were involved in grant work often published their service-learning results in peer-reviewed journals for external stakeholders. 


\section{Chapter Seven}

Assessment of Health Professions Service-Learning Courses: Cross Site Analysis of Institutions

\section{Introduction}

The purpose of this study was to examine how service-learning courses were assessed in order to determine if students achieved the intended learning outcomes. In this chapter, the researcher discusses the overarching themes that surfaced across three institutions of higher education in conducting this study and how the findings support or contradict relevant literature. This discussion will also revisit the following research question areas: development of intended learning outcomes for service learning, assessment of the service-learning course outcomes, design of the servicelearning courses to optimize learning, utilization of assessment results to determine service-learning outcomes achieved, and utilization of assessment results to enhance and improve service-learning courses.

The cyclical nature of assessment was readily identified in the literature (Erwin, 1991; Huba \& Freed, 2000; Palomba \& Banta, 1999). Key components of assessment include the collection of data about student learning from a variety of sources in order to use the information gained to improve student learning and development. The concept map in Figure 1 and presented in Chapter 1 offers a visual representation of the assessment cyclical process.

Intended Learning Outcomes for Service-Learning Courses

According to Jacoby and Associates (1996) service learning, as a pedagogy, is "education that is grounded in experience as a basis for learning and on the centrality 
and intentionality of reflection designed to enable learning to occur" (p.9). Faculty are responsible for determining the methods by which they will impart course content to students, and they search for the best way to teach students so that their learning will be enhanced. Instructors often find that service learning is the teaching pedagogy that will best help students gain real world experience and advance their learning and development. Students get the opportunity to apply their knowledge and skills developed in the classroom to projects that benefit the community.

Faculty across the participating institutions in this study did utilize service learning as their main pedagogy. This was evident because faculty planned their courses intentionally by requiring students to apply their knowledge and skills to a specific community context. They also integrated reflections across the course to get students more thoughtful perspectives about their learning through their work in the community. The implementation of structured reflection opportunities (Batchelder \& Root, 1994; Bittle, Duggleby \& Ellison, 2002; Eyler, 2002; Eyler \& Giles, 1999; Gray et al., 1999; Hales, 1997; Honnet \& Poulson, 1989; Mabry, 1998; Strage, 2000; Whitbourne, Collins \& Skultety, 2001) is common in service-learning courses. Faculty reported that service learning allowed students to gain real world experiences within the community setting as well as reflect on those experiences. Instructors implemented reflection activities at a variety of times and in different forms throughout the servicelearning experience. Reflections will be discussed in greater depth in the next section.

Faculty indicated at each institution that course outcomes evolved from the programmatic outcomes. Huba and Freed (2000) indicated that professional associations typically guided the development of intended learning outcomes for 
programs, but that individual faculty often developed the course-level outcomes. For example, upon examination of assessment reports, accreditation self-study reports, and college bulletins, the researcher found that in the nursing programs across institutions the intended programmatic learning outcomes were developed from the characteristics of the graduate and based on accreditation standards such as the Commission on Collegiate Nursing Education (CCNE) or the National League for Nursing (NLN). Characteristics of the baccalaureate nursing graduate, as outlined in an assessment report from Gamma University, addressed teaching and learning, research and inquiry, nature of practice, leadership, ethics, collaboration, communication, and policy development.

At the course level, the development of student learning outcomes went through a variety of processes, but faculty were clearly involved across institutions. At Alpha University, approval for service-learning courses was required to go through the university's service learning center to gain approval as a service-learning course; however, faculty were responsible for the development of such courses. Both Beta University and Gamma University received external grant funding to integrate service learning into the curriculum. In these institutions as well, faculty were the primary individuals responsible for developing the learning outcomes they intended students to achieve. Once the service-learning course was developed, faculty curriculum committees gave the final approval of the course.

Service learning was institutionalized differently at each site. At Alpha University, there was a service-learning center that provided necessary support in the form of workshops and seminars for faculty in order for them to develop quality service-learning 
courses. In addition, before a course could be identified as service learning at Alpha University it had to be submitted to the center for review and discussion by a committee. Service learning at Beta University did not have a service-learning center to provide direction and support for faculty; however, the grant funded Healthy Communities Center provided programmatic direction for service learning through the health professions community advisory board that sponsored workshops and seminars to guide faculty in service-learning curriculum development. Service learning at Gamma University was the least institutionalized though a community service center was available; however, the main purpose of this center was to establish dialogues and relationships with the local community.

Faculty implemented service learning to help students achieve the intended learning outcomes for their courses. Utilizing service learning as a method to achieve specific learning outcomes is an important dimension discussed in the literature (Astin, Vogelgesang, Ikeda, \& Yee, 2000; Batchelder \& Root, 1994; Cohen, \& Milone-Nuzzo, 2001; Eyler \& Giles, 1999; Gray et al., 1999; Honnet \& Poulson, 1989; Kendrick, 1996; Osbourne, Hammerich \& Hensley, 1998). Faculty across institutions indicated that their service-learning courses were only different from other courses in that they focused on applying knowledge and skills within a community project. Faculty advised that the course outcomes as well as the content covered would have been the same even if service learning had not been incorporated into the course. This is a surprising result because the literature reveals that there are special outcomes associated with servicelearning courses. Such outcomes typically include improving the students' awareness of the community in which they work, helping them develop a greater sense of civic 
responsibility, and advancing students' skills in applying academic knowledge to practical problems or issues (Angelidis, Tomic \& Ibrahim, 2004). Gelmon and associates (2001) found that service learning is particularly relevant for strengthening the following outcomes: awareness of community, commitment to service, and sensitivity to diversity.

Huba and Freed (2000) emphasized that student learning outcomes should focus on learning and not the activity. Stated student-learning outcomes should identify what students will know, understand and be able to do at the completion of the learning activity or course. In the course syllabi analyzed for this study, faculty consistently outlined what students were able to do and know at the completion of the servicelearning experience.

Palomba and Banta (1999) identified the cognitive, affective and psychomotor domains as categories in which learning outcomes should be developed. Several of the faculty interviewed verbally identified cognitive outcomes as well as several learning outcomes in the affective domain. However, at all three participating institutions, analysis of the course syllabi by the researcher revealed the majority of the outcomes were located in the cognitive domain $(96.7 \%)$, very few in the affective domain (3.2\%) and none in the psychomotor domain (see Table 31).

Table 31

Breakdown by Taxonomy in Course Syllabi Across Institutions

\begin{tabular}{lcccc}
\hline Taxonomy & $\begin{array}{c}\text { Alpha } \\
\text { University }\end{array}$ & $\begin{array}{c}\text { Beta } \\
\text { University }\end{array}$ & $\begin{array}{c}\text { Gamma } \\
\text { University }\end{array}$ & $\begin{array}{c}\text { \% of outcomes } \\
\mathrm{N}=156\end{array}$ \\
\hline Cognitive & 44 & 82 & 25 & 96.7 \\
Affective & 5 & 0 & 0 & 3.2 \\
Psychomotor & 0 & 0 & 0 & 0.0 \\
Total & 49 & 82 & 25 & 99.9 \\
\hline
\end{tabular}


The emphasis on the cognitive outcomes as Table 31 illustrated is consistent with research conclusions drawn by Field et al. (1984) who reported a focus on cognitive behaviors in health professions courses; specifically, baccalaureate nursing programs. The researcher's analysis of the course syllabi from all three study institutions revealed that within the cognitive domain about one-third of the outcomes (34.4\%) resided at the application level of the taxonomy (see Table 32). The fewest $(26.5 \%)$ outcomes were at the highest two levels (synthesis and evaluation) of the cognitive taxonomy. Finally, $31.9 \%$ of the outcomes identified in the course syllabi were at the knowledge and comprehension levels.

Table 32

Cognitive Outcomes Identified in Course Syllabi

\begin{tabular}{lcccc}
\hline $\begin{array}{c}\text { Cognitive } \\
\text { taxonomy }\end{array}$ & $\begin{array}{c}\text { Alpha } \\
\text { University }\end{array}$ & $\begin{array}{c}\text { Beta } \\
\text { University }\end{array}$ & $\begin{array}{c}\text { Gamma } \\
\text { University }\end{array}$ & $\begin{array}{c}\text { \% of Cognitive } \\
\text { outcomes } \\
\text { N=151 }\end{array}$ \\
\hline Knowledge & 1 & 7 & 10 & 12.0 \\
Comprehension & 12 & 18 & 0 & 19.9 \\
Application & 10 & 35 & 7 & 34.4 \\
Analysis & 13 & 12 & 4 & 19.2 \\
Synthesis & 5 & 5 & 1 & 7.3 \\
Evaluation & 3 & 5 & 3 & 7.3 \\
Totals & 44 & 82 & 25 & 100.1 \\
\hline
\end{tabular}

\section{Assessing Learning Outcomes in Service-Learning Courses}

Faculty across all three institutions identified themselves as the main individuals involved in assessing the intended learning outcomes. In addition, these faculty identified students and community agencies as participants in the assessment process, but at varied phases throughout the course. Students were involved in the assessment 
at the end of the course. Faculty at all three institutions indicated that students participated in the assessment process throughout the course since they regularly completed reflections. The reflection activities often provided faculty with useful feedback in order to make informed adjustments to service-learning activities. Students offered feedback regarding their experiences in the community and learning of course content through course evaluations and surveys. However, faculty at the three study sites advised that students were rarely consulted in the development of student learning outcomes for individual courses. This finding contradicts the leadership role that Schneider (1998) suggested students assumed at best practice service-learning institutions.

Community involvement in the assessment process also occurred at various phases across the three study institutions. Several faculty at all three institutions indicated that community agencies were involved at the beginning of the course. The main reason for their early involvement was to allow faculty to identify the student learning outcomes for their agencies. This led to the agency assistance in the development of projects and products that students would complete in order to meet the student learning outcomes of the course. As a result, community agencies were rarely involved in the development of the actual student learning outcomes for a course, but played an integral part in the development of projects and products that helped students meet the learning outcomes faculty identified. Schneider (1998) found that individuals in community agencies in best practice models for service learning worked with faculty to design the courses. The results from this current study do not completely support the results of Schneider's study. In addition, Schneider found that community agencies in 
her study were involved in the "evaluat[tion of] student volunteers" (p. 3) but in this study community agencies did not evaluate students.

Banta et al. (1996) discussed the importance of involving those from the educational community in the assessment process. These key stakeholders included people inside the institution such as faculty and students as well as those individuals outside the institution such as accrediting agencies; however, Banta et al. stated faculty "play the single most important role" (p.36). The research results confirm these conclusions drawn by Banta et al. (1996).

Multiple methods should be implemented when student-learning outcomes are assessed (Huba \& Freed, 2000; Palomba, 2001a). Direct assessments require students to demonstrate their learning while indirect assessments allow students to reflect on their own perceived learning (Hernon, 2004; Huba \& Freed, 2000; Palomba \& Banta, 1999). The implementation of multiple assessment methods occurred across institutions; however, grading for the service-learning course activities and assignments varied among and within the study institutions.

Across study institutions, most faculty reported service-learning projects, poster and/or team presentations and reflections as the most widely utilized methods to assess student learning and development. The projects and poster presentations, typically due at the end of the semester, were the summative assessments implemented and faculty used this student work to determine student grades.

The reflections typically served as formative assessment for faculty in servicelearning courses. These reflection activities often provided opportunities for students to discuss their experiences, which in turn provided useful information to the instructor who 
made appropriate adjustments during the service-learning course. This research confirms what Palomba and Banta (1999) suggested in the way of formative assessments where faculty at all three institutions were able to modify learning experiences as necessary, shape the progression of the course, and improve their courses based on feedback received from reflections.

Reflections were an integral part of the service-learning course assessment. However, the manner in which reflections were graded varied across and within institutions. Each of the institutions had at least one course where strict criteria were required in reflection responses. The main reason faculty offered for incorporating specific criteria into reflection activities was that it encouraged students to think critically about their experiences in the community and the objectives of the course. There were other courses across institutions as well that simply incorporated the reflections as a way to obtain feedback from students and were awarded points based on their responses. One instructor at Alpha University indicated that the reflections were graded, but not in a manner that would be stressful for the students to complete because she wanted to increase open and honest reflections from students.

Eyler and Giles (1999) suggested that reflection opportunities allowed students to make connections between classroom content and service-learning experiences. There were a variety of reflection assessments across institutions. A faculty member at Gamma University implemented the "What? So What? Now What?" reflection exercise as a method for grading which incorporated pre- and post- reflection activities. Prior to the service-learning experience, students were asked to describe the manner in which they prepared for the service-learning experience, indicate three professional objectives 
they hoped to achieve as well as their thoughts and concerns about the service experience. After the service-learning course students were expected to complete a post experience journal in which they identified the specific learning outcome(s) they achieved during the service activity and responded to the items "What? So What? Now What?". This exercise allowed the students to summarize, analyze and examine implications of their service-learning experience.

In the multi-disciplinary service-learning course at Beta University faculty implemented graded reflection activities that were more guided in nature where students were given a list of criteria in which to respond either as individuals or as a part of a multi-disciplinary group. In this instance, students responded to discipline specific reflection items during the first segment of the course. Toward the end of the final weeks of the experience, students reflected within the multi-disciplinary teams in which they were assigned.

A faculty member at Alpha University implemented a graded reflection activity called the "ABCDs" of reflection. In this activity, students discussed their feelings, emotions, learning as well as the diversity they experienced in their service placement. This was the only course in this study where students were required to reflect only once on their service experience which occurred at the end of the course. However, in the remaining courses at Alpha University as well as the other two institutions students were typically required to reflect on service-learning experiences and activities weekly. Mabry (1998) indicated that students who reflected on a more frequent basis had significant increases in both cognitive and affective outcomes in service-learning experiences. 


\section{Optimizing Student Learning and Development in Service-Learning Courses}

Palomba (2001b) suggested that assessment methods should be closely related to the learning outcomes selected by faculty. In this study, faculty implemented health and education activities for students to complete. However, the students were not always able to choose the project or product they would complete for the course. For example, with the exception of the multi-professional course, students at Beta University were permitted little latitude in selecting their service-learning project. Students were typically limited to service-learning activities that faculty identified. However, at Alpha University, students were typically able to select service projects from an established list or were free to select their own project that was appropriate for the service site. In general, Gamma University students also had flexibility in selecting their own servicelearning project.

In addition, the extent of student participation in teams during their servicelearning experiences varied. Decisions about whether students worked in teams or individually depended greatly on the following factors: (1) size of the service site, (2) needs of the service site, and (3) the product or project students were expected to complete. The rationale faculty offered regarding the size of a service site addressed the issue that some service sites were not physically capable to utilize an entire class of individual students, but were able to take an individual student who could meet the need of the service site. In addition, a service site may have required a team of students to meet their service need. In that case, students would be assigned accordingly. Finally, in order to incorporate an appropriate project, the faculty at Beta University were able to find a service site in which they were able to implement the multi-professional team at a 
community service site. The rationale given for this was that health professionals rarely operated independent of other professions, so the service-learning site provided students with the opportunity to work with other health professionals in a community setting in order to complete the service project. By selecting appropriate community sites where students were able to work as individuals or teams, faculty were able to optimize student learning and development, meet student learning outcomes, provide good experiences for students as well as meet community needs.

Achieved Student Learning Outcomes in Service-Learning Courses

Steinke and Buresh (2002) indicated that students were better able to illustrate understanding and develop solutions to societal problems when high quality servicelearning projects were implemented. Osborne et al. (1998) described the increase in cognitive complexity in students who participate in service learning. Across institutions faculty believed students were achieving a variety of cognitive learning that they had identified as important within their service-learning courses. These cognitive outcomes identified included understanding populations, resources, and community healthcare needs, and developing leadership, communication, research, team building, and collaboration skills. The methods by which faculty knew whether students achieved the identified outcomes included course reflections, pre- and post- attitude and knowledge surveys and faculty observation.

Student learning outcomes that were not achieved across institutions varied. Several faculty believed their students achieved every outcome outlined. Even though faculty stressed the importance of affective outcomes during the interviews, the researcher found that these outcomes were seldom stated in the course syllabi. At Beta 
University and Gamma University there were no affective outcomes identified on any of the service-learning syllabi analyzed for this study, and only five affective outcomes were identified in course syllabi analyzed at Alpha University. Faculty believed affective outcomes were important, but they did not communicate this in their syllabi.

The literature suggested that affective outcomes increased when students participated in service-learning experiences (Giles \& Eyler, 1994; Hales, 1997; Kendrick, 1996; Markus et al., 1993; Vogelgesang \& Astin, 2000). However, as reported by faculty, in some instances in this study that was not the case. At Alpha University, faculty outlined a variety of outcomes they believe students did not achieve. One faculty reported that students achieved the cognitive piece of the course, but some students felt that the service portion was not the best use of their time. Not recognizing the value of the service experience to the community was an outcome students did not achieve as reported by Alpha University as well as Gamma University faculty. Faculty reported that students at Beta University did not perceive they had a positive impact on the community in which they served, and they did not feel comfortable providing service to those who were different from themselves.

There was a disconnect between what faculty verbally reported as student learning outcomes, what students achieved, and what was observed in course syllabi. Most faculty verbally reported affective outcomes they intended students to achieve; yet Alpha University was the only institution found to include affective outcomes on course syllabi. Schneider (1998) suggested that "to best assess outcomes, they must be clearly defined" and that faculty "may need to focus more attention on assessment" ( $p$. 4 ) in order to ensure the outcomes are measurable. 


\section{Using Assessment Data and Results to Enhance Service-Learning Courses}

Palomba and Banta (1999) indicated that deciding what to do with student results once they were obtained was an important step in the cyclical process of assessment. Faculty in this study were willing to make adjustments and enhancements to the service-learning course based on student and community feedback. Faculty across all three institutions considered what students and community agencies had to say before, during and after service-learning courses, which improved and enhanced student learning and development. Based upon the assessment results, faculty discussed the following actions:

- Changing or adjusting their course learning activities. For example, at Alpha University, an agency and site orientation was added to the service-learning course based on student feedback. Service-learning activities were modified or deleted, and they were scaled back as necessary to enhance student learning at Beta University. Service projects were often scaled back because the faculty member did not believe students understood the entire scope of the course content, and that by scaling back the project students would have more time to focus on mastering the course outcomes. Informal discussions between faculty and students at Gamma University revealed students did not perceive their time was utilized effectively to complete course activities. Faculty, at the same institution, met at the end of the semester to determine if changes in servicelearning course activities were needed based on challenges encountered from previous semesters. 
- Selecting community agencies more carefully. Faculty gathered data from students at Alpha University and utilized the information to change a service site selection because of poor learning experiences. This was typically the result of a miscommunication between the course faculty and the agency representative regarding service expectations among students, faculty and the agency.

- Changing community agencies during the course. Gamma University faculty considered changing service sites because student learning was not taking place. Other projects were implemented at the site and it was determined if feedback from students continued to be negative the community agency would not longer be utilized.

- Changing their teaching styles. A faculty member at Alpha University reported that based on student feedback adjustments would be made to improve the effectiveness of the course. She adjusted the way she taught course content to address the effectiveness issue which she believed improved student learning and development.

Continuous improvement in teaching and learning were emphasized by Palomba and Banta (1999) and Shipman (2004) as ways in which assessment results were used. Huba and Freed (2000) stated that faculty should discuss assessment results since these conversations help increase their ability to make informed decisions about curricular changes. The faculty in this study shared assessment information on servicelearning courses with internal and external audiences as the literature suggested (Banta et al., 1996; Huba \& Feed, 2000; \& Palomba \& Banta, 1999). At institutions in this study, service-learning course assessment data was shared with community agencies, 
other faculty at faculty meetings, curriculum committee meetings within the college, college and university press releases, and peer reviewed articles (see Table 33). Beta University utilized diverse approaches to disseminate assessment results to external stakeholders, while Gamma University reported two methods in which they shared assessment results with external stakeholders. Across the study institutions, community agencies often received assessment results through verbal discussions or in hand-written notes. These communications were generally informal in nature.

Table 33

Method of Sharing Assessment Results Across Institutions

\begin{tabular}{lccc}
\hline \multicolumn{1}{c}{ Method } & $\begin{array}{c}\text { Alpha } \\
\text { University }\end{array}$ & $\begin{array}{c}\text { Beta } \\
\text { University }\end{array}$ & $\begin{array}{c}\text { Gamma } \\
\text { University }\end{array}$ \\
\hline Faculty meeting & $\mathrm{X}$ & $\mathrm{X}$ & $\mathrm{X}$ \\
$\begin{array}{l}\text { Curriculum meeting } \\
\text { Press Releases }\end{array}$ & $\mathrm{X}$ & $\mathrm{X}$ & \\
Peer reviewed articles & $\mathrm{X}$ & $\mathrm{X}$ & $\mathrm{X}$ \\
Newsletters & $\mathrm{X}$ & $\mathrm{X}$ & \\
$\begin{array}{l}\text { Reports } \\
\text { Service-Learning }\end{array}$ & & $\mathrm{X}$ & $\mathrm{X}$ \\
Conference & & & \\
\hline
\end{tabular}

Across the study institutions, faculty felt that the assessment process was successful in their service-learning courses. Faculty believed that student learning was enhanced and students were achieving most of the course objectives. At Alpha University, a faculty member suggested that the college currently was able to examine learning and had made fundamental changes to the service-learning courses. At Beta University, one instructor reported that assessment was not well defined within the college, but countered by indicating that she felt, based on student feedback, that learning was taking place and good products were produced for the community. 
However, another instructor at Beta University advised that assessment was a comprehensive process in which data was gathered from multiple stakeholders that informed decisions made regarding student learning. Overall, faculty at Gamma University indicated that assessment was achieving goals set forth and that data had been gathered and articles were published to illustrate and confirm the findings. Across all study sites many faculty indicated they had an increased ability to make changes to the course, feedback on student learning was obtained from a variety of stakeholders, and students had a positive impact on the community.

Faculty offered several reasons for the success of the service-learning experience. Alpha University faculty advised that implementing service learning increased knowledge of public health, projects had a direct and measurable benefit to the community, and that faculty had a commitment to service learning as a teaching methodology. Service-learning courses were successful at Beta University in that faculty reported that they developed good community partnerships and provided a variety of learning experiences for students. Faculty at Gamma University reported that service-learning courses were successful because students met course objectives by being in the community, and the service activities made direct links between the student learning outcomes and the service-learning experience.

Faculty also identified several challenges in the assessment of service-learning courses. One faculty member at Alpha University indicated that a challenge in the service-learning assessment process was that learning outcomes were measured at one point in time. However, student learning continues when they are employed and provide additional service to their communities upon graduation. Such post-graduate 
experiences could transform college alumni. Most institutions do not know what the effects of service-learning experiences were on their students once they graduate and this requires a longitudinal study design. Furco (2003) addresses this issue and states that because there is often not enough time for the learning to completely manifest itself that "service-learning studies should investigate outcomes and impacts in a more longitudinal vein whereby the long-term impacts of service-learning are investigated" (p.20t).

Palomba and Banta (1999) indicate that the assessment process should begin with discussions regarding the purpose of assessment and involve a variety of stakeholders in the process. For one faculty member, at Beta University this was not the case, and it was reported that the assessment process at the college was not well defined and difficult to know whether goals and objectives were articulated and assessed properly. In addition, it was also reported at Beta University that assessment was not systematic throughout the entire institution and defining each person's role and responsibility in the service-learning experience was difficult.

At Alpha University, a challenge in assessing service-learning was in the development of assessments for service-learning. One faculty member described how students in the classroom typically all have the same learning experiences while in service-learning courses each student's experience in the community was different which influenced the learning among students. Huba and Freed (2000) recommended a student-centered approach in developing learning outcomes in which they suggest faculty focus on the result of the learning activity not the actual activity itself. 
Finally, an area for improvement identified at Gamma University, was to better include the community agencies in the assessment process. The literature suggests that multiple stakeholders be involved in the assessment process. Specifically, Banta et al. (1996) state, "successful assessment requires collaborative efforts" (p. 35) whereby key stakeholders interact, participate, offer direction and join in a collective effort to ensure student success.

\section{Summary}

Service learning was implemented across institutions as a method by which to impart course content to health professions students. Utilizing this pedagogical method allowed faculty to achieve the intended learning outcomes identified for the course. Faculty reported that the emphasis on community projects was the only difference between service-learning and non-service-learning courses.

The development of intended learning outcomes for service-learning courses evolved from programmatic outcomes which were often guided by professional associations. Curriculum committees or an institution's service-learning center often had the final authority over the course outcomes; however, faculty across institutions were very involved in the development of the outcomes. There was a disconnect between the cognitive and affective intended learning outcomes faculty reported and what the researcher found in the course syllabi.

Across the study institutions, faculty identified themselves as the main individuals responsible for assessing student learning outcomes. Students participated in this part of the assessment cycle through reflections during the course as well as through 
surveys and course evaluations. Community involvement in the assessment of outcomes was informal.

Multiple methods were implemented across institutions to assess student learning. Projects, posters, team presentations and reflections were a few of the methods discussed by faculty. Reflection activities were integral in each of the servicelearning courses as they promoted critical thinking, and allowed students to reflect on their experiences.

A variety of health and education related activities were implemented into the service-learning courses among the study institutions. Activities were adjusted according to factors such as the size and need of the site. Affective outcomes that were typically expected to increase with participation in service-learning courses did not occur in every course in this study. Faculty were able to identify outcomes they believed students did not achieve.

Faculty used the assessment results to enhance the course to improve student learning. Faculty considered feedback from students and community agencies regarding the experiences within the service-learning courses and made appropriate adjustments to the course as required. Faculty believed these actions improved and enhanced student learning for current students as well as for the students in the future.

Faculty shared assessment results with stakeholders. However, each study institution varied in the extent to which results were disseminated. Community agencies often received informal communications regarding the assessment results, but faculty at one institution believed the community agencies needed to be included more throughout the entire assessment process. 


\section{Chapter Eight}

\section{Recommendations for Practice and Further Research}

\section{Introduction}

Health professions faculty who want their students to achieve the intended learning outcomes set in their service-learning courses can ensure success by following the cyclical assessment process as developed by Huba and Freed (2000) and illustrated in Figure 1, found in Chapter 1. This chapter will begin with major conclusions and then offer suggestions for practice as well as recommendations for further research in assessing service-learning courses.

\section{Research Conclusions}

Service learning was the method faculty in this study utilized to meet the outcomes of selected health professions courses. The faculty reported that there were no differences in their learning outcomes in their service-learning courses when compared with other courses they taught. The only difference they reported was the emphasis on community projects in which students participated. Faculty believed that learning outcomes were the same regardless of the implementation of the servicelearning strategy.

In this study, programmatic outcomes were often based on the characteristics of the graduate. For example, in nursing colleges those characteristics were outlined in the accreditation standards of the Commission on Collegiate Nursing Education (CCNE) or the National League for Nursing (NLN). The programmatic outcomes were the foundation for the course outcomes and curriculum committees were typically involved in the approval of course outcomes. However, faculty played an integral part in the 
development of these outcomes. Across institutions the outcomes identified on course syllabi indicated what faculty expected students to know or be able to do at the conclusion of the course.

Faculty identified mainly cognitive outcomes in their course syllabi. However, when faculty were asked about outcomes they believed students achieved, a majority of faculty reported affective outcomes more frequently than cognitive outcomes. Of the cognitive outcomes identified on course syllabi, slightly more than one-third were at the application level of the taxonomy, about the same percent were at the knowledge and comprehension levels of the taxonomy and somewhat more than one-quarter of the remaining outcomes were at the highest two levels of the taxonomy (synthesis and evaluation).

This study found that the assessment of student learning outcomes was the main responsibility of the faculty. Instructors reported that they integrated students in the assessment process through reflection opportunities across the course and utilized this information to make changes in the course. Faculty also reported that students participated in the assessment process by completing course evaluations and surveys at the end of the semester. Community agencies were rarely involved in the development of student learning outcomes of a course, but were involved in guiding the development of student projects.

Instructors implemented multiple methods to assess student learning across institutions. Projects, posters, presentations and reflections were the most widely discussed methods faculty implemented to assess student learning. Instructors most frequently used reflections as the formative method of assessment. In addition, they 
articulated specific response criteria that encouraged critical thinking and problem solving within the context of course content and community experiences.

In order to optimize student learning and development, faculty reported that several factors influenced whether students would participate in service-learning activities as individuals or as teams. These factors included the size of the service site, needs of the service site, and the product students completed. However, selection of the appropriate type and size of site allowed faculty to better achieve the student learning outcomes and meet community needs.

Faculty reported many outcomes they believed students achieved through the service-learning course. Faculty advised the methods they used to determine if students met the outcomes of the course included reflections, pre- and post- attitude and knowledge surveys and faculty observations. Outcomes faculty believed students did not achieve were from the affective taxonomy which was the area most neglected on course syllabi across institutions. In addition, this was the area where a disconnect occurred between what faculty reported and what course syllabi revealed as far as intended learning outcomes.

Faculty reported that they used the assessment data for a variety of reasons. Faculty often received feedback from students through weekly reflections. This feedback helped them identify the appropriate adjustments to implement in course learning activities. Another example faculty discussed was that they used feedback from student reflections to make better and more careful selection of community agencies or to change agencies during the course. Faculty stated that sometimes community agencies did not understand their responsibilities. When this occurred, 
faculty reported dropping these agencies as sites in the future for students because they did not present good learning experiences for their students.

Faculty also used assessment results to report findings to a variety of stakeholders. Reporting these results took the form of reports, press releases, peer reviewed articles, and newsletters to name a few. Faculty indicated that the reports were shared in faculty committee meetings, curriculum committee meetings and even conferences. However, faculty advised when they reported assessment results to community agencies they took the form of informal verbal discussions or handwritten notes. In addition, the types of methods faculty utilized to share assessment results varied across institutions.

Faculty reported that the assessment process and service-learning experiences were successful. Faculty believed learning was taking place, good products were being developed for the community, and students were meeting needs in the community. One challenge that surfaced in addressing the assessment of service learning was that faculty attempted to measure student learning at one point in time when a more longitudinal study design was required because learning that occurs in service-learning courses may not be apparent immediately. Another challenge that emerged was the development of appropriate assessments in service-learning courses because each student's experience was different based on the student's community placement. Recommendations for Practice

There are several recommendations for practice that derived from the major findings in this research. The first recommendation is that faculty within an institution need to reach a consensus about what constitutes high quality service-learning courses. 
The literature provides numerous insights regarding what these important characteristics are (Angelidis et al., 2004; Eyler \& Giles, 1999; Gelmon \& Associates, 2001). Such a consensus would be important as curriculum committees review these courses and make decisions as to whether they can be labeled as service learning. There should be a formal review process to make decisions about whether servicelearning courses that are identified meet the standards of high quality service-learning course. Creating guidelines and an infrastructure to promote continued growth and success is consistent with the theme of complexity Schneider (1998) identified.

The second recommendation is faculty should carefully consider and articulate learning outcomes for their service-learning courses which is consistent with Schneider's (1998) recommendation that learning outcomes should be clearly defined. In this study, faculty mentioned both cognitive and affective outcomes that they intended students to achieve. Yet, the only outcomes typically included on the course syllabi were the cognitive outcomes. There should be a balance of outcomes represented on service-learning course syllabi. Faculty may have neglected the affective domain because of the difficulty in measuring these outcomes. However, it is essential for faculty to present all of the important course outcomes they want students to achieve on course syllabi because students often do not see the importance of values, beliefs, and attitudes

Diamond (1998) indicates that by effectively designing courses and curricula, faculty are developing the competencies necessary for students to be successful. Diamond further states a "carefully designed comprehensive syllabus can improve the students' learning" (p.193). Habanek (2005) indicates that the course syllabus is the 
manner in which "faculty members define learning outcomes for students and the methods by which those outcomes will be realized" (p. 62). Habanek goes on to state that the course syllabus is an opportunity for faculty to "explain the learning goals or objectives for the course to let students know what they will know more about and will be able to do at the end of the term" (p. 62). As a result, students may achieve the outcomes faculty intend if the outcomes are clearly outlined on the course syllabi, and students understand what is expected of them in the course.

A third recommendation is the implementation of faculty development workshops or seminars to help instructors identify the particular outcomes and best assessment methods associated with service learning. In order for faculty to understand the assessment process, and develop appropriate student learning outcomes, the literature recommends faculty development workshops or seminars should be offered (Palomba \& Banta, 1996; Shipman, 2004). This will promote development of student learning outcomes for service-learning courses that are clear and measurable. In addition, the important learning outcomes (including cognitive and affective) need to be articulated because they provide direction for all instructional activity and they form the basis of assessment within the course (Huba \& Freed, 2000). By implementing a formal faculty development process, instructors can more thoughtfully design and develop servicelearning courses. They can strive to make their courses high quality service-learning experiences and not simply provide students with a volunteer opportunity. In order for faculty development to occur, appropriate support from key administrators is crucial to create quality service-learning courses (Schneider, 1998). 
The fourth recommendation is that faculty should incorporate diverse reflection opportunities frequently throughout the course to promote students' understanding of the complex social issues and to gather feedback about student achievement of the learning objectives. Rubin (2001) states reflection is the most critical component in a service-learning experience for students because it "ties the service to the learning" ( $p$. 24). Diverse and frequent reflection opportunities throughout the course allow students to apply course content to the complex social issues they face in the community. Highly integrated reflection activities enhance student development and learning. This can be done by asking specific questions after each class meeting and allowing students to expand on the affective outcomes of the course (Rubin, 2001). Relating course content to specific on-site observations will promote student analysis and critical thinking in their reflections especially when students are asked to discuss a theory or concept they learned in class and observed in the community (Rubin, 2001). However, reflection activities may foster additional questions by students regarding service experiences. Discussion opportunities that exist between faculty, students, and community agencies should move beyond simply sharing experiences toward more of an opportunity to integrate the experiences students' gain with the course content.

The fifth recommendation for practice is the implementation of more diverse communication of the assessment results especially to community agencies. Thompson and Bartels (1999) report that in order to improve student learning, assessment results should be systematically communicated to key stakeholders. This study revealed that there should be more diverse methods by which communication of assessment results with community agencies are disseminated. Informal notes and verbal communications 
were the main form of reporting assessment results to community agencies. This should become more formalized in a meaningful way so that community agencies are able to clearly see the positive experience and the student learning that takes place as a result of their participation in service learning.

Recommendations for Research

This study examined how service learning is assessed at the course level in health professions programs. In 2003, the Association of American Colleges and Universities (AACU) and Campus Compact sought to deepen the relationship between liberal education and civic engagement through the general education curricula (AACU, 2006). It would be useful for this study to be replicated by examining service-learning courses in general education. Service learning is represented in general education courses and is typically found in different disciplines while some courses may be interdisciplinary. A study of this type would allow the examination of assessment practices in general education courses across the curriculum as well as how or if service learning is implemented.

Research could also investigate the formal types of faculty development opportunities available and offered through various units including service-learning centers as well as teaching and learning centers. By selecting a variety of Carnegie classified institutions, a researcher could analyze the formal programs and seminars offered to help faculty develop appropriate student learning outcomes and conduct assessment in service-learning courses. In addition, the researcher could determine if these programs were formally evaluated and how these seminars helped faculty. 
Health professions faculty have implemented service learning in order to help students think critically, solve problems, and reflect on community needs. Defining the intended learning outcomes has not been at the forefront of research in service learning (Eyler, 2000). Future researchers could conduct a cross discipline analysis of an institution's service-learning syllabi to identify course level outcomes for service learning and the taxonomies represented. This would provide informative data to faculty regarding the cognitive and affective taxonomies incorporated into service-learning courses, whether they are truly represented as faculty believe they are as well as guidance as to whether the course outcomes need to be redeveloped.

This research also examined service-learning reflection activities and how they were utilized in the course level assessment process. Further research could examine the quality and frequency of reflection activities that are incorporated into servicelearning courses. This research could be conducted in a variety of settings such as general education, health professions schools, or across a variety of Carnegie classified institutions.

A limitation of this study was that student and community agency perspectives regarding the service-learning experience were not obtained. Further research could examine the relationship between the quality and frequency of service-learning reflections implemented throughout the course with students' perceptions of their achievement of the intended student learning outcomes as identified in course syllabi. Finally, further research based on the participating community agency's perceptions of the service-learning experience and student achievement of the learning outcomes could be conducted. 
This research study has provided some insight into the assessment practices of health professions faculty in service-learning courses. As a result of this research, additional areas for research have surfaced and have been offered in this chapter. There is room to expand on this study and further examine additional perspectives of the assessment and service-learning processes not only in health professions schools, but across other disciplines in higher education. 


\section{References}

Aloi, S. L. (2004). The use of assessment data in academic strategic planning. Doctoral Dissertation, West Virginia University.

American Association of Colleges of Nursing. (1998). The essentials of baccalaureate education for professional nursing Washington, D.C.: American Association of Colleges of Nursing.

Angelidis, J., Tominc, I., \& Ibrahim, N. A. (2004). Service-learning projects enhance student learning in strategic management courses. Review of Business, 25(2), 32-36.

Association of American Colleges and Universities. (2006). Center for liberal education and civic engagement. Retrieved February 24, 2006, from http://www/aacu.org/civic_engagement/index.cfm

Astin, A. W., Banta, T. W., Cross, K. P., El-Khawas, E., Ewell, P. T., Hutchings, P. et al. (1992). 9 Principles of good practice for assessing student learning. AAHE Assessment Forum. Retrieved May 26, 2003, from http://www.aahe.org/principl.htm

Astin, A. W., Vogelgesang, L. J., Ikeda, E. K., \& Yee, J. A. (2000). Executive summary: How service learning affects students. University of California, Los Angeles: Higher Education Research Institute. 
Banta, T. W. \& Associates. (2002). Building a scholarship of assessment. San Francisco, CA: Jossey-bass, Inc.

Banta, T. W., Lund, J. P., Black, K. E., \& Oblander, F. W. (1996). Assessment in practice: Putting principles to work on college campuses. San Francisco: Jossey-Bass.

Batchelder, T. H. \& Root, S. (1994). Effects of an undergraduate program to integrate academic learning and service: Cognitive, prosocial cognitive, and identity outcomes. Journal of Adolescence, 17, 341-355.

Bers, T. H. (2001). Measuring and reporting competencies. In R. A.Voorhees (Ed.), New Directions for Institutional Research (pp. 29-40). San Francisco: Jossey-Bass, Inc.

Billig, S. H. (2003). Introduction. In S. H.Billig \& A. S. Waterman, (Eds.), Studying service-learning: Innovations in education research methodology (pp. vii-xiv). Mahwah, NJ: Lawrence Erlaum Associates.

Bittle, M., Duggleby, W., \& Ellison, P. (2002). Implementation of essential elements of service-learning in three nursing courses. Journal of Nursing Education, 41, 129132.

Bloom, B. S. (1956). Taxonomy of educational objectives: The classification of educational goals. Handbook I, Cognitive domain. New York: David McKay. 
Boland, D. L. \& Laidig, J. (2001). Assessment of student learning in the discipline of nursing. In C.A.Palomba \& T. W. Banta (Eds.), Assessing student competence in accredited disciplines: Pioneering approaches to assessment in higher education (pp. 71-94). Sterling, VA: Stylus Publishing, LLC.

Bradshaw, A. (1997). Defining 'competency' in nursing (Part I): A policy review. Journal of Clinical Nursing, 6, 347-354.

Bradshaw, A. (1998). Defining 'competency' in nursing (Part II): An analytical review. Journal of Clinical Nursing, 7, 103-111.

Campus Compact. (1994). Campus Compact: Service-learning toolkit definitions and principles. From Brevard Community College, The Power, 1994. Retrieved May 26, 2003, from http://www.compact.org/publication/s-I_toolkit/definitions-print.html

Campus Compact. (2002). A season of service: A report of 2002 Campus Compact activity and impact Providence, RI: Campus Compact.

Carnegie Foundation for the Advancement of Teaching. (2000). Carnegie classification of institutions of higher education. Carnegie Foundation for the Advancement of Teaching. Retrieved August 4, 2004, from http://www.carnegiefoundation.org/classification/CIHE 2000

Carter, J. \& Dunn, B. (2002). A service-learning partnership for enhanced diabetes management. Journal of Nursing Education, 41, 450-452. 
Cherry, R. D. \& Meyer, P. R. (1993). Reliability issues in holistic assessment. In B. A. Williamson \& B. A. Hout (Eds.), Validating holistic scoring for writing assessment: Theoretical and empirical foundations (pp. 109-141). Cresskill, NJ: Hampton Press.

Childs, J. C., Sepples, S. B., \& Moody, K. A. (2003). Mentoring youth: A servicelearning course within a college of nursing. Journal of Nursing Education, 42, 182-185.

Cohen, S. S. \& Milone-Nuzzo, P. (2001). Advancing health policy in nursing education through service learning. Advances in Nursing Science, 23, 28-40.

Commission on Collegiate Nursing Education. (2002). Commission on Collegiate Nursing Education: 2002 Annual Report. Washington, DC: American Association of Colleges of Nursing.

Commission on Collegiate Nursing Education. (1998). Standards for accreditation of baccalaureate and graduate nursing education programs. Washington, DC: American Association of Colleges of Nursing. Retrieved October 13, 2004, from http://www.aacn.nche.edu/Accreditation/standrds.htm

Creswell, J. W. (1994). Research design: Qualitative and quantitative approaches. Thousand Oaks, CA: Sage Publications.

Creswell, J. W., Plano Clark, V. L., Gutmann, M. L., \& Hanson, W. E. (2003). Advanced mixed methods research designs. In A. Tashakkori \& C. Teddlie (Eds.), 
Handbook of mixed methods in social \& behavioral research. Thousand Oaks: Sage Publications.

Diamond, R. M. (1998). Designing and assessing courses and curricula. (2nd ed.) San Francisco: Jossey-Bass Inc.

Erwin, T. D. (1991). Assessing learning and development: A guide to the principles, goals, and methods of determining college outcomes. San Francisco, CA: Jossey-Bass, Inc.

Eyler, J., Giles, D. E., \& Braxton, J. (1997). The impact of service learning on college students. Michigan Journal of Community Service Learning, 4, 5-15.

Eyler, J. \& Giles, D. E. (1999). Where's the learning in service learning? San Francisco: Jossey-Bass, Inc.

Eyler, J. (2000). What do we most need to know about the impact of service-learning on student learning? Michigan Journal of Community Service Learning, Special Issue.

Eyler, J. (2002). Reflecting on service: Helping nursing students get the most from service-learning. Journal of Nursing Education, 41, 453-456.

Field, W. E., Gallman, L., Nicholson, R., \& Dreher, M. (1984). Clinical competencies of baccalaureate students. Journal of Nursing Education, 23, 284-293.

Fraenkel, J. R. \& Wallen, N. E. (2000). How to design and evaluate research in education. (4th ed.) Boston: McGraw Hill. 
Furco, A. (2001). Advancing service-learning at research universities. New Directions for Higher Education, 114, 67-78.

Furco, A. (2003). Issues of definitions and program diversity in the study of servicelearning (pp. 13-33). In S. H. Billig \& A. S. Waterman (Eds.), Studying servicelearning: Innovations in education research methodology. Mahwah, $\mathrm{NJ}$ : Lawrence Erlbaum Associates.

Gelmon, S. B., Holland, B. A., Driscoll, A., Spring, A., \& Kerrigan, S. (2001). Assessing service-learning and civic engagement: Principles and techniques. Providence, RI: Campus Compact.

George Mason University. (2004). Krathwohl's taxonomy of affective domain. Retrieved July 6, 2004, from http://classweb.gmu.edu/ndabbagh/Resources/Resources2/krathstax.htm

Giles, D. E., Honnet, E. P., \& Migliore, S. (1991). Research agenda for combining service and learning in the 1990s. Racine, Washington: National Society for Internships and Experiential Education.

Giles, D. E. \& Eyler, J. (1994). The theoretical roots of service-learning in John Dewey: Toward a theory of service learning. Michigan Journal of Community Service Learning, 1, 77-85.

Giles, D. E. \& Eyler, J. (1994). The impact of a college community service laboratory on students' personal, social and cognitive outcomes. Journal of Adolescence, 17, 327-339. 
Gray, M. J., Ondaatje, E. H., Fricker, Jr. R. D., Geschwind, S. A., Goldman, C. A., Kaganoff, T. et al. (1999). Combining service and learning in higher education: Evaluation of the learn and serve America, higher education program. Santa Monica, CA: RAND Corporation.

Gugerty, C. R. \& Swezey, E. D. (1996). Developing campus-community relationships. In B.Jacoby \& Associates (Eds.), Service-learning in higher education: Concepts and practices (pp. 92-108). San Francisco: Jossey-Bass, Inc.

Habanek, D. V. (2005). An examination of the integrity of the syllabus. College Teaching, 53(2), 62-64.

Hales, A. (1997). Service-learning within the nursing curriculum. Nurse Educator, 22, 15-18.

Hernon, P. (2004). Selecting from the assessment tool chest. In P. Hernon \& R. E. Dugan (Eds.), Outcomes assessment in higher education (pp. 149-173). Westport: Libraries Unlimited.

Hesser, G. (1995). Faculty assessment of student learning: Outcomes attributed to service learning and evidence of changes in faculty attitudes about experiential education. Michigan Journal of Community Service Learning, 2, 33-42.

Hird, V. (1995). Nursing competencies: The artistry of nursing [Monograph]. St.Vincent's Hospital Sydney: Under the Care of the Sisters of Charity Retrieved May 10, 2004, from http://www.clininfo.health.nsw.gov.au/hospolic/stvincents/1995/a05.html 
Honnet, E. P. \& Poulsen, S. J. (1989). Principles of good practice for combining service and learning: A Wingspread special report. National Service-Learning Cooperative Clearinghouse Retrieved May 28, 2004, from http://www.servicelearning.org/article/archive/87/

Howard, J. (1993). Community service learning in the curriculum. In J.Howard (Ed.), Praxis I: A faculty casebook on community service learning (pp. 3-12). Ann Arbor: OCSL Press.

Hoy, W. K. \& Miskel, C. G. (2001). Educational administration: Theory, research and practice. (6 ed.) Boston: McGraw Hill.

Huba, M. E. \& Freed, J. E. (2000). Learner-centered assessment on college campuses: Shifting the focus from teaching to learning. Needham Heights, MA: Allyn and Bacon.

Jacoby, B. (1996). Service-learning in today's higher education. In B.Jacoby \& Associates (Eds.), Service-learning in higher education: Concepts and practices (1st ed., pp. 3-25). San Francisco: Jossey-Bass, Inc.

Johnson, B. \& Turner, L. A. (2003). Data collection strategies in mixed methods research. In A.Tashakkori \& C. Teddlie (Eds.), Handbook of mixed methods in social and behavioral research. Thousand Oaks: Sage Publications.

Jones, E. A. (2002). Transforming the curriculum: Preparing students for a changing world [Monograph]. ASHE-ERIC Higher Education Report 29[3]. 
Jones, E. A., Voorhees, R. A., \& Paulson, K. (2002). Defining and assessing learning: Exploring competency-based initiatives (NCES 2002-159) Washington, D.C.: U.S. Department of Education, National Center for Education Statistics.

Kendall, J. \& Associates (1990). Combining service and learning Raleigh. NC: National Society for Internships and Experiential Education.

Kendrick, J. R. (1996). Outcomes of service learning in an introduction to sociology course. Michigan Journal of Community Service Learning, 3, 72-81.

Kolb, D. A. (1984). Experiential learning: Experience as the source of learning and development. Englewood Cliffs, NJ: Prentice-Hall, Inc.

Krathwohl, D. R., Bloom, B. S., \& Mesia, B. B. (1964). Taxonomy of educational objectives. (vols. 1-2) New York: David McKay.

Kuh, G. D. (1993). In their own words: What students learn outside the classroom. American Educational Research Journal, 30, 101-122.

Labuschagne, A. (2003). Qualitative research-Airy Fairy or Fundamental? The Qualitative Report, 8 (1), 100-103. Retrieved August 4, 2004, from http://www.nova.edu/ssss/QR/QR8-1/labuschagne.pdf

Lopez, C. L. (1997). Opportunities for improvement: Advice from consultant-evaluators on programs to assess student learning. North Central Accreditation Commission on Institutions of Higher Education. 
Mabry, J. B. (1998). Pedagogical variations in service learning and student outcomes: How time, contact, and reflection matter. Michigan Journal of Community Service Learning, 5, 32-47.

Maki, P. L. (2002). Developing an assessment plan to learn about student learning. Journal of Academic Librarianship, 28, 8-13.

Markus, G. B., Howard, J. P. F., \& King, D. C. (1993). Integrating community service and classroom instruction enhances learning: Results from an experiment. Educational Evaluation and Policy Analysis, 15, 410-419.

McMillan, J. H. (2000). Educational Research . (3rd ed.). New York: Addison Wesley Longman.

McMullan, M., Endacott, R., Gray, M. A., Jasper, M., Miller, C. M., Scholes, J. et al. (2003). Portfolios and assessment of competence: A review of the literature. Journal of Advanced Nursing, 41, 283-294.

Mintz, S. D. \& Hesser, G. (1996). Principles of good practice in service-learning. In B.Jacoby \& Associates (Eds.), Service-learning in higher education: Concepts and practices (pp. 26-52). San Francisco: Jossey-Bass, Inc.

Narsavage G.L., Lindell, D., Chen, Y., Savrin, C., \& Duffy, E. (2002). A community engagement initiative: Service-learning in graduate nursing education. Journal of Nursing Education, 41, 457-461. 
Narsavage G.L., Lindell, D., \& Chen, Y. (2003). Developing personal and community learning in graduate nursing education through community engagement. Nursing Education Perspectives, 24, 300-205.

Norbeck, J. S., Connolly, C., \& Koerner, J. (1998). Caring and community: Concepts and models for service-learning in nursing. Washington, D.C.: American Association for Higher Education.

O'Neil, E. H. (1993). Health professions education for the future: Schools in service to the nation. San Francisco, CA: Pew Health Professions Commission.

O'Neil, E. H. (1997). Using accreditation for your purposes. AAHE Bulletin. Retrieved April 2, 2004, from http://www.aahebulletin.com

O'Neil, E. H. \& Pew Health Professions Commission (1998). Recreating health professional practice for a new century: The fourth report of the Pew Health Professions Commission San Francisco, CA: Pew Health Professions Commission.

Osborne, R. E., Hammerich, S., \& Hensley, C. (1998). Students effects of service learning: Tracking change across a semester. Michigan Journal of Community Service Learning, 5, 5-13.

Palomba, C. A. \& Banta, T. W. (1999). Assessment essentials: Planning, implementing, and improving assessment in higher education. San Francisco, CA: JosseyBass, Inc. 
Palomba, C. A. (2001a). Assessment experiences in accredited disciplines. In C.A.Palomba \& T. W. Banta (Eds.), Assessing student competence in accredited disciplines: Pioneering approaches to assessment in higher education (pp. 245268). Sterling, VA.: Stylus Publishing, LLC.

Palomba, C. A. (2001b). Implementing effective assessment. In C.A.Palomba \& T. W. Banta (Eds.), Assessing student competence in accredited disciplines: Pioneering approaches to assessment in higher education (pp. 13-28). Sterling, VA: Stylus Publishing, LLC.

Patton, M. Q. (2002). Qualitative Research and Evaluation Methods. (3rd ed.). Thousand Oaks: Sage Publications.

Paul, R. (1993). Critical thinking: What every person needs to know to survive in a rapidly changing world. Rohnert Park, CA: Center for Critical Thinking.

Pew Health Professions Commission (1995). Critical Challenges: Revitalizing the health professions for the twenty-first century. San Francisco, CA: UCSF Center for Health Professions.

Rubin, M. S. (2001). A smart start to service-learning. New Directions for Higher Education, 114, 15-26.

Schneider, M. K. (1998). Models of good practice for service-learning programs. AAHE Bulletin. Retrieved June 1, 2004, from http://www.aahe.org/service/bulletin\%20article.htm 
Sedlak, C. A., Doheny, M. O., Panthofer, N., \& Anaya, E. (2003). Critical thinking in students' service-learning experiences. College Teaching, 51, 99-103.

Seifer, S. D. (1998). Service-learning: Community--campus partnerships for health professions education. Academic Medicine, 73, 273-277.

Seifer, S. D. (2002). From placement site to partnership: The promise of servicelearning. Journal of Nursing Education, 41, 431-432.

Seifer, S. D. \& Vaughn, R. L. (2002). Partners in caring and community: Servicelearning in nursing education. Journal of Nursing Education, 41, 437-439.

Shipman, D. G. (2004). Examining internal programmatic assessments implemented by physician assistant educators. Doctoral Dissertation, West Virginia University.

Short, E. C. (1984). Competence re-examined. Educational Theory, 34, 201-207.

Sigmon, R. L. (1990). Service-learning: Three principles. In J.C.Kendall \& Associates (Eds.), Combining service and learning: A resource book for community and public service (pp. 56-64). Raleigh, NC: National Society for Internships and Experiential Education.

Steinke, P. \& Buresh, S. (2002). Cognitive outcomes of service-learning: Reviewing the past and glimpsing the future. Michigan Journal of Community Service Learning, 8.

Sternas, K. A., O'Hare, P., Lehman, K., \& Milligan, R. (1999). Nursing and medical student teaming for service learning in partnership with the community: An 
emerging holistic model for interdisciplinary education and practice. Holistic Nursing Practice, 13, 66-77.

Strage, A. A. (2000). Service-learning: Enhancing student learning outcomes in a college-level lecture course. Michigan Journal of Community Service Learning, 7, $5-13$.

Strauss, A. \& Corbin, J. (1990). Basics of qualitative research: Grounded theory procedures and techniques. Newbury Park, CA: Sage Publications.

Tellis, W. (1997). Application of a case study methodology. The Qualitative Report, 3 (3). Retrieved on August 4, 2004, from http://www.nova.edu/ssss/QR/QR33/tellis2.html

The Center for the Health Professions. (n.d.). Pew Health Professions Commission: 1989-1999. The Center for the Health Professions: University of California, San Francisco. Retrieved May 15, 2004, from http://www.futurehealth.ucsf.edu/pewcomm/factsht3.html

The University of Mississippi. (2003a). Bloom's taxonomy: Cognitive domain. The University of Mississippi, School of Education. Retrieved May 19, 2004, from http://www.olemiss.edu/depts/educ_school2/docs/stai_manual/manual8.htm

The University of Mississippi. (2003b). Bloom's taxonomy: Affective domain. The University of Mississippi, School of Education. Retrieved May 19, 2004, from http://www.olemiss.edu/depts/educ_school2/docs/stai_manual/manual9.htm 
The University of Mississippi. (2003c). Bloom's taxonomy: Psychomotor domain. The University of Mississippi, School of Education. Retrieved May 19, 2004, from http://www.olemiss.edu/depts/educ_school2/docs/stai_manual/manual10.htm

Thompson, C., \& Bartels, J. E. (1999). Outcomes assessment: Implications for nursing education. Journal of Professional Nursing, 15, 170-178.

U.S. Department of Health and Human Services. (2000). Healthy people 2010:

Understanding and improving health. (2nd. ed.) (vols. 1) Washington, D.C.: U.S. Government Printing Office.

Vogelgesang, L. J. \& Astin, A. W. (2000). Comparing the effects of community service and service-learning. Michigan Journal of Community Service Learning, 7, 25-34.

Whitbourne, S. K., Collins, K. J., \& Skultety, K. M. (2001). Formative reflection on service-learning in a course on the psychology of aging. Educational Gerontology, 27, 105-115.

Yin, R. K. (1994). Case study research: Design and methods. (2nd ed.) (vols. 5) Thousand Oaks: Sage.

Zhang, Z., Luk, W., Arthur, D., \& Wong, T. (2001). Nursing competencies: Personal characteristics contributing to effective nursing performance. Journal of Advanced Nursing, 33, 467-474. 
Zucker, D. M. (2001). Using case study methodology in nursing research. The Qualitative Report, 6 (2). Retrieved August 4, 2004, from http://www.nova.edu/ssss/QR/QR6-2/zucker.html 


\section{APPENDIX A:}

Letter to Request Institutional Site Approval 
Letter to request institutional site approval (on WVU letterhead)

Date

Address

Dear (---Person responsible for site approval---),

I am a doctoral student majoring in Educational Leadership at West Virginia University, and am conducting research for my dissertation study regarding the assessment practices in service-learning courses of health profession programs. This letter is intended to follow up my initial letter requesting information on your program I obtained from you in early November.

I have selected your institution as a site in which to conduct interviews for my dissertation research. I would like to seek your assistance in securing permission to visit your institution as part of my dissertation research. This letter will outline the purpose of my visit and the steps necessary to obtain written approval to conduct this research on your campus.

Specifically, I am requesting your permission to interview approximately 12 full-time faculty who integrate service learning in at least one undergraduate course. Your guidance in identifying faculty with whom I can schedule interviews would be greatly appreciated. I would also like to analyze relevant documents such as assessment plans, service-learning assessment plans, assessment reports written for any of the plans just mentioned above as well as programmatic syllabi that have service learning integrated into the course. I plan to visit your campus to conduct the interviews during the months of March and April 2005.

The purpose of my research study is to determine how service-learning courses are assessed in order to determine if students achieve intended learning outcomes. The analysis of my data will provide insight into how health profession students achieve the goals of service learning as well as how faculty assess these outcomes. This study is significant in that it will provide information from which faculty can better understand the assessment practices of service-learning within health profession programs that integrate service learning.

To request Human Subjects Exemption Review from West Virginia University's Institutional Review Board, I am required to submit a letter from you granting permission for me to conduct research at your institution. I am attaching a letter template, which you may alter as you prefer, and then copy on your institutional letterhead. Please forward this letter me by (---due date---) so that I may proceed with my study. Once I receive this letter of consent from you, I will immediately initiate the review process at West Virginia University. After exemption approval has been granted, I will schedule the interviews on your campus, with your assistance or that of an individual you identify. 
I want to assure you that the results of this study will be used specifically for my dissertation, and that I will maintain confidentiality of data and preserve the anonymity of the interviewees at all times. It will also be made clear to all participants in your school that their involvement in this project is entirely voluntary. I will gladly share an executive summary of the study with you or any of the participants upon request.

Should you have any questions or concerns regarding this process, please feel free to contact me by telephone at (304-293-3803 X1702) or email at tanderson2005@aol.com. I look forward to visiting your campus.

Sincerely,

Tracey Anderson Doctoral Candidate West Virginia University 304-293-3803 X1702 tanderson2005@aol.com 


\section{APPENDIX B:}

Letter from Institution Granting Permission for Site Visit 
Letter from institution granting permission for site visit (on letterhead from case institution)

Date

Ms. Tracey Anderson

WVU mailing address

Dear Tracey,

I am writing to convey my support for your doctoral dissertation research and visit to (--name of institution---). I understand that you will need to interview various members of our faculty to discuss how service-learning experiences are assessed in our health profession program. In addition, I understand that you will be provided with various documents related to service learning, assessment, and the program.

Please feel free to contact (---name of liaison---) at (---contact information---) in order to begin scheduling your interviews during March and April 2005. I understand individual interview appointments will be approximately 45-60 minutes each, and you have agreed to emphasize to these individuals that their participation is entirely voluntary. I also understand that you will protect the confidentiality of these discussions; neither the participants nor our nursing program will be identified in your dissertation.

Thank you for requesting my approval for this project.

Sincerely,

(---Person responsible for site approval---)

Title 
Assessing Student Learning Outcomes 233

\section{APPENDIX C:}

Letter to Individual Participants 
Letter to individual participants

(on WVU letterhead)

Date

WVU mailing address

Dear (---Individual participant---),

As a doctoral student majoring in Educational Leadership at West Virginia University, I am conducting research for my dissertation on how service-learning courses are assessed in health profession programs. Your institution was identified as a best practice model for service learning, and since there is a health profession program I will be visiting your campus. (---Dr. Liaison---) has recommended you as a participant in my study regarding your role in implementing service learning.

The purpose of my research study is to determine how service-learning courses are assessed in order to determine if students achieve intended learning outcomes. The analysis of my data will provide insight into how health profession students achieve the goals of service-learning as well as how faculty assess these outcomes. This study is significant in that it will provide information from which individuals can better understand the assessment practices of service learning within health profession programs that integrate service learning.

I will be visiting your campus (---date of visit---) and would like to interview you for approximately 45 to 60 minutes regarding how you integrate and assess service learning within your courses taught in 2004 . Your responses will remain confidential, and I will preserve the anonymity of each interviewee at all times. I also want to emphasize that your participation in my study is entirely voluntary and that you may withdraw your consent at any time. In addition, you are not obligated to answer all of the questions in the interview.

In addition, I would also like to analyze relevant documents such as assessment plans, assessment reports, course syllabi that have service learning integrated into the course, as well as department meeting minutes that discuss service learning. Your assistance in obtaining this documentation is greatly appreciated.

Please indicate your agreement to participate in my study by contacting me by telephone at (304-293-3803 X1702) or email tanderson2005@aol.com to schedule our interview. In the meantime, please do not hesitate to contact me should you have any questions or wish to discuss further details of my study. I look forward to hearing from by (---date that is two weeks post mailing---).

Sincerely, 
Tracey Anderson

Doctoral Candidate

West Virginia University

304-293-3803 X1702

tanderson2005@aol.com 
Assessing Student Learning Outcomes 236

\section{APPENDIX D:}

Telephone Interview Protocol 
Telephone Interview Protocol

Script: Hello, my name is Tracey Anderson. I am a doctoral candidate in the Educational Leadership program at West Virginia University. I am calling to obtain information regarding your health profession program at (---name of institution---) to guide my selection of cases in my dissertation. The purpose of my research study is to determine how service-learning courses are assessed in order to determine if students achieve intended learning outcomes. The analysis of my data will provide insight into how health profession students achieve the goals of service-learning as well as how faculty assess these outcomes. This study is significant in that it will provide information from which individuals can better understand the assessment practices of service-learning within health profession programs. Are you able to answer a few questions at this time?

Institution:

Date and time of interview:

Name of participant:

Title of participant:

Contact information:

1. Approximately how many health profession courses implemented service learning in your institution during the Spring, Summer and Fall 2004 semesters?

2. Approximately how many health profession faculty were involved in implementing service-learning in their courses during the Spring, Summer and Fall 2004 semesters?

3. Do the health profession programs have assessment plans? In what year were they developed?

4. Have the assessment plans been implemented?

5. Do service-learning courses, within the health profession programs, have stated student learning outcomes that are routinely assessed?

6. Are assessment methods articulated in the assessment plan?

7. Are the results used to advance student learning within the health profession programs? 


\section{APPENDIX E:}

Interview Protocol for Faculty 
Interview Protocol for Faculty

Script: Hello, my name is Tracey Anderson. I am a doctoral candidate in the Educational Leadership program at West Virginia University. Thank you for agreeing to participate in my project studying how service-learning courses, in health profession programs, are assessed in order to determine if students achieve intended learning outcomes. The information gathered in my research will be used in my doctoral dissertation. Your participation is entirely voluntary, and you do not have to respond to every question. Please be assured that your responses will remain anonymous, and that your confidentiality will be maintained throughout the data collection and reporting process. Do I have your permission to tape record this interview and take notes to ensure that accuracy of your responses? yes no

Institution:

Location of interview:

Date and time of interview:

Name of participant:

Title of participant:

General Questions:

1. Please identify service-learning course(s) you currently, or within the 2004 academic year, teach. (Request syllabus)

2. Is your course required or elective? How many students are typically enrolled in your class?

3. How do you identify service-learning sites?

4. What service-learning sites participate?

5. How far are students required to travel to the service-learning sites?

6. How many hours are students required to spend at the service-learning site in a semester?

7. Please explain the assessment process at your institution and who is involved.

8. Please explain the assessment process within your school and who is involved.

[RQ1: What are the intended outcomes for students enrolled in service-learning courses?]

9. What are the intended learning outcomes for students enrolled in servicelearning courses? Probe: What should they know and be able to do as a result of the course?

10. How are student learning outcomes in service-learning courses different from other courses? Probe: Is there an emphasis placed on cognitive, affective or psychomotor outcomes in service-learning courses?

11. How are student learning outcomes for service-learning courses determined?

12. In what taxonomy (cognitive, affective, psychomotor) would you say most of the student learning outcomes for service-learning courses reside? Reminder: Be able to define the terms in parentheses.

13. How do you involve the community and students in the development of student learning outcomes of service-learning courses? 
[RQ2: How are the learning outcomes assessed in service-learning courses?]

14. Who is involved in assessing student learning outcomes in service learning courses?

15. How do you involve the community and students in assessing the student learning outcomes of service-learning courses?

16. How are these individuals selected?

17. What assessment methods are used for grading or to offer formal feedback to students in service-learning courses? Please describe the methods. Probe:

Please indicate all and others that apply.

a. Student activity report

b. Site or field supervisor evaluation

c. Student portfolio

d. Journal

e. Oral presentation

f. Final paper

g. Student interview

[RQ3: How are service-learning courses designed to optimize student learning and development? a.) assignment/activities; b.) reflections; c.) team vs.

individual; d.) active learning?]

18. In what type of assignments/activities do students participate? Please describe.

19. In what kind of reflection activities do students participate? Please describe.

20. How often throughout the service-learning course do students participate in reflection activities?

21. Do students participate as individuals in service-learning courses? What is the rationale for this?

22. Do students participate as teams in service-learning courses? What is the rationale for this?

23. What types of service-learning projects and/or products have students produced at service-learning sites? What are examples?

[RQ4: How do faculty use assessment results to determine if students reach the intended learning outcomes developed for service-learning courses?]

24. What student learning outcomes were achieved? How do you know?

25. What student learning outcomes were not achieved? How do you know?

26. How are assessment results used to determine if students reach the intended learning outcomes developed for service-learning courses?

[RQ5: How are assessment data and the results used to enhance the course and improve student learning?]

27. How are the assessment data and the results, from service-learning courses, used to enhance the course?

28. How are the assessment data and the results, from service-learning courses, used to improve student learning?

29. a. How do you share service-learning assessment data and the results within the school and throughout the campus? b. With whom do you share this information?

30.a. How are service-learning assessment data and the results shared with external stakeholders? b. With whom do you share this information? 
31. How are assessment results from service-learning courses used for accreditation?

32. Do you feel that the assessment process, for your program, is achieving it goals? Explain.

33. Do you feel that the service-learning experience in your program is achieving its goals? Explain.

34.Please offer any feedback concerning the benefits and drawbacks associated with assessing service learning. If possible, please provide institutional data.

Do you have any additional comments you would like to add? 


\section{APPENDIX F:}

Document Analysis Protocol 


\section{Document Analysis Protocol}

Institution: Author:

Date of analysis: ument was written:

Title of document:

Purpose of document:

Intended audience of document:

Source of the document:

\begin{tabular}{|c|c|c|c|c|}
\hline \multirow[b]{2}{*}{$\begin{array}{l}\text { Document } \\
\text { Analyzed }\end{array}$} & \multicolumn{4}{|c|}{ Questions to ask about each document. } \\
\hline & RQ 1 & RQ 2 & RQ 3 & RQ 4 \\
\hline $\begin{array}{l}\text { Assessment } \\
\text { plans }\end{array}$ & $\begin{array}{l}\text { What is the } \\
\text { purpose of the } \\
\text { assessment } \\
\text { plan? } \\
\text { Are intended } \\
\text { learning } \\
\text { outcomes for } \\
\text { students in } \\
\text { service- } \\
\text { learning } \\
\text { courses } \\
\text { clearly } \\
\text { documented? } \\
\text { Is the process } \\
\text { of selecting } \\
\text { service } \\
\text { learning sites } \\
\text { described? }\end{array}$ & $\begin{array}{l}\text { Who is } \\
\text { responsible for } \\
\text { assessment of } \\
\text { student } \\
\text { learning } \\
\text { outcomes? } \\
\text { How are } \\
\text { faculty } \\
\text { involved in } \\
\text { curriculum } \\
\text { modifications? } \\
\text { Do individuals } \\
\text { who } \\
\text { participate in } \\
\text { the } \\
\text { assessment } \\
\text { process also } \\
\text { participate in } \\
\text { faculty } \\
\text { development? }\end{array}$ & & $\begin{array}{l}\text { Are } \\
\text { improvements } \\
\text { from the use } \\
\text { of previous } \\
\text { assessment } \\
\text { data } \\
\text { described? } \\
\text { What } \\
\text { evidence is } \\
\text { there that } \\
\text { institutional } \\
\text { and } \\
\text { programmatic } \\
\text { support is } \\
\text { available? } \\
\text { What } \\
\text { evidence is } \\
\text { there that } \\
\text { faculty } \\
\text { development } \\
\text { is available? }\end{array}$ \\
\hline $\begin{array}{l}\text { Assessment } \\
\text { reports }\end{array}$ & $\begin{array}{l}\text { Are key } \\
\text { stakeholders } \\
\text { made aware } \\
\text { of intended } \\
\text { learning } \\
\text { outcomes? } \\
\text { Are learning } \\
\text { outcomes } \\
\text { implemented } \\
\text { for } \\
\text { accreditation } \\
\text { purposes? }\end{array}$ & & & $\begin{array}{l}\text { Are } \\
\text { improvements } \\
\text { that will be or } \\
\text { have been } \\
\text { made } \\
\text { indicated? } \\
\text { How are } \\
\text { curriculum } \\
\text { changes } \\
\text { reported? }\end{array}$ \\
\hline
\end{tabular}




\begin{tabular}{|c|c|c|c|c|}
\hline \multirow[b]{2}{*}{$\begin{array}{l}\text { Document } \\
\text { Analyzed }\end{array}$} & \multicolumn{4}{|c|}{ Questions to ask about each document. } \\
\hline & RQ 1 & RQ 2 & RQ 3 & RQ 4 \\
\hline Course syllabi & $\begin{array}{l}\text { What are the } \\
\text { intended } \\
\text { learning } \\
\text { outcomes } \\
\text { listed? } \\
\text { Do students } \\
\text { participate in a } \\
\text { service- } \\
\text { learning } \\
\text { orientation? }\end{array}$ & $\begin{array}{l}\text { How are } \\
\text { students and } \\
\text { community } \\
\text { members } \\
\text { involved in } \\
\text { assessing } \\
\text { student } \\
\text { learning } \\
\text { outcomes? } \\
\text { Describe. }\end{array}$ & $\begin{array}{l}\text { What } \\
\text { opportunities } \\
\text { do students } \\
\text { have to } \\
\text { receive formal } \\
\text { feedback? } \\
\text { What types of } \\
\text { reflection } \\
\text { activities are } \\
\text { included? }\end{array}$ & \\
\hline
\end{tabular}

